University of Louisville

ThinkIR: The University of Louisville's Institutional Repository

Electronic Theses and Dissertations

$5-2018$

\title{
Addition of exothermic reaction scale-up lab to unit operations curriculum.
}

Lisa A Anderson

University of Louisville

Follow this and additional works at: https://ir.library.louisville.edu/etd

Part of the Catalysis and Reaction Engineering Commons, and the Engineering Education Commons

\section{Recommended Citation}

Anderson, Lisa A, "Addition of exothermic reaction scale-up lab to unit operations curriculum." (2018). Electronic Theses and Dissertations. Paper 2884.

https://doi.org/10.18297/etd/2884

This Master's Thesis is brought to you for free and open access by ThinkIR: The University of Louisville's Institutional Repository. It has been accepted for inclusion in Electronic Theses and Dissertations by an authorized administrator of ThinkIR: The University of Louisville's Institutional Repository. This title appears here courtesy of the author, who has retained all other copyrights. For more information, please contact thinkir@louisville.edu. 


\title{
ADDITION OF EXOTHERMIC REACTION SCALE-UP LAB TO UNIT OPERATIONS CURRICULUM
}

\author{
By \\ Lisa A. Anderson \\ B.S., University of Louisville, 2017
}

\begin{abstract}
A Thesis
Submitted to the Faculty of the

University of Louisville

J. B. Speed School of Engineering as Partial Fulfillment of the Requirements

for the Professional Degree
\end{abstract}

MASTER OF ENGINEERING

Department of Chemical Engineering

May 2018 



\title{
ADDITION OF EXOTHERMIC REACTION SCALE-UP LAB TO UNIT OPERATIONS CURRICULUM
}

\author{
Submitted by: \\ Lisa A. Anderson \\ A Thesis Approved On \\ (Date)
}

by the Following Reading and Examination Committee:

Dr. Gerold A. Willing, Thesis Director

Dr. Jim Gerstle

Dr. Jacqueline McNeil 


\section{ACKNOWLEDGEMENTS}

I would like to thank the members of my thesis reading committee namely Dr. Willing, Dr. Gerstle and Dr. McNeil. You all were incredibly helpful to me during the process of completing the project and writing the thesis. I would like to especially thank Dr. Gerstle for giving me the opportunity to not only create the exothermic reaction scaleup lab for the Unit Ops lab but also be a teaching assistant for the lab.

I would also like to thank my family and friends for all of their support during my Masters year. I would also like to show my appreciation for the Spring 2018 CHE 486 Unit Ops students for their feedback, cooperation and support throughout the semester as we

added this new experiment to the coursework. Their participation made this project a success.

Lastly, and most importantly, I would like to give honor and glory to God for blessing me with every opportunity I have had throughout my chemical engineering academic career. He is the reason for any and all of my success. 


\section{TABLE OF CONTENTS}

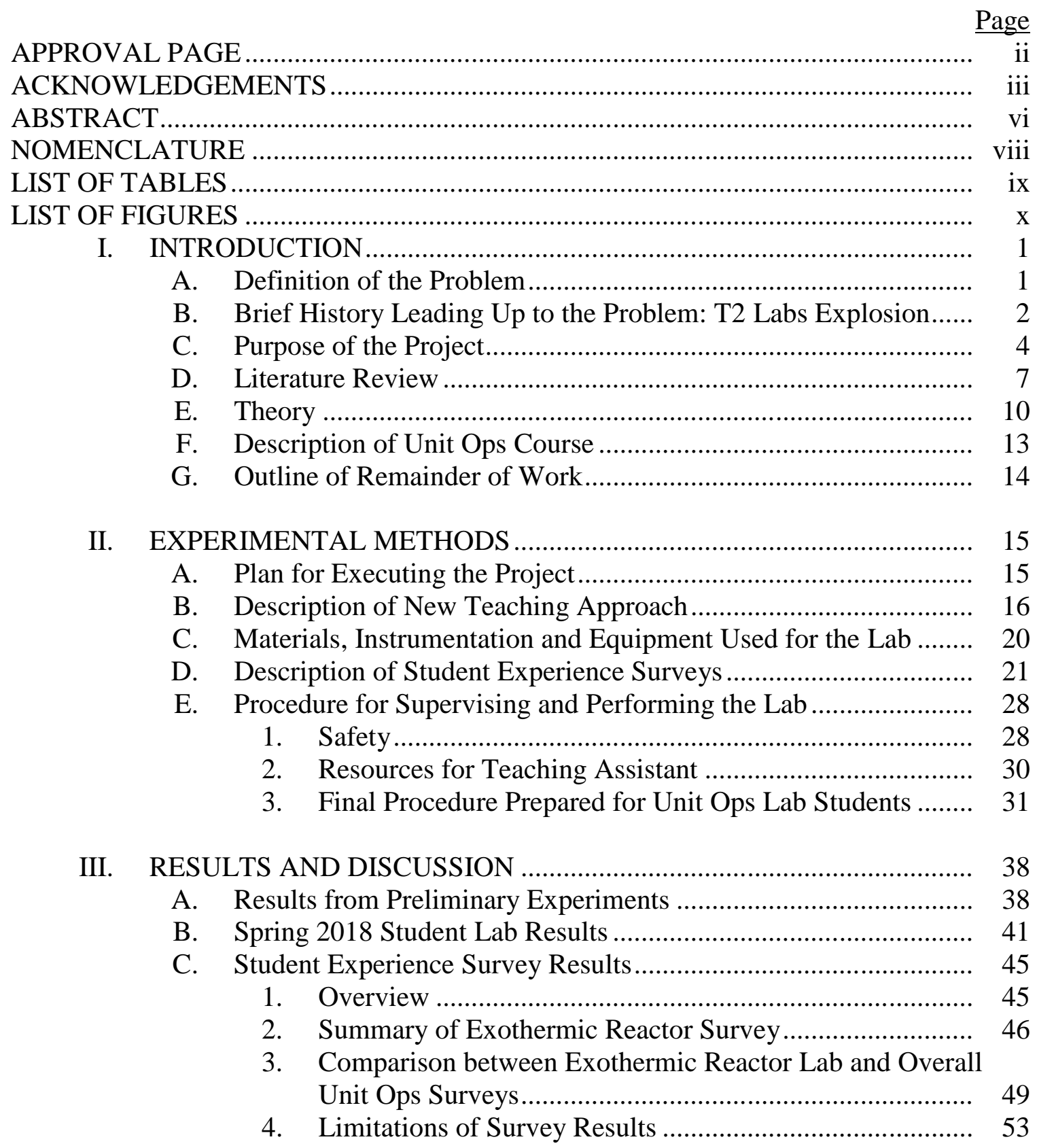


IV. CONCLUSIONS ....................................................................... $\frac{\text { Page }}{58}$

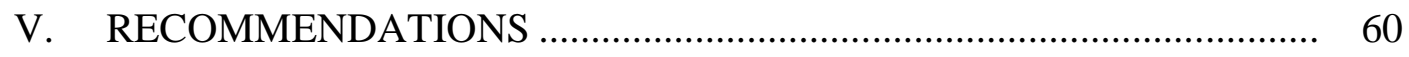

REFERENCES CITED ........................................................................... 63

APPENDIX I. SAMPLE CALCULATIONS FOR DETERMINING U-VALUE

AND OBTAINING THEORETICAL RESULTS ....................... 64

APPENDIX II. STUDENT EXPERIENCE SURVEYS AND MINITAB

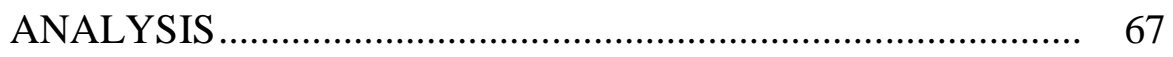

APPENDIX III. RESOURCES FOR TEACHING ASSISTANT ........................... 81

APPENDIX IV. PRELAB ASSIGNMENT AND FINAL REPORT

DELIVERABLES ............................................................ 93

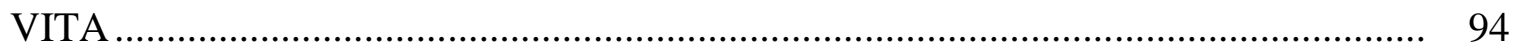




\begin{abstract}
According to the Chemical Safety Board's 2002 report entitled "Improving Reactive Hazard Management," the CSB identified 167 serious accidents involving uncontrolled chemical reactions in the United States between 1980 and 2001 causing 108 deaths and hundreds of millions of dollars in property damage. Of the 167 accidents, $35 \%$ involved runaway reactions. One noteworthy incident from recent history is the fatal explosion that occurred at T2 Laboratories in Jacksonville, FL as a result of improper scaleup and an insufficient cooling design for the system.
\end{abstract}

One recommendation resulting from the CSB investigation of the incident was that the Accreditation Board for Engineering and Technology Inc. (ABET) and the American Institute of Chemical Engineers (AICHE) work together to add reactive hazard awareness to baccalaureate chemical engineering curricula requirements. In response to this recommendation, a lab teaching the hazards of exothermic reaction scale-up was created and added to the University of Louisville Chemical Engineering Department Unit Operations II Laboratory course. This lab involves performing the exothermic iodide catalyzed decomposition of hydrogen peroxide using tabletop lab equipment and having students analyze the temperature versus time results for increasing reactor volume while other parameters remain constant. Results of these experiments prove the proposed Exothermic Reactor Scale-Up lab is repeatable and able to be used as a viable experiment in future years of the Unit Ops II course.

Introducing this new experiment to the Unit Ops lab allowed for experimentation with new teaching techniques with the goal of facilitating improved student learning in the lab. In order to test whether these new changes were beneficial to student learning, student 
experience surveys were created and distributed to everyone enrolled in the Spring 2018 Unit Ops II course. Results confirm that the exothermic reactor scale up lab is well-received by students and that the new teaching techniques are successful. Statistical analysis shows that the exothermic lab is significantly different from other Unit Ops II labs when similar categories are compared thus showing improvement to the Unit Ops course. Overall, the Exothermic Reaction Scale-Up lab is a valuable addition to the Unit Ops II laboratory. 


\section{NOMENCLATURE}

$$
\begin{aligned}
A & =\text { area of heat transfer }\left[\mathrm{m}^{2}\right] \\
c_{p} & =\text { specific heat of solution }[\mathrm{J} /(\mathrm{kg}-\mathrm{K})] \\
E_{a} & =\text { activation energy }[\mathrm{J} / \text { mol] } \\
\Delta H & =\text { enthalpy change of reaction }[\mathrm{J}] \\
{\left[H_{2} O_{2}\right] } & =\text { concentration of hydrogen peroxide }[\mathrm{mol} / \mathrm{L}] \\
{[I-] } & =\text { concentration of potassium iodide }[\mathrm{mol} / \mathrm{L}] \\
k_{o} & =\text { pre-exponential rate constant }[\mathrm{L} /(\mathrm{mol}-\mathrm{s})] \\
m & =\text { mass of solution }[\mathrm{kg}] \\
Q & =\text { heat accumulation term }[\mathrm{J}] \\
Q_{g} & =\text { heat generated }[\mathrm{J}] \\
Q_{r} & =\text { heat removed }[\mathrm{J}] \\
R & =\text { gas constant }[\mathrm{J} /(\text { mol- } \mathrm{K})] \\
T & =\text { temperature }[\mathrm{K}] \\
T_{i} & =\text { temperature }[\mathrm{K}] \\
U & =\text { overall heat transfer coefficient }\left[\mathrm{W} /\left(\mathrm{m}^{2}-\mathrm{K}\right)\right] \\
V & =\text { volume }[\mathrm{L}] \\
T & \\
T &
\end{aligned}
$$




\section{LIST OF TABLES}

TABLE I - VOLUMES OF REACTANTS (AND WATER) FOR EXPERIMENTAL MEASUREMENTS IN DIFFERENT FLASKS... .33

TABLE II - SURFACE AREAS OF HEAT TRANSFER FOR EACH FLASK (ASSUMING 50\% LIQUID LEVEL) ................................................ 33

TABLE III - SUMMARY OF POOR COOLING CONDITIONS RESULTS FOR

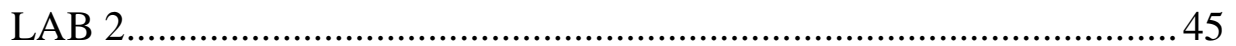

TABLE IV - SUMMARY OF TWO-SAMPLE T-TEST AND ONE-WAY ANOVA RESULTS COMPARING EXOTHERMIC REACTOR LAB TO "LEAST FAVORITE", 53

TABLE V - SUMMARY OF TWO-SAMPLE T-TEST AND ONE-WAY ANOVA RESULTS COMPARING EXOTHERMIC REACTOR LAB TO "FAVORITE" 


\section{LIST OF FIGURES}

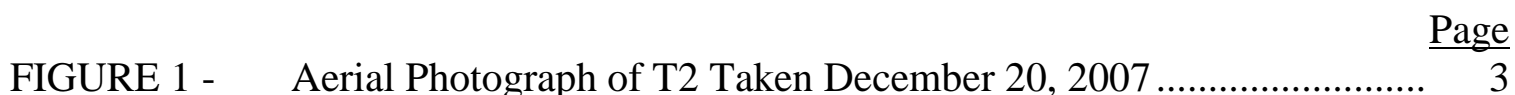

FIGURE 2 - $\quad$ Portion of the Overall Student Experience Survey - "Favorite" Lab . 23

FIGURE 3 - Portion of the Overall Student Experience Survey - "Least Favorite"

Lab ........................................................................................ 24

FIGURE 4 - $\quad$ First Part of the Student Experience Survey for the Exothermic Reactor

Scale-Up Lab ............................................................................... 25

FIGURE 5 - $\quad$ Second Part of the Student Experience Survey for the Exothermic Reactor Scale-Up ................................................................. 26

FIGURE 6 - $\quad$ Sketch of Round Bottom Flask Setup ............................................ 32

FIGURE 7 - $\quad$ Proper Setup of Round Bottom Flask in Ice Bath Showing Major Equipment ........................................................................... 32

FIGURE 8 - $\quad$ Experimental Temperature versus Time Data ................................. 39

FIGURE 9 - $\quad$ Lab 2 Experimental Temperature versus Time Data ........................ 44

FIGURE 10 - $\quad$ Lab 2 Experimental Temperature versus Time Results ..................... 44

FIGURE 11 - $\quad$ Descriptive Statistics for Exothermic Reactor Scale-Up Lab Survey 48

FIGURE 12 - One-Way ANOVA Results for Comparing Seven Identical Survey Questions.............................................................................. 50

FIGURE 13 - Tukey Pairwise Comparisons for Seven Identical Survey Questions. 51

FIGURE 14 - Labs Students Believe They Benefited the Most From (Inc Exo) ...... 55

FIGURE 15 - Labs Students Believe They Benefited the Most From (Exc Exo)..... 55

FIGURE 16 - Labs Students Believe They Benefited the Least From (Inc Exo)..... 56

FIGURE 17 - Labs Students Believe They Benefited the Most From (Exc Exo).... 56 


\section{INTRODUCTION}

\section{A. Definition of the Problem}

According to the Chemical Safety Board's 2002 report entitled "Improving Reactive Hazard Management," the CSB identified 167 serious accidents involving uncontrolled chemical reactions in the United States between 1980 and 2001 causing 108 deaths and hundreds of millions of dollars in property damage (Chemical Safety Board, 2002). Of the 167 accidents, 35\% involved runaway reactions. The majority of these accidents could have been prevented simply by having a better understanding of the chemistry behind these reactions and implementing the appropriate engineering controls.

Many of these incidents were due to improper scale-up of the reaction. In many cases of scale-up, the cooling mechanism was not sufficient for the exponentially increasing amount of heat generation of the larger reaction. Because exothermic chemical reactions are prevalent in the chemical industry, it is imperative for chemical engineers to understand the kinetics and heat transfer of these reactors in order to prevent runaway reactions.

Because of the severity of the hazards associated with exothermic reactions and how common these reactions are in the chemical manufacturing industry, universities must train chemical engineering students to be aware of these hazards. Currently, the University 
of Louisville undergraduate chemical engineering curricula formally covers this topic briefly in a Safety, Health and Environmental course. The lack of emphasis on this subject matter in the undergraduate chemical engineering curricula led to the creation and addition of the exothermic reaction scale-up experiment to the University of Louisville chemical engineering department's Unit Operations laboratory ("Unit Ops lab") as described in this work.

Furthermore, having been a student in this course in her senior year, I observed a few deficiencies in the way students experienced and learned the Unit Ops lab curriculum. I sought to use this project of creating a new lab experiment for the purpose of trying new teaching techniques in the Unit Ops environment. The process of doing so as well as the results obtained are also described in this work.

\section{B. Brief History Leading Up to the Problem: T2 Laboratories Explosion}

Several major incidents in recent history show the importance of teaching the hazards of exothermic reaction scale-up in industry. One very well-known example is the fatal incident that occurred at T2 laboratories in Jacksonville, Florida on December 19, 2007 (Chemical Safety Board, 2009). T2 Laboratories produced methylcyclopentadienyl manganese tricarbonyl (MCMT) in batches using a 2,500 gallon reactor. An operator controlled the process using a computerized system in a nearby control room. In normal operation of the reactor that produced MCMT, the operator would heat the reaction mixture via a hot oil system until it reached a temperature of $300^{\circ} \mathrm{F}$. Then, the operator would allow the exothermic reaction mixture to reach a temperature of $360^{\circ} \mathrm{F}$ from the energy released 
from the reaction. After this, he would periodically fill the reactor cooling jacket with cooling water to bring the reaction temperature under control.

On the day of the incident, the operator tried to add cooling water to the reactor cooling jacket but the cooling system failed. This left the exothermic reaction mixture uncooled and quickly rising in temperature and pressure. This runaway reaction led to an explosion that killed four people and injured 32 others.

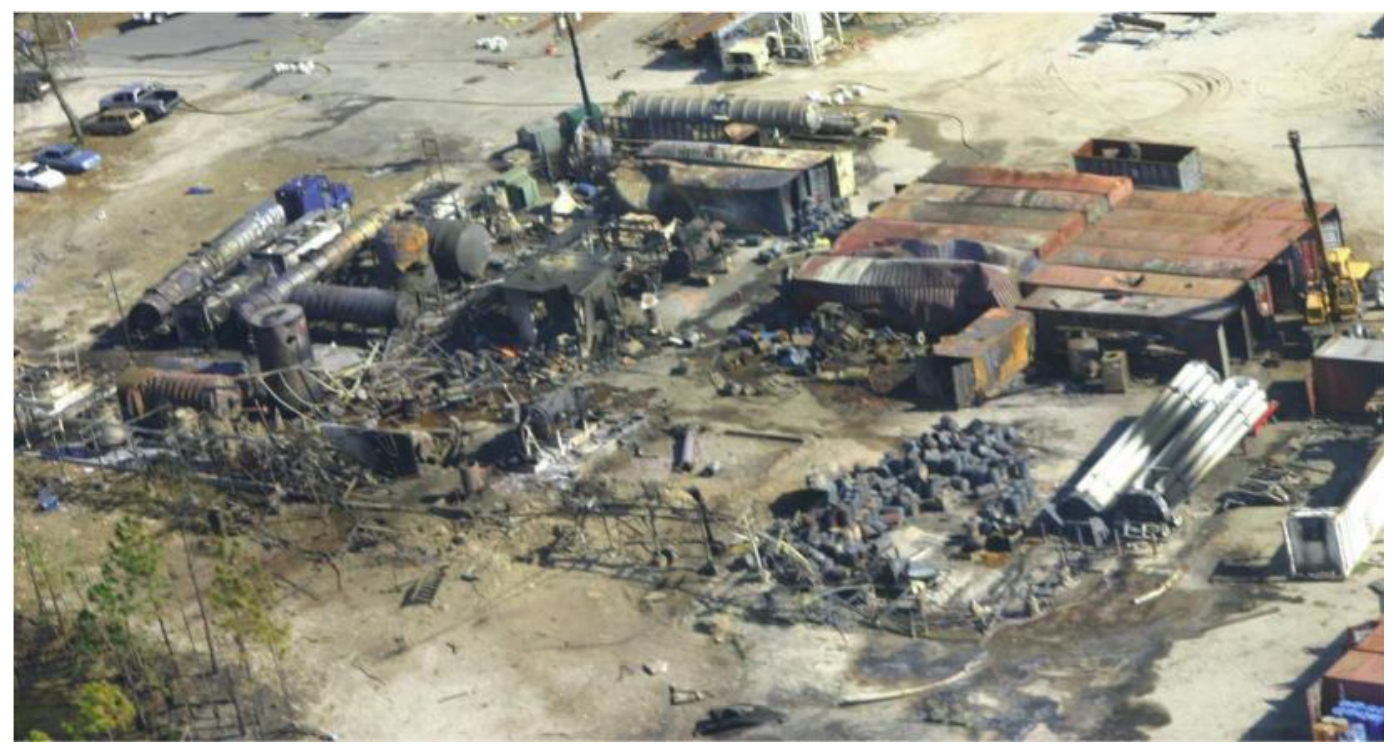

FIGURE 1 - Aerial Photograph of T2 Taken December 20, 2007 (Chemical Safety Board, 2009)

As part of their investigation into T2 Laboratories, the Chemical Safety Board found evidence that the company had improperly scaled up their MCMT process. T2 Laboratories developed the MCMT process using a one-liter reactor and then directly scaled up the process to a 2,500 gallon reactor. After 41 batches, T2 Laboratories increased the batch size again. With every increase in reactor volume, it became increasingly difficult for the system to provide effective cooling for the reaction. The following excerpt from the Final Report on T2 labs describes what the Chemical Safety Board found: 
"In 2005, at Batch 42, T2 increased the batch size by one third. There are no records of additional chemical or process analysis conducted as part of this recipe change, which may have introduced significant new risks. A greater volume of reactants increased the energy that the reaction could produce, and likely altered cooling and pressure relief requirements. When the MCMT process yielded unexpected results in early batches, $\mathrm{T} 2$ did not halt production, investigate causes, and redesign the process. Instead, T2 attempted to control unexpected reaction results on-line through operator controls or minor alterations to continue running the process as it was already constructed. As demand grew, T2 increased batch size and frequency with no additional documented hazard analysis" (Chemical Safety Board, 2009). The Chemical Safety Board's key findings state that the desired exothermic reaction ran away due to a cooling system failure which led to a second undesired exothermic reaction. T2 designed the reactor to have a simple cooling system which "lacked design redundancy and was susceptible to single-point failure." The T2 owner/chemical engineer designed the pressure relief system for normal operating conditions, and it was unable to relieve the second exothermic reaction. Furthermore, the $\mathrm{T} 2$ owner/chemical engineer probably was not aware of the second exothermic reaction that could occur at high temperatures. Lastly, the CSB concluded that "most baccalaureate chemical engineering curricula in the U.S. do not specifically address reactive hazard recognition or management."

\section{Purpose of the Project}

The purpose of this project is to create a viable experiment for the University of Louisville Chemical Engineering Department's Unit Operations Laboratory that exposes 
students to the dangers of exothermic reactions with the potential for thermal runaway. This project creates a lab that equips students with the knowledge and experience to work with these reactions and hazards in their future chemical engineering careers. The results of this work can also be used to improve student experience in the Unit Ops lab overall. Completing this project satisfies educational recommendations put forth by the Chemical Safety Board during their investigation of T2 laboratories.

After the Chemical Safety Board concluded their investigation of the T2 Laboratories explosion, one of their recommendations was that the Accreditation Board for Engineering and Technology Inc. (ABET) and the American Institute of Chemical Engineers (AICHE) work together to add reactive hazard awareness to baccalaureate chemical engineering curricula requirements (Chemical Safety Board, 2009). Simply mentioning the dangers of exothermic reaction scale-up in a lecture or briefly discussing the consequences of T2 Laboratories' improper scale-up in the classroom may be an appropriate response to this recommendation, but how much more would students understand the dangers of exothermic reaction scale-up if they had the opportunity to experience it personally through the performance of a laboratory exercise?

According to a publication from the National Academies Press entitled "America's Lab Report," laboratory experiences may help students learn to address the challenges inherent in directly observing and manipulating the material world, including troubleshooting equipment used to make observations, understanding measurement error, and interpreting and aggregating the resulting data. Laboratory experiences may be the only way to advance the goal of helping students understand the complexity and ambiguity of empirical work (Singer, Hilton et al. 2006). Although, the research presented in 
"America's Lab Report" was done specifically for high school laboratory exercises, it stands to reason that this principle holds for collegiate level laboratories as well. Moreover, the benefits of laboratory exercises described in this publication, carry more weight for chemical engineering students because of the need for practicing chemical engineers to be able to understand "the complexity and ambiguity of empirical work." In other words, laboratory experiences help chemical engineering students connect to the real world more effectively than traditional classroom learning. Therefore, teaching the hazards of exothermic reaction scale-up to chemical engineering students will be most successful if done using an interactive laboratory experiment.

The purpose of the project is achieved when students are able to complete the learning objectives written for the lab. For this experiment, several learning objectives were developed using Bloom's Taxonomy as a guide. There are six major cognitive categories of Bloom's Taxonomy of Educational Objectives: knowledge, comprehension, application, analysis, synthesis, and evaluation. According to an article analyzing general chemistry lab procedure manuals for higher order cognitive thinking, Daniel Domin found that the overwhelming majority of general chemistry laboratory manuals provide tasks that require the use of only the lower-order cognitive skills: knowledge, comprehension, and application (Domin, 1999). Domin asserts that higher-order thinking skills are recognized as a valuable component of science education and a necessity for young adults entering the work force. He furthers his point by quoting an article from human resource executives by the Bayer Corporation which focused on science education issues and skills needed for entry-level jobs, saying that nearly $80 \%$ of the executives believe employers "will best be 
served by employees with skills for hands-on experimentation, problem solving and critical thinking."

The exothermic reaction scale-up lab was designed to achieve five learning objectives. After completing the lab, students should be able to:

- $\quad$ Discuss the dangers of runaway reactions using evidence from well-known industrial accidents.

- $\quad$ Explain how runaway reactions can be prevented especially when caused by improper scale-up.

- $\quad$ Relate the components of the tabletop reaction to the process of scaling up in industry.

- Compare experimental and theoretical temperature versus time data for exothermic reactions.

- Use kinetics and heat transfer principles to predict when runaway reactions will occur.

The first two learning objectives require the use of the lower-order cognitive skills of knowledge, comprehension and application. The last three learning objectives require the use of the higher-order cognitive skills of analysis, synthesis and evaluation.

\section{Literature Review}

The Exothermic Reaction Scale-Up Lab created for the Chemical Engineering Department's Unit Ops laboratory at the University of Louisville is largely based on a similar experiment from Worcester Polytechnic Institute as described in a Chemical Engineering Education (CEE) article by William Clark. Their exact experiment was not 
replicated as described in the procedure from Worcester Polytechnic Institute but instead a similar experiment was created to focus on teaching the same principles of the hazards of exothermic reaction scale-up.

In the CEE article entitled "An Experiment to Illustrate the Hazards of Exothermic Reaction Scale-Up," William Clark concludes that "conditions have been identified for conducting a relatively safe experiment that provides a dramatic illustration of the need to account for heat removal when scaling up an exothermic reaction" (Clark, Lei et al. 2017). In the article, Clark describes the experimental setup used at Worcester Polytechnic Institute. This experiment is designed to either be conducted by small student teams in a laboratory course or used as a demonstration by an instructor in a classroom setting. For the lab course, each team of students should be able to measure the heat transfer coefficient and conduct the reaction in two different sized flasks in a 3-hour lab session. The team at Worcester Polytechnic Institute found that performing the reaction first with a $100 \mathrm{~mL}$ flask then followed by a $1000 \mathrm{~mL}$ flask gave the most dramatic effect. This experiment uses much the same equipment and setup as is described for the University of Louisville version of the lab discussed in detail in the Methods section of this work.

The laboratory experiment from Worcester Polytechnic Institute is called "Scaleup of an Exothermic Batch Reaction" and is designed to help students "discover and then explain and discuss some of the hazards that can arise when scaling up an exothermic chemical reaction" (Worcester Polytechnic Institute, 2015). The Worcester Polytechnic Institute experiment was created based on research done for "Heat Transfer in Reactor Scale-Up" a major qualifying report submitted to Worcester Polytechnic Institute as a part of a capstone project done by a group of senior chemical engineering students from the 
school. This report was written to "investigate differences in heat transfer between round bottom flasks and industrial sized equipment through research, laboratory experiments, and computer modeling" (Dickerson, Kirichenko et al. 2015). The report establishes non-linear relationship between reactor size and cooling capability and provides heat transfer data for the iodide catalyzed decomposition reaction as performed in $100 \mathrm{~mL}, 250 \mathrm{~mL}, 500 \mathrm{~mL}$ and 1000 mL flasks.

The Exothermic Reaction Scale-Up Lab created for the University of Louisville uses the majority of the values for constants established by the research done by Dickerson, Kirichenko, et al. in their major qualifying report. The only exception is in the case of the value for the activation energy of the iodide-catalyzed decomposition of hydrogen peroxide. Instead of using the value of $-98,000 \mathrm{~J} /(\mathrm{mol}-\mathrm{K})$, the value $-98,300 \mathrm{~J} /(\mathrm{mol}-\mathrm{K})$ is used. This value comes from an article in the Journal of Chemical Education in which a lab experiment for an efficient method to determine activation energy for this specific reaction is proposed (Sweeney, Lee et al. 2014). The lab created for the University of Louisville also draws heavily on the theory and methodology for calculations that is presented in the CEE article for the Worcester Polytechnic Institute Scale-up of an Exothermic Batch Reaction lab. The main difference in the lab designed for the University of Louisville and that of Worcester Polytechnic Institute is that the former scales up between $100 \mathrm{~mL}, 250 \mathrm{~mL}$ and $500 \mathrm{~mL}$ while the latter uses $100 \mathrm{~mL}$ and $1000 \mathrm{~mL}$ flasks only. Another difference is that for the lab designed for the University of Louisville, students can see the effects of poor cooling conditions (which mimic examples of loss of cooling or system failure in industry) in addition to the consequences of scaling up reaction volume while keeping all else constant. 


\section{E. Theory}

The exothermic reaction scale-up lab uses the iodide-catalyzed decomposition of hydrogen peroxide as shown in Equation 1.

$$
\mathrm{H}_{2} \mathrm{O}_{2} \stackrel{\text { \ } \mathrm{KII}}{\longrightarrow} \mathrm{H}_{2} \mathrm{O}+\frac{1}{2} \mathrm{O}_{2}
$$

The students will perform the experiment in different sized flasks and observe the differences in behavior in each of them. In each case, an ice bath will be used as the cooling mechanism to keep the reaction under control. Students will obtain temperature versus time data for each reaction.

The iodide catalyzed decomposition of hydrogen peroxide is described by the following rate equation:

$$
\text { rate }=\frac{-\mathrm{d}\left[\mathrm{H}_{2} \mathrm{O}_{2}\right]}{\mathrm{dt}}=\mathrm{k}_{\mathrm{o}} \exp \left(\frac{-\mathrm{Ea}}{\mathrm{RT}}\right)\left[\mathrm{H}_{2} \mathrm{O}_{2}\right]\left[\mathrm{I}^{-}\right]
$$

with the total amount of heat in the system given by

$$
\mathrm{Q}=\mathrm{Q}_{\mathrm{g}}+\mathrm{Q}_{\mathrm{r}}
$$

where $\mathrm{Q}_{\mathrm{g}}$ is the amount of heat generated and $\mathrm{Q}_{\mathrm{r}}$ is the amount of heat removed. The heat of a system can be expressed as 


$$
\mathrm{Q}=\mathrm{mc}_{\mathrm{p}} \frac{\mathrm{dT}}{\mathrm{dt}}
$$

where $c_{p}$ is the specific heat and $m$ is the mass of the solution. Heat is removed from the reaction via an ice bath and is given by

$$
\mathrm{Q}_{\mathrm{r}}=\mathrm{UA}\left(\mathrm{T}_{\mathrm{i}}-\mathrm{T}\right)
$$

where $\mathrm{U}$ is the overall heat transfer coefficient, $\mathrm{A}$ is the area available for heat transfer and $\mathrm{T}_{\mathrm{i}}$ is the temperature of the ice bath. Throughout the experiment, the ice bath temperature can be assumed to remain nearly constant at $0^{\circ} \mathrm{C}$. This assumption is possible when the ice bath is sufficiently stirred and an adequate amount of ice is maintained. When performing this lab, students are prompted in the procedure to monitor the ice bath temperature via a local thermometer and add ice, if necessary, to maintain the temperature at $0^{\circ} \mathrm{C}$. This creates a constant heat sink for the experiment. The heat generated by the reaction is given by

$$
\mathrm{Q}_{\mathrm{g}}=-\mathrm{V} \Delta \mathrm{H}^{\mathrm{o}} \text { (rate) }
$$

As this reaction is exothermic the heat of reaction is negative and it follows that $\mathrm{Q}_{\mathrm{g}}$ is positive or heat is indeed generated. On the other hand, $Q_{r}$ is negative because $T_{i}$ is less than the reaction temperature $\mathrm{T}$ as seen in Equation 5. Any imbalance between the rate of 
heat generation and rate of heat removal will result in energy accumulation and a concomitant temperature change within the reactor given by

$$
\mathrm{mc}_{\mathrm{p}} \frac{\mathrm{dT}}{\mathrm{dt}}=-\mathrm{V} \Delta \mathrm{H}^{\mathrm{o}}(\text { rate })+\mathrm{UA}\left(\mathrm{T}_{\mathrm{i}}-\mathrm{T}\right)
$$

Both the specific heat and the mass are assumed to be constant here. (Neglect any loss of mass due to water saturated oxygen bubbles.) Solving Equations 2 and 7 simultaneously provides information for $\mathrm{T}$ and $\left[\mathrm{H}_{2} \mathrm{O}_{2}\right]$ in the reactor as a function of time. The constants, $\mathrm{c}_{\mathrm{p}}, \quad \mathrm{H}^{\mathrm{o}}$, and Ea can be found in the literature to be $4.18 \mathrm{~J} / \mathrm{g} \mathrm{K}$ (assuming the value for water), $-98.3 \mathrm{~kJ} / \mathrm{mol}$, and $56 \mathrm{~kJ} / \mathrm{mol}$, respectively. The value of $\mathrm{U}$ can be estimated in a separate experiment using only water. This is done by using an ice bath to cool a known mass of water, $\mathrm{m}$, at a known initial temperature, $\mathrm{T}_{\mathrm{o}}$ with an experimental setup almost identical to the decomposition reaction experiment. Because there is no reaction taking place, the rate term in Equation 7 is zero. Rearranging and integrating Equation 7 gives

$$
\frac{\left(T_{i}-T_{o}\right)}{\left(T_{i}-T\right)}=\exp \left(\frac{U A t}{m_{p}}\right)
$$

To find $\mathrm{U}$, plot $\ln \left[\left(\mathrm{T}_{\mathrm{i}}-\mathrm{T}_{\mathrm{o}}\right) /\left(\mathrm{T}_{\mathrm{i}}-\mathrm{T}\right)\right]$ versus $\mathrm{t}$. This yields a straight line and $\mathrm{U}$ can be obtained as

$$
\mathrm{U}=\frac{\text { slope } * \mathrm{~m} * \mathrm{c}_{\mathrm{p}}}{\mathrm{A}}
$$


To complete the solution of Equations 2 and 7, the pre-exponential constant, $\mathrm{k}_{\mathrm{o}}$, must be known or estimated. For this lab experiment use the estimated value of $3.083 \times 10^{8}$ L/mol s.

\section{F. Description of Unit Ops Course}

In order to facilitate an understanding of the development and execution of this project, it is necessary to provide a current description of the Unit Ops lab course in the chemical engineering department of the University of Louisville. The lab course is split into two parts and is usually taken during a chemical engineering student's senior year. The first part (CHE 485) is taught in the fall semester and covers simple experiments relating to fluid mechanics, momentum and heat transfer (Jim Gerstle, 2017). These experiments include studying thermal conductivity, heat exchangers, packed columns, pumps and a stirred tank. The second part of the course (CHE 486) is taught in the Spring semester and includes "selected mass transfer experiments covering such areas as filtration, drying, distillation, evaporation, kinetics, reactor scale-up, fermentation, environmental concerns, etc" (Jim Gerstle, 2018). The Exothermic Reactor Scale-Up lab was created for Unit Ops II and introduced to the course in the Spring semester of 2018.

The Unit Ops II course is currently designed so that each lab group performs three labs throughout the semester. Each experiment includes a prelab day, a lab day and a calculation review day with a week in between each of these. The final report is generally due the week after the calculation review day which also doubles as the prelab day for the next lab. Each section of the class meets only on their designated class day each week. 


\section{G. An Outline of the Remainder of the Work}

The remainder of this work shows the development and execution of the project to create the Exothermic Reaction Scale-Up lab. The Experimental Methods section describes the plan I followed to complete the project. This section also describes the materials, instrumentation and equipment needed for the lab as well as resources for the teaching assistant to prepare for and safely supervise the performance of the experiment. The Experimental Methods section concludes with the final procedure proposed for future iterations of this lab.

The Results and Discussion section presents the experimental results from each of the labs performed in preparation for and during the Spring 2018 semester. This section discusses the numerical results of each lab as well as the issues encountered with performing each experiment and what was done to improve the experiment at key steps throughout the project. A statistical analysis of the student experience surveys is included in this section as well. Finally, the work ends with a section discussing the conclusions drawn from the results and recommendations for the future. 


\section{EXPERIMENTAL METHODS}

\section{A. Plan for Executing Project}

The development of the lab went through several trials to get to the form that is proposed for future semesters of Unit Ops II lab. Each stage of development is described below to show the process of how I created the final version of the experiment that is recommended for use in future years for the Unit Ops laboratory. Note, the results and discussion section is broken up into segments that follow the stages described below.

The first stage of the development for the Exothermic Reaction Scale-Up lab was to start with the "Scale-up of an Exothermic Batch Reaction" lab procedure provided by Worcester Polytechnic Institute and create a version of the lab for use at the University of Louisville. Then I performed preliminary experiments to get an idea of the experimental setup and timing that would work for the Unit Ops II lab. During this time, I planned for what changes she wanted to make to the way the lab would be taught in comparison to the other Unit Ops II labs. Once an experimental design proved to work with one person performing the experiment, I asked a team of three chemical engineering graduate students to perform the experiment as if they were Unit Ops II students and I was their teaching assistant. These trials brought many issues with the experimental setup to light but also 
allowed for a breakthrough in the design to improve students' experience with the lab. The exothermic reactor lab was then officially added to the syllabus for the Spring 2018 semester of Unit Ops II and nine groups totaling 37 students performed the experiment on three different weeks. Student experience surveys were created to evaluate the students' experience with the exothermic reactor scale-up lab and then compare this with students' experience of the Unit Ops II labs overall.

\section{B. Description of New Active Learning Techniques}

One of the major differences between the Exothermic Reactor Scale-Up lab and the other labs in Unit Ops II is the way the prelab day is handled. Prelab for the other Unit Ops II labs usually consists of students having to read the procedure for the lab, jot down necessary safety precautions, look at the equipment they are to use, make a rough sketch of the experimental setup, propose a data collection table to be used during the experiment, verbally describe how they will perform the lab and check in with their assigned teaching assistant to briefly go over all of these items. The team of students would complete these tasks before approaching their assigned teaching assistant to check in for their participation

points for the day. The teaching assistant would then talk to the students for about ten to fifteen minutes to make sure they had completed the prelab tasks before giving them their participation points and allowing them to leave for the day. Based on her previous experience, I concluded that this approach to prelab day did not provide much insight for why a lab was important or how the theory and key equations related to the actual performance of the lab. Because of this, I decided to take a different approach to prelab day. 
Overall, I created a new way of handling prelab day that requires more involvement from teaching assistants which is intended to facilitate a better learning environment for students. This would include engaging the students in more levels of Bloom's Taxonomy as previously mentioned. I began each prelab session by asking students to review the experimental procedure together with their teammates. Then, I led a prelab discussion that described why the lab is important to chemical engineering students. This discussion reviewed what runaway reactions are and what causes them (i.e. more heat is generated in a system than the amount that can be removed which leads to an uncontrollable increase in temperature). I also explained how the key equations listed in the theory section of the procedure relate to how runaway reactions occur. Basically, instead of only focusing on how students were to perform the lab, I led a prelab discussion that described why the lab is important, how the key equations relate to the concepts presented in the lab and how to actually perform the lab.

The prelab discussion consisted of meeting with one group of four or five students near the lab equipment. Open and closed questions were asked in order to facilitate dialogue between me (who was also the teaching assistant) and the Unit Ops students. Simple closed questions were used as a way to engage everyone in the group especially those who were more shy or hesitant to participate. For instance, I would ask the students to hypothesize what color the reaction mixture would be once the potassium iodide was added to the hydrogen peroxide. Each student would give their guess before the teaching assistant would give the answer: deep orange or yellow. This provided a low risk situation to encourage student participation and would usually engage the lower levels of Bloom's Taxonomy like knowledge. Then I would ask a more open question based on basic 
chemistry/chemical engineering knowledge such as "explain why one can assume the potassium iodide concentration in the rate law equation does not change." Most students answered correctly saying that the potassium iodide was a catalyst and therefore is not consumed in the reaction. If anyone did not understand or seemed not to understand, then I would explain the concept further. Open questions like this one allowed students to engage in higher levels of Bloom's Taxonomy such as application because students would be applying their previous knowledge of chemistry to understand the calculation regarding the reaction they were performing.

The most significant change to the prelab day is the addition of a prelab assignment. No other lab in Unit Ops II currently includes a prelab assignment. The prelab assignment for the Exothermic Reactor Scale-Up lab is designed to expose students to well-known industrial accidents that resulted from runaway reactions, have students explain how runaway reactions can be prevented especially when caused by improper scale-up, allow students to begin a portion of their calculations and finally, relate the components of the tabletop reaction to what these components would be if the experiment was scaled up in industry. The prelab assignment is a reasonable length with only three questions and students are encouraged to complete the assignment as a group. I would inform the students that the prelab assignment was not going to be collected and formally graded but instead would serve as the material for discussion the following week before students were allowed to begin performing their lab. On the day of the lab, I would spend the first 15 minutes of class time verbally going over the prelab assignment in detail with every member of the group. This way even if the group split up the work between themselves, every student in the group would be exposed to the correct answers. Completion of the prelab assignment 
not only gives students valuable information to include in their final reports but also helps students meet three of the five learning objectives associated with this lab. Several questions are included in the student experience surveys to evaluate student experience for the prelab discussion and assignment. A copy of the prelab assignment is located in Appendix V.

In addition to trying new active learning techniques with prelab, I also sought to improve students' learning on lab day. On lab days, I verbally asked questions to promote learning of the concepts regarding exothermic reactor scale-up throughout the time students performed the lab. These questions usually prompted students to answer why they were taking certain steps in the procedure or what their observations from the reaction meant. One example of a verbal question asked was "can you explain why there is a color change after the potassium iodide is added into the hydrogen peroxide? What is happening on a molecular level?" Another example of an included question was "what should the contents of the reaction flask look like if the reaction goes to completion? Why is this so?" Questions like these facilitate discussion in which students can gain a better understanding of the underlying concepts of an experiment while they are performing it. Sometimes I would pose the question to every group member while other times I would only ask one or two of the students. The questions were meant to engage the students during key points of the lab so that they could easily apply the concepts they were learning to the lab they were doing. The student experience survey includes several questions asking for feedback regarding students' interaction with the teaching assistant during the lab.

The last area for improvement was the calculation review day. From past experience, I observed that many students in Unit Ops II lack an understanding of the 
underlying concepts of each lab until it is time to write the final report Even then students struggle or feel "lost" not knowing where to begin their writing. For this reason, I used the calculation review day as an opportunity to solidify the theory concepts in the minds of the students before they were to begin writing their final reports. Throughout the Spring 2018 semester, it became clear that a structured way of reviewing the calculations and preparing students for the final report was necessary. Because of this, I created a list of calculation guidelines and final report deliverables to be given to students on calculation review day. Both lists were not all inclusive but instead acted as quick checklists for steps or ideas that should not be excluded from the calculation and writing processes. The student experience survey also includes several questions asking for feedback regarding students' calculation review and final report writing experience.

\section{Materials, Instrumentation and Equipment Used for the Lab}

Below is a list of the safety equipment, materials, glassware, instrumentation and other equipment required for the full experiment to be performed by students.

\section{$\underline{\text { Safety Equipment: }}$}

- $\quad$ Safety glasses

- $\quad$ Nitrile gloves

Materials:

- $\quad 30 \%$ hydrogen peroxide (chilled)

- $\quad 0.1 \mathrm{M}$ potassium iodide

- Water

- Ice 


\section{Glassware:}

- $\quad 12$ quart clear containers (2)

- $\quad 25 \mathrm{~mL}$ pipette and bulb

- $\quad$ Graduated cylinders

- $\quad 100 \mathrm{~mL}$ round bottom flasks (2)

- $\quad 250 \mathrm{~mL}$ round bottom flasks (2)

- $\quad 500 \mathrm{~mL}$ round bottom flasks (4)

Instrumentation and Other Equipment:

- $\quad$ Small stir bars (for flasks)

- $\quad$ Large stir bars (for ice bath)

- $\quad$ Funnels

- $\quad$ Clamps and clamp stands

- $\quad$ Traceable ${ }^{\circledR}$ thermometers (4)

- $\quad$ National Instrument USB TC-01 thermocouples (2)

- $\quad$ Laptop with available USB port (must be compatible with National Instrument thermocouples)

\section{Description of Student Experience Surveys}

In order to assess the effectiveness of the Hazards of Exothermic Reaction ScaleUp experiment on student learning, the Mater's student created and administered two surveys at the end of the Spring 2018 semester. This was done the week after the final reports for Lab 3 were to be submitted to get feedback from the 61 students enrolled in the course. The first survey was given to each student enrolled in the course and was meant to evaluate their experience with the Unit Ops II labs overall. The second survey was given 
to the 37 students who performed the Exothermic Reaction Scale-Up lab throughout the semester. Both surveys used a Likert scale for the closed-type questions using the following scheme: 1-strongly disagree, 2-disagree, 3-neither agree nor disagree, 4-agree and 5strongly agree. Both surveys also included optional open-ended questions where suggestions could be made.

In order to create these surveys, I sought validation from two engineering education professionals: Dr. Gerstle and Dr. McNeil. Dr. Gerstle was the Unit Ops lab instructor for Spring 2018 and was therefore very knowledgeable of the course. Once I created drafts of the surveys, Dr. Gerstle provided insight into how to structure the surveys so that the length would be reasonable thereby encouraging a higher response rate among students. He also agreed with me that the surveys should be distributed via paper copies and personally given to each student also with the goal of a higher response rate. Dr. McNeil was a professor in the Speed School Engineering Fundamentals department and had several years of experience researching student learning. She validated the format and content of the survey and suggested adding questions regarding gender and race. Once both of these professors validated the surveys, they were distributed to students.

The first survey was the shorter of the two surveys and asks for students' feedback from their overall experiences with the course. The survey was split up into three sections: questions regarding the lab students feel they benefited from the most; questions regarding the lab students feel they benefited from the least; and optional free response questions focused on allowing students to give suggestions for overall improvement. There was also space provided for students to voluntarily indicate their gender and race. Figures 2 and 3 show portions of the front page of this survey. The back page provides space for students 
to describe what they enjoyed most from Unit Ops II lab, any issues they experienced with the labs and what they personally think could be done to make the course better. The overall survey was designed in such a way that it could be used in future iterations of the course to provide meaningful feedback for the instructor. This survey was created with the goal of continuous improvement for the Unit Ops II labs and also as a comparison to the results obtained from the second student experience survey which was specific to the Exothermic Reactor Scale-Up lab.

\begin{tabular}{|c|c|c|c|c|c|c|}
\hline \multicolumn{7}{|c|}{ Overall Experience: Please write out your responses to the following. } \\
\hline & \multicolumn{6}{|l|}{ 1) Which lab did you get the most out of? } \\
\hline & \multicolumn{6}{|l|}{ 2) Which lab did you get the least out of? } \\
\hline \multicolumn{7}{|c|}{ Individual Lab Experience: For each of the items below, indicate your response: } \\
\hline & rongly Disagree; $\quad 2$-Disagree; 3 - Neither agree nor disagree; $4-A_{\varepsilon}$ & & $5-5$ & ong & Agre & \\
\hline \multicolumn{7}{|c|}{ Favorite Lab (the lab you got the most out of) } \\
\hline 1) & $\begin{array}{l}\text { The prelab discussion led by the Teaching Assistant (on my scheduled } \\
\text { prelab day) for the lab adequately prepared me to perform the } \\
\text { experiment on my scheduledlab day. }\end{array}$ & 1 & 2 & 3 & 4 & 5 \\
\hline 2) & $\begin{array}{l}\text { The prelab discussion led by the Teaching Assistant (on my scheduled } \\
\text { prelab day) was very useful in helping me understand the overall } \\
\text { purpose of the lab. }\end{array}$ & 1 & 2 & 3 & 4 & 5 \\
\hline 3) & $\begin{array}{l}\text { The written procedure provided to me was easy to understand and } \\
\text { follow. }\end{array}$ & 1 & 2 & 3 & 4 & 5 \\
\hline 4) & $\begin{array}{l}\text { I felt that I was given enough tasks to keep me busy throughout the } \\
\text { scheduled lab time. }\end{array}$ & 1 & 2 & 3 & 4 & 5 \\
\hline 5) & $\begin{array}{l}\text { The Teaching Assistant gave me clear instructions on how to perform the } \\
\text { calculations necessary to obtain results from my experimental data. }\end{array}$ & 1 & 2 & 3 & 4 & 5 \\
\hline 6) & $\begin{array}{l}\text { I felt "Iost" and did not know where to begin when writing the Results } \\
\text { and Discussion portions of our report. }\end{array}$ & 1 & 2 & 3 & 4 & 5 \\
\hline 7) & $\begin{array}{l}\text { My group and I clearly understood the expectations for what was to be } \\
\text { discussed in the final report. }\end{array}$ & 1 & 2 & 3 & 4 & 5 \\
\hline
\end{tabular}

FIGURE 2 - Portion of the Overall Student Experience Survey - "Favorite" Lab 


\begin{tabular}{|c|c|c|c|c|c|c|}
\hline \multicolumn{7}{|c|}{ Least Favorite Lab (the lab you got the least out of) } \\
\hline 1) & $\begin{array}{l}\text { The prelab discussion led by the Teaching Assistant (on my scheduled } \\
\text { prelab day) adequately prepared me to perform the experiment on my } \\
\text { scheduled lab day. }\end{array}$ & 1 & 2 & 3 & 4 & 5 \\
\hline 2) & $\begin{array}{l}\text { The prelab discussion led by the Teaching Assistant (on my scheduled } \\
\text { prelab day) was very useful in helping me understand the overall } \\
\text { purpose of the lab. }\end{array}$ & 1 & 2 & 3 & 4 & 5 \\
\hline 3) & $\begin{array}{l}\text { The written procedure provided to me was easy to understand and } \\
\text { follow. }\end{array}$ & 1 & 2 & 3 & 4 & 5 \\
\hline 4) & $\begin{array}{l}\text { I felt that I was given enough tasks to keep me busy throughout the } \\
\text { scheduled lab time for this experiment. }\end{array}$ & 1 & 2 & 3 & 4 & 5 \\
\hline 5) & $\begin{array}{l}\text { The Teaching Assistant gave me clear instructions on how to perform the } \\
\text { calculations necessary to obtain results from my experimental data. }\end{array}$ & 1 & 2 & 3 & 4 & 5 \\
\hline 6) & $\begin{array}{l}\text { I felt "lost" and did not know where to begin when writing the Results } \\
\text { and Discussion portions of our report for this lab. }\end{array}$ & 1 & 2 & 3 & 4 & 5 \\
\hline 7) & $\begin{array}{l}\text { My group and I clearly understood the expectations for what was to be } \\
\text { discussed in the final report for this lab. }\end{array}$ & 1 & 2 & 3 & 4 & 5 \\
\hline \multicolumn{7}{|c|}{ Individual Student Information: Please indicate your gender and race below. } \\
\hline Gender: & Prefer Not to Answer & & & & & \\
\hline Race: & Prefer Not to An & wer & & & & \\
\hline
\end{tabular}

\section{FIGURE 3 - Portion of the Overall Student Experience Survey - "Least Favorite" Lab}

The second student experience survey was specific to the Exothermic Reaction Scale-Up lab. The survey was meant to analyze students' experiences with the entirety of this lab from prelab day to the completion of the final report. Many of the questions were written with the intention of evaluating new active learning methods that were introduced through the exothermic reaction lab. Some of the same questions appear on both the overall survey and the exothermic reaction lab survey. This was to allow for statistical comparison of the results between different labs. In addition to these questions, much like the overall survey, the back page provides space for students to describe what they enjoyed most from the exothermic reaction lab, any issues they experienced with the lab and what they personally think could be done to make the lab better. Portions of this survey are shown in Figures 4 and 5. Additionally, complete copies of both of these surveys can be found in Appendix II. 


\begin{tabular}{|c|c|c|c|c|c|c|}
\hline \multicolumn{7}{|c|}{ Individual Lab Experience: For each of the items below, indicate your response: } \\
\hline & rongly Disagree; $\quad 2$-Disagree; 3 - Neither agree nor disagree; $4-\mathrm{Ag}$ & & $5-S$ & ong & Agre & \\
\hline \multicolumn{7}{|c|}{ Exothermic Reactor Scale-Up Lab } \\
\hline 1) & $\begin{array}{l}\text { The prelab discussion led by the Teaching Assistant (on my scheduled } \\
\text { prelab day) for this lab adequately prepared me to perform the } \\
\text { experiment on my scheduled lab day. }\end{array}$ & 1 & 2 & 3 & 4 & 5 \\
\hline 2) & $\begin{array}{l}\text { The prelab discussion led by the Teaching Assistant (on my scheduled } \\
\text { prelab day) was very useful in helping me understand the overall } \\
\text { purpose of the lab. }\end{array}$ & 1 & 2 & 3 & 4 & 5 \\
\hline 3) & $\begin{array}{l}\text { The overall prelab experience (prelab discussion and assignment) was } \\
\text { useful for writing my final report. }\end{array}$ & 1 & 2 & 3 & 4 & 5 \\
\hline 4) & $\begin{array}{l}\text { I would have preferred to have had the prelab assignment given to me as } \\
\text { an individual assignment rather than a group assignment. }\end{array}$ & 1 & 2 & 3 & 4 & 5 \\
\hline 5) & $\begin{array}{l}\text { I would have preferred to have the prelab assignment formally graded } \\
\text { rather than informally discussed prior to performing the experiment. }\end{array}$ & 1 & 2 & 3 & 4 & 5 \\
\hline 6) & $\begin{array}{l}\text { The prelab assignment was unreasonably long in terms of how much } \\
\text { time it took to complete. }\end{array}$ & 1 & 2 & 3 & 4 & 5 \\
\hline 7) & $\begin{array}{l}\text { The prelab assignment was unnecessary and did not help me at all in } \\
\text { terms of understanding the importance of learning about the hazards of } \\
\text { exothermic reaction scale-up. }\end{array}$ & 1 & 2 & 3 & 4 & 5 \\
\hline 8) & $\begin{array}{l}\text { The written procedure provided to me for the exothermic reactor lab was } \\
\text { easy to understand and follow. }\end{array}$ & 1 & 2 & 3 & 4 & 5 \\
\hline 9) & $\begin{array}{l}\text { The additional verbal instructions given to me by the Teaching Assistant } \\
\text { throughout the lab were helpful to me. }\end{array}$ & 1 & 2 & 3 & 4 & 5 \\
\hline 10) & $\begin{array}{l}\text { I would have preferred the Teaching Assistant to have been less "hands } \\
\text { on" during the performance of the exothermic reactor lab. }\end{array}$ & 1 & 2 & 3 & 4 & 5 \\
\hline 11) & $\begin{array}{l}\text { The questions the Teaching Assistant asked my group as we performed } \\
\text { the lab helped me understand what was happening in the lab. }\end{array}$ & 1 & 2 & 3 & 4 & 5 \\
\hline
\end{tabular}

FIGURE 4 - First Part of the Student Experience Survey for the Exothermic Reactor

\section{Scale-Up Lab}




\begin{tabular}{|c|c|c|c|c|c|c|}
\hline 12) & $\begin{array}{l}\text { The questions the Teaching Assistant asked my group as we performed } \\
\text { the lab helped me understand the real world implications of the } \\
\text { exothermic reactor lab. }\end{array}$ & 1 & 2 & 3 & 4 & 5 \\
\hline 13) & $\begin{array}{l}\text { The Teaching Assistant was hel pful in answering the questions my group } \\
\text { had while performing the lab. }\end{array}$ & 1 & 2 & 3 & 4 & 5 \\
\hline 14) & $\begin{array}{l}\text { The work for performing the experiment was divided equally between my } \\
\text { teammates and I so that we could finish in a reasonable amount of time. }\end{array}$ & 1 & 2 & 3 & 4 & 5 \\
\hline 15) & $\begin{array}{l}\text { I felt that I was given enough tasks to keep me busy throughout the } \\
\text { scheduled lab time for the exothermic reactor lab. }\end{array}$ & 1 & 2 & 3 & 4 & 5 \\
\hline 16) & $\begin{array}{l}\text { The Teaching Assistant gave me clear instructions on how to perform the } \\
\text { calculations necessary to obtain results from my experimental data. }\end{array}$ & 1 & 2 & 3 & 4 & 5 \\
\hline 17) & $\begin{array}{l}\text { I felt "lost" and did not know where to begin when writing the Results } \\
\text { and Discussion portions of our report for the exothermic reactor scale- } \\
\text { up lab. }\end{array}$ & 1 & 2 & 3 & 4 & 5 \\
\hline 18) & $\begin{array}{l}\text { My group and I clearly understood the expectations for what was to be } \\
\text { discussed in the final report for exothermic reactor scale-up. }\end{array}$ & 1 & 2 & 3 & 4 & 5 \\
\hline 19) & $\begin{array}{l}\text { Performing the exothermic reaction scale-up lab allowed me to see the } \\
\text { dangers of a runaway reaction first hand. }\end{array}$ & 1 & 2 & 3 & 4 & 5 \\
\hline 20) & $\begin{array}{l}\text { I think it would be useful if every group performing the exothermic } \\
\text { reaction lab would get to see the reaction run away (as characterized by } \\
\text { rapid increase in observed temperature of the reaction mixture). }\end{array}$ & 1 & 2 & 3 & 4 & 5 \\
\hline 21) & $\begin{array}{l}\text { Performing the exothermic reactoin lab has increased my awareness of } \\
\text { the dangers of exothermic reaction scale-up in industry. }\end{array}$ & 1 & 2 & 3 & 4 & 5 \\
\hline 22) & $\begin{array}{l}\text { After completing the exothermic reaction lab, I have a better } \\
\text { understanding of how runaway reactions can be prevented in industry } \\
\text { especially when scale-up is involved. }\end{array}$ & 1 & 2 & 3 & 4 & 5 \\
\hline
\end{tabular}

FIGURE 5 - Second Part of the Student Experience Survey for the Exothermic Reactor

$$
\text { Scale-Up Lab }
$$

Minitab 2018 was the statistical software used to analyze the survey results from both the "Exothermic Reactor Scale-Up Lab" and the "ChE 486 Unit Ops II" surveys. Descriptive statistics including mean, standard deviation, mode, minimum and maximum were obtained for each question from each set of survey results. In order to compare the results from one data set (i.e. exothermic reactor lab survey) versus the results from another set (i.e. overall Unit Ops II lab survey), a two-sample T-test and an ANOVA were performed.

One can use a two-sample T-test to determine whether the difference between the population means is statistically significant by comparing the calculated p-value to the 
significance level. In this study, all results are reported with $95 \%$ confidence therefore making the significance level equal to 0.05. One can use a one-way ANOVA (analysis of variance) to determine whether the difference between means is statistically significant. The ANOVA method of analysis is much more robust than the two-sample T-test. This means that if the ANOVA results show that one parameter is insignificant and the twosample T-test shows the same parameter to be significant, the ANOVA results carry more weight and the analyst should conclude the parameter is insignificant. This study analyzes the grouping information provided by Tukey comparisons to find which of the groups are significantly different from each other. The Tukey method assigns letters to groups based on their means. Groups that do not share a letter are significantly different.

It is important to note that the raw survey data received from students was on a Likert scale with options ranging 1-5 with 1 indicating the student strongly disagreed with a statement and 5 indicating the student strongly agreed with a statement. In order to simplify the data analysis, the survey results were rescaled so that 1 represented a negative response, 2 represented a neutral response and 3 represented a positive response. In the original survey, some questions had a reverse scale so that if one strongly disagreed with the statement it would actually indicate a positive response. Designing the survey this way adds to the quality of the responses. For example, someone who strongly disagrees with the statement "I felt "lost" and did not know where to begin when writing the Results and Discussion portions of our report for the exothermic reactor scale-up lab" is actually indicating a positive experience with the lab. For the purposes of analysis, questions with a reverse scale were considered to have a positive response ("3") if a student strongly disagreed or disagreed with the statement, a neutral response ("2") if a student neither 
agreed nor disagreed and a negative response ("1") if a student agreed or strongly agreed with the statement.

\section{E. Procedure for Supervising and Performing Exothermic Reactor Scale-Up Lab}

\section{Safety}

The exothermic reaction should not be performed by students without the supervision of an experienced teaching assistant or instructor. Any person being trained to assist with this lab must thoroughly understand the safety hazards associated with the chemicals involved as well as the reaction itself.

Hydrogen peroxide (CAS No. 7722-84-1) and potassium iodide (CAS no. 7681-110) are toxic and skin irritants. Peroxide is also a strong oxidant. Gloves and safety glasses should be worn when handling these materials. Round-bottom flask reactors need to be open to the atmosphere to avoid pressure build-up from the oxygen produced. No flammable materials or ignition sources should be present during the production of oxygen via the reaction. Temperatures near or above the boiling point of the mixture $\left(\sim 100^{\circ} \mathrm{C}\right)$ can be reached in any flask that is removed from the ice bath before the reaction is complete. Care should be taken when handling these mixtures and especially in avoiding contact with escaping steam from the flasks.

Because the lab is focused on teaching the hazards of exothermic reaction scale-up, the design of the experiment intentionally calls for poor cooling conditions that will lead to rapid increase in temperatures that may approach or exceed the boiling point of the mixture. It is imperative for instructors and teaching assistants to be aware of and prepared for this likely occurrence so as to keep the students and themselves safe during the duration 
of the experiment. The students should be wearing gloves at all times while completing the lab even if they are only working on the water-only portion of the lab.

During lab days, the teaching assistant must be directly supervising the experiment while the exothermic reaction is being performed in the $500 \mathrm{~mL}$ flask. (This flask size has the most potential for high temperatures and violent bubble production.) The teaching assistant should prepare cold water and place it near the experiment set up to be used to quench the reaction if necessary. Usually this preventive measure will not be necessary because in the event that the reaction mixture experiences violent bubble production so that the reaction mixture begins to overflow the round bottom flask, the contents of the reaction mixture will still be safely contained in the ice bath. The teaching assistant should prepare the cold water for quenching and explain to students that this would be representative of a redundant cooling mechanism used to control the reaction in the event of failure of the primary cooling system.

The teaching assistant should advise the students to keep a safe distance from the reaction once rapid temperature increase is observed. Again, the design of the lab intentionally calls for these conditions to give students a chance to see a runaway reaction take place. However, it is the responsibility of the teaching assistant and instructor to ensure the reaction is contained and done safely. Students should be encouraged to document detailed observations of the reaction in the form of pictures, videos and written notes; however, the teaching assistant must ensure students take the observations safely. 


\section{Resources for Teaching Assistant}

Because this thesis has the potential to be used as a reference for when the Exothermic Reaction Scale-Up lab is performed in the future, I thought it necessary to include instructions for the instructors and teaching assistants who will be involved in the lab. The information contained and referenced in this section is meant to be a tool used by instructors and teaching assistants in order to make them aware and teach them of the potential hazards associated with the lab as well as their responsibilities for supervising the lab.

The teaching assistant is not only responsible for ensuring the students perform the lab correctly and safely but also for helping students learn the underlying concepts and implications of the lab. In order to help future teaching assistants prepare for and supervise each lab, I prepared several resources which are briefly described below and can be found in Appendix III. These resources include the following: procedure for preparing $0.1 \mathrm{M}$ potassium iodide; checklists for prelab, post-lab, calculation review and calculation grading; and the overall procedure for the lab. The "TA Checklists" are meant to be a quick reference guide used for each time the teaching assistant is to meet with the students. The checklists help the teaching assistant to be as consistent as possible between different groups.

The teaching assistant should be provided with a copy of the most recently revised procedure for the exothermic reactor scale-up lab. This can be found in the Unit Ops II lab manual for the course. The final procedure that was used for Lab 3 of the Spring 2018 semester is provided in the following section. 


\section{Final Procedure Prepared for Unit Ops Lab Students}

The following procedure was used for Lab 3 during the Spring 2018 semester. The full document to be presented in the Unit Ops Lab manual for student use can be found in Appendix III; this document includes a brief summary of the background and theory as well as other aids to help with their report writing. This procedure is representative of the most recent changes and improvements made to the lab procedure given to the students. It is important to note that although each lab group is divided into two teams to perform the experiment, the teaching assistant should encourage the teams to work together if one gets ahead of the other in terms of tasks completed.

There are two parts to this lab: the water-only experiment to determine the $U$ value and the hydrogen peroxide decomposition reactions. When performing the decomposition reaction, students should take detailed notes documenting their observations. Refer to Figures 6 and 7 for guidance on how to set up the experiment. Refer to Table II for a list of how much reactant (or water) to add for each flask size. 
Place the thermocouple probe in the spout that is clamped.

Use a funnel to carefully add liquids.

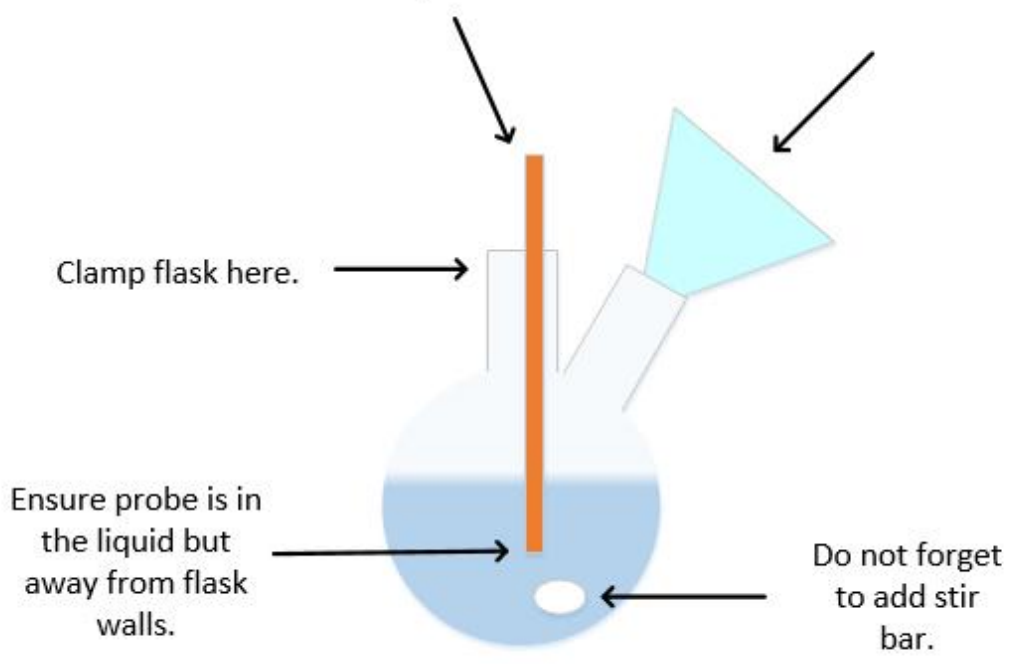

FIGURE 6 - Sketch of Round Bottom Flask Setup

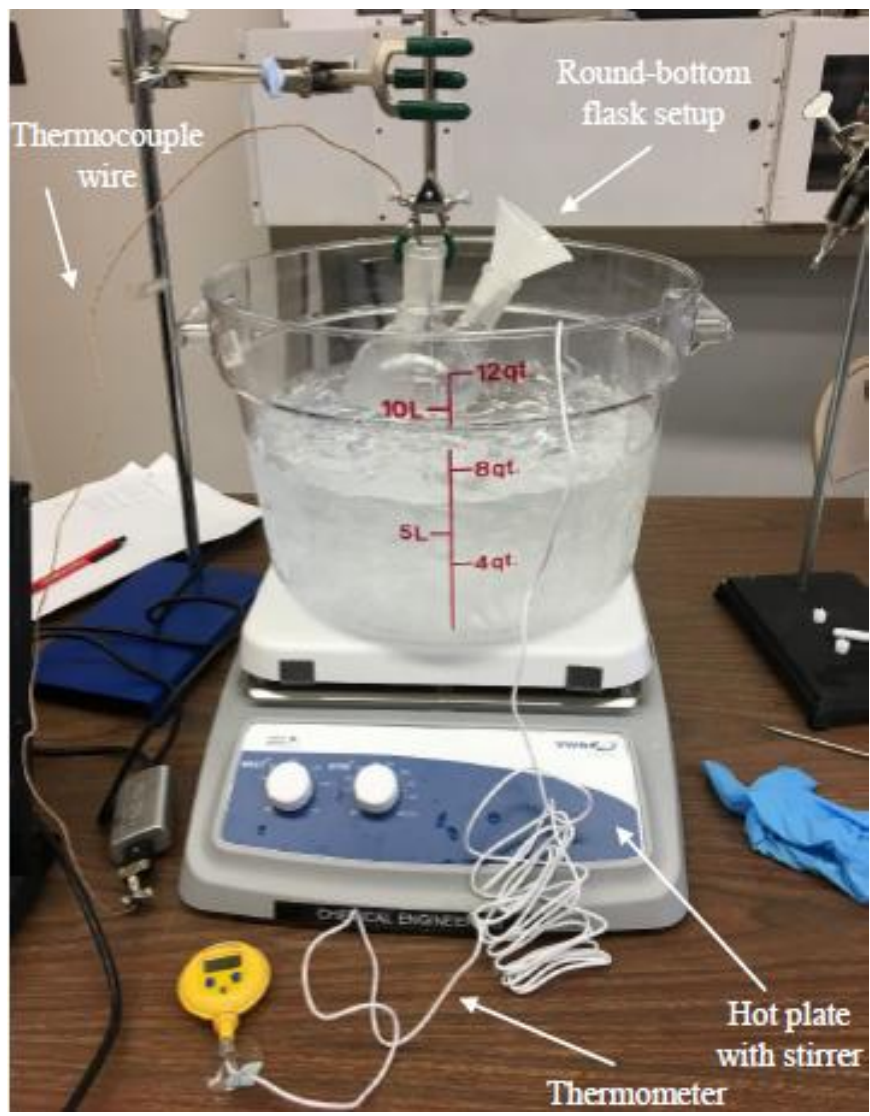

FIGURE 7 - Proper Setup of Round Bottom Flask in Ice Bath Showing Major Equipment 
TABLE I

VOLUMES OF REACTANTS (AND WATER) FOR EXPERIMENTAL MEASUREMENTS IN DIFFERENT FLASKS

\begin{tabular}{|c|c|c|}
\hline Flask Size & $\begin{array}{c}\text { Volume of } 30 \% \mathrm{H}_{2} \mathrm{O}_{2} \\
\text { (cold water) }\end{array}$ & $\begin{array}{c}\text { Volume of 0.1 M KI } \\
\text { (hot water) }\end{array}$ \\
\hline$(\mathrm{ml})$ & $(\mathrm{ml})$ & $(\mathrm{ml})$ \\
\hline 100 & 30 & 15 \\
\hline 250 & 75 & 37.5 \\
\hline 500 & 150 & 75 \\
\hline
\end{tabular}

TABLE II

SURFACE AREAS OF HEAT TRANSFER FOR EACH FLASK (ASSUMING 50\% LIQUID LEVEL)

\begin{tabular}{|c|c|}
\hline Flask Size & Surface Area \\
\hline$(\mathrm{ml})$ & $\left(\mathrm{m}^{2}\right)$ \\
\hline 100 & 0.00558 \\
\hline 250 & 0.01009 \\
\hline 500 & 0.01586 \\
\hline
\end{tabular}

Experiment to determine overall heat transfer coefficient, U for flasks (WATER ONLY)

1. Prepare both ice baths. Take one of the 12 quart plastic bowls and fill it with about 5 liters of water from a faucet. Pour approximately half of this water into the other plastic bowl. Put 3 large scoops of ice into each plastic bowl. The second ice bath is for the hydrogen peroxide decomposition reaction.

2. Place a large stir bar in the center of the ice bath and slowly turn on the stir plate ( 500 rpm). Insert a Traceable ${ }^{\circledR}$ thermometer probe into the water near the center of the container careful not to disturb the spinning of the stir bar. Ensure the ice 
bath has enough ice to keep the water at $0^{\circ} \mathrm{C}$ throughout the entirety of the experiment.

3. Acquire cold water from the TA. To keep the water cold for the second experiment, keep ice cubes in the cold water container.

4. Set up the experiment as shown in Figure 6 so that the flask is submerged in the ice bath. Remember to add a stir bar to the flask!

5. Insert a thermocouple probe into the flask. Plug the thermocouple into the USB port of a laptop and click "Run TC01Launcher.exe" then "Temperature Logger" to get to the data collection window. You may have to find and select the TC01 Launcher in your computer's devices. Do not "start logging" the temperature yet. (This would gather unnecessary data.) Change the units to Celsius and type a description for your specific experiment in the description box (e.g. Group \#, water-only or reaction, experimental conditions).

6. Using a funnel, pour the appropriate amount of cold water into your group's assigned flask size (refer to Table II). Monitor the temperature of the cold water in each flask. Use this time to ensure the temperature probes of both TC01 thermocouples are positioned adequately (below the liquid level of the flask, away from flask wall if possible). Also, make sure each flask is positioned low enough so that the stir bars in the flasks spin.

7. Using Table II, acquire the appropriate amount of hot water from a faucet. Once the temperature of the cold water in each flask stops decreasing $\left(\sim 1^{\circ} \mathrm{C}\right)$, measure and record the temperature of the hot water.

8. STOP. CHECK IN WITH YOUR TA BEFORE PROCEEDING. 
9. With the approval of the TA, make sure your "description" is correct and then start the temperature logging by clicking "Start Logging". Pour the appropriate amount of hot water into each flask using a funnel.

10. Record the temperature of the contents of the flask for 10 minutes.

11. "Stop logging" the data. Copy and paste the data into an Excel file.

12. Empty the water from the flask into a drain and set the flask aside.

13. Repeat steps 2-10 with the other assigned flask for your group. Pay special attention to the poor cooling conditions you are assigned to test.

14. While waiting for all of the data to be collected for the second flask, begin cleaning up the used lab equipment. Thoroughly rinse out all glassware and graduated cylinders. When using soap, be sure to adequately flush away all soap used on the equipment. Failure to do so will result in a totally different experiment the next time that glassware is used for the reaction portion of the lab (search "hydrogen peroxide soap experiment" on YouTube if you don't believe me).

15. Be sure to collect stir bars during cleanup to prevent them from being lost or accidentally discarded into waste containers. After cleaning up the experiment, remove your gloves and wash your hands before leaving the lab.

\section{Exothermic decomposition of hydrogen peroxide experiment}

1. Acquire the appropriate amounts of hydrogen peroxide for your group's assigned flasks (refer to Table II). Use a funnel. Measure as closely as you can and discard any excess hydrogen peroxide into the waste container (rather than back into the original container). 
2. Using a pipette and bulb, carefully remove the appropriate amount of KI for your group's assigned flasks (refer to Table II).

3. Set up the experiment as shown in Figure 6. Position them so that the flask is submerged in the ice bath. Remember to add a stir bar to the flask!

4. Insert a thermocouple probe into the flask. Plug the thermocouple into the USB port of a laptop and click "Run TC01Launcher.exe" then "Temperature Logger" to get to the data collection window. You may have to find and select the TC01 Launcher in your computer's devices. Do not "start logging" the temperature yet. (This would gather unnecessary data.) Change the units to Celsius and type a description for your specific experiment in the description box (e.g. Group \#, water-only or reaction, experimental conditions).

5. Using a funnel, pour the appropriate amount of hydrogen peroxide into your assigned flask. Monitor the temperature of the hydrogen peroxide. Use this time to ensure the temperature probes of both TC01 thermocouples are positioned adequately (below the liquid level of the flask, away from flask wall if possible). Also, make sure each flask is positioned low enough so that the stir bars in the flasks spin.

6. Once the hydrogen peroxide in each flask stops decreasing $\left(\sim 1^{\circ} \mathrm{C}\right)$, measure and record the temperature of the potassium iodide.

7. STOP. CHECK IN WITH YOUR TA BEFORE PROCEEDING.

8. With the approval of the TA, make sure your "description" is correct and then start the temperature logging by clicking "Start Logging". Be sure to record detailed 
observations of the reaction. Take pictures. Note any changes and the times the changes take place.

9. Using a funnel, pour the appropriate amount of KI into your assigned flask.

10. Record the temperature of the contents of both flasks for about 20 minutes.

11. "Stop logging" the data. Select all of the data (CTRL+A), copy (CTRL+C) and paste $(\mathrm{CTRL}+\mathrm{V})$ the data into an Excel file. Email this Excel spreadsheet to your TA for data compilation.

12. Repeat steps 3-11 with a $500 \mathrm{~mL}$ flask and apply the poor cooling conditions as your TA directs you to.

13. Once your reaction mixture temperature begins to decrease, have one person begin to clean up while the other continues to observe the reaction. Thoroughly rinse out all glassware and graduated cylinders. When using soap, be sure to adequately flush away all soap used on the equipment. Failure to do so will result in a totally different experiment the next time that glassware is used for the reaction portion of the lab (search "hydrogen peroxide soap experiment" on YouTube if you don't believe me).

14. Be sure to collect stir bars during cleanup to prevent them from being lost or accidentally discarded into waste containers. After cleaning up the experiment, remove your gloves and wash your hands before leaving the lab. 


\section{RESULTS AND DISCUSSION}

\section{A. Results from Preliminary Experiments}

The preliminary work for this project was completed in the Summer and Fall semesters of 2017. During this time, I researched the work done by Worcester Polytechnic Institute, built the experimental setup, had volunteers perform the lab and provide feedback and improved the overall design of the experiment. First, I performed the "water-only" experiment several times in order to figure out the logistics of the lab. In other words, these independent experiments helped me write a procedure for the lab and understand the timing for most tasks. Once I was comfortable with the "water-only" procedure, she performed the decomposition reaction experiment in much the same way and obtained results analogous to those provided by Worcester Polytechnic Institute. It was during this time that I decided to use $100 \mathrm{~mL}, 250 \mathrm{~mL}$ and $500 \mathrm{~mL}$ flasks for the reaction instead of only a 100 $\mathrm{mL}$ flask and a 1,000 mL flask in order to prevent the need for a fume hood. Finally, I asked a group of three chemical engineering graduate students to volunteer to act as Unit Ops students performing the experiment while I acted as a teaching assistant.

It was during the chemical engineering graduate student trials that I discovered the idea

of intentionally causing a runaway reaction. During the trials, the graduate students had trouble keeping the ice bath at a constant $0^{\circ} \mathrm{C}$ thus providing poor cooling to the reaction 
vessel. It was also discovered that one of the graduate students inadvertently added an additional $3 \mathrm{~mL}$ of catalyst to the reaction vessel when performing the $500 \mathrm{~mL}$ decomposition reaction. On the day of the lab, the group had issues getting the stir bar in the ice bath to spin. All of these factors contributed to the poor cooling experienced in the $500 \mathrm{~mL}$ reactor vessel. This reaction was predicted to reach a maximum temperature of about $25^{\circ} \mathrm{C}$, but because of the poor cooling conditions the reaction reached $72^{\circ} \mathrm{C}$ as shown in Figure 8. We had unintentionally caused the reaction to run away. After carefully considering the events leading up to the runaway reaction, I realized that creating poor cooling conditions to intentionally cause the reaction to runaway could be a valid part to add to the lab experiment.

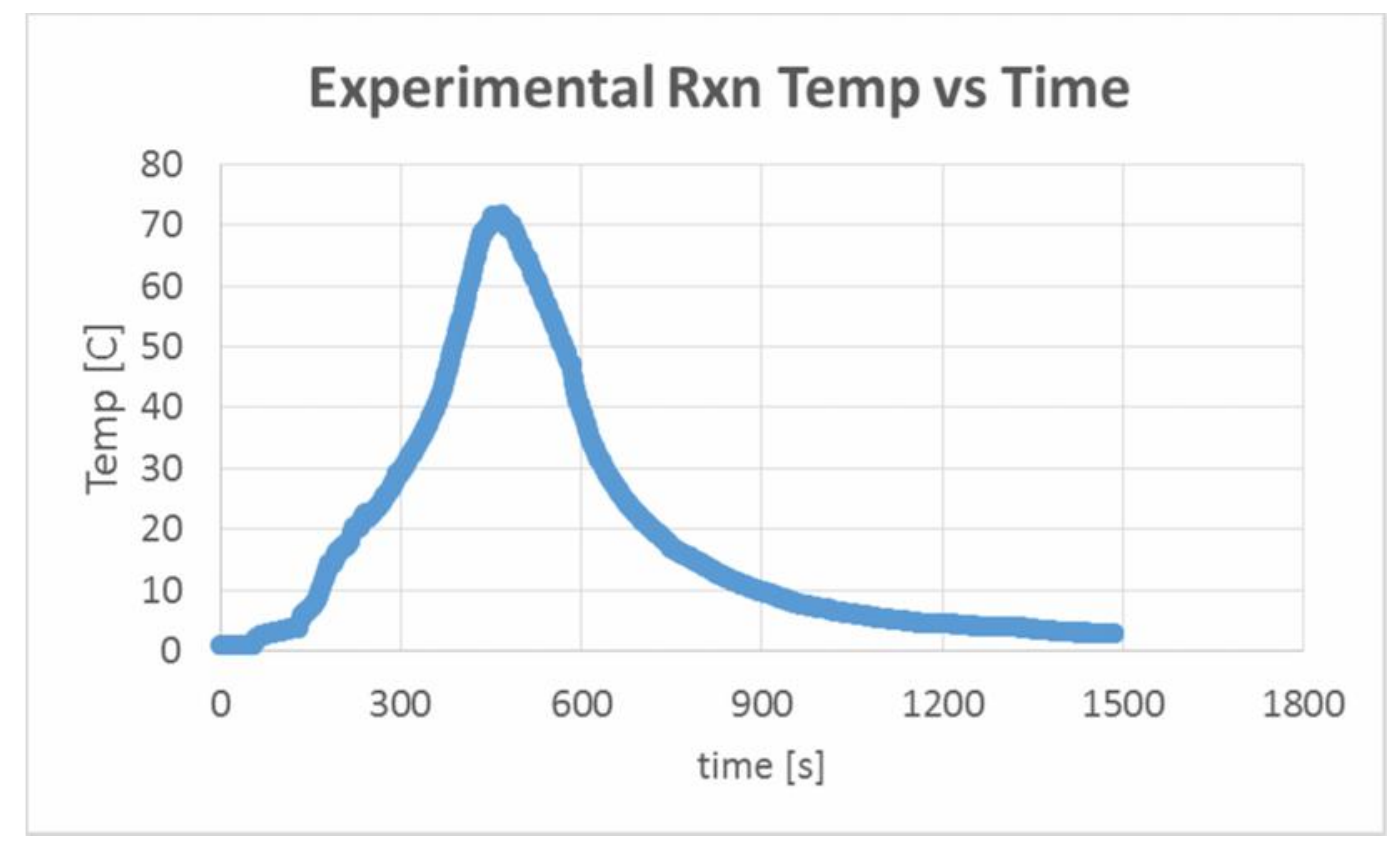

FIGURE 8 - Experimental Temperature versus Time Data for Chemical Engineering Graduate Student Trials using $500 \mathrm{~mL}$ Flask

After the chemical engineering graduate student trials, the student performed the reaction portion of the experiment several times independently in an attempt to recreate the 
conditions that led to the unintentional runaway reaction. I found that by manipulating the stirring and level of submergence of the reactor vessel in the ice bath, several different poor cooling conditions could be achieved. The experiment could be altered to create poor cooling conditions by removing the stirring from the flask but not the ice bath, from the ice bath but not the flask or from both the flask and the ice bath. The level of submersion could be changed from fully submerged to halfway submerged or a quarter submerged. Results of comparing the cooling conditions are discussed in the Spring 2018 Student Results section. In addition to the idea to intentionally cause runaway reactions to occur, the chemical engineering graduate school trials yielded other results. It became clear at this time that having three people responsible for one experiment (i.e. water-only or decomposition reaction) was too much and led to the team completing tasks very early and then having to wait for long periods of time. Because of this I decided to duplicate the set up so that both the water-only experiment and the decomposition reaction experiment could be done simultaneously. These trials also highlighted the need to create a teaching assistant checklist to prepare for the lab. The trials also made it clear that the procedure and prelab discussion needed to be improved to include portions regarding proper pipette and bulb use, times for students to stop and check in with the teaching assistant before proceeding and safety precautions specifically in the case a runaway reaction occurs. These changes were all incorporated prior to the Spring 2018 semester. 


\section{B. Spring 2018 Student Lab Results}

The goals for the Spring 2018 Unit Ops course were as follows:

- Continue to improve procedure

- Further study runaway reactions caused by poor cooling conditions

- Implement new active learning techniques

- Gather student feedback of the lab

During the first week of the lab, the students experienced several issues with the experiment. The main overarching issue common to all three groups that performed the Exothermic Reaction Scale-Up Lab during Lab 1 was inconsistency in the experiments that were intended to have adequate cooling. This was evidenced by results showing lower overall heat transfer coefficients than were expected for the adequately cooled runs thus causing a higher maximum temperature to be observed. During that lab, the students were instructed to perform the water-only experiment for the following conditions: $100 \mathrm{~mL}, 250 \mathrm{~mL}$ and $500 \mathrm{~mL}$ flasks all with adequate cooling and then one $500 \mathrm{~mL}$ flask with poor cooling conditions. At the same time, the other half of the group would perform the decomposition reaction but only for two of the four flasks/conditions listed. The results of the $500 \mathrm{~mL}$ flask that was intended to have adequate cooling were very similar to the results of the $500 \mathrm{~mL}$ flask with poor cooling. To correct this, I changed the experiment set up so that each group only performed their experiments on two of the four possible flasks/conditions: one adequately cooled flask and one $500 \mathrm{~mL}$ flask with poor cooling conditions. I also stressed the need for the 
group to try to mimic their water-only experiment setup when performing the reaction experiment to ensure an accurate overall heat transfer value is calculated.

It was clear during Lab 1 that the procedure was written in such a way that led to inefficiency in how the lab was done. The lab originally took almost three hours for students to complete during the first week of the lab (not including the time to clean up after the lab) so I saw the need to streamline the procedure to make it more efficient. By simply rearranging steps to require multitasking during preparatory work, much of the time spent sitting and waiting was eliminated. Another example involves requiring the teaching assistant to chill the hydrogen peroxide and cold water used during the first portion of both experiments prior to the start time of the lab for that particular day. This change easily eliminated the combined 20-30 minutes students would spend waiting on the ice baths to cool the room temperature hydrogen peroxide and cool water. These changes resulted in the lab taking a little over two hours to complete including the time students took to help clean up after the lab.

Throughout the semester, other minor changes were made to the lab. During Lab 2, soap bubbles were observed in the $250 \mathrm{~mL}$ reaction flask indicating the glassware was not cleaned properly prior to the lab. This prompted me to stress the importance of proper cleanup to the Lab 3 students. In order to do this, I would gather all of the team members around a computer and watch an "elephant toothpaste" YouTube video which shows a similar catalyzed hydrogen peroxide reaction but intentionally includes adding dish soap to the hydrogen peroxide before the catalyst is added. A link to the particular YouTube video I used is included in the teaching assistant post-lab checklist in Appendix III. Once the catalyst is added, the reaction rapidly produces oxygen gas 
which becomes trapped in the soap bubbles and in a matter of seconds the foamy mixture shoots out of the reaction vessel. This allowed students to have a light-hearted conclusion to the lab while also emphasizing the importance of proper cleanup.

The results the students obtained throughout the semester can be represented by Figures $\mathrm{X}$ and $\mathrm{X}$ which comes from Lab 2 data. Each group of students would begin by plotting the experimental temperature versus time curves from the combined data from that week provided to them by the teaching assistant. This way each group could analyze the three different flask sizes that had adequate cooling (indicated by "100 mL", "250 mL" and "500 mL Baseline" in Figures 9 and 10) in addition to three 500 $\mathrm{mL}$ flasks that each had different poor cooling conditions (indicated by " $500 \mathrm{~mL}$ Group 1", "500 mL - Group 6" and "500 mL - Group 11" in Figures 9 and 10). Then, the students would calculate the overall heat transfer coefficient for each flask run using the methods described in the theory section. Once the students found the overall heat transfer coefficient, they would then plug this value into their theoretical calculations and obtain theoretical temperature versus time results and compare this to the experimental data. 


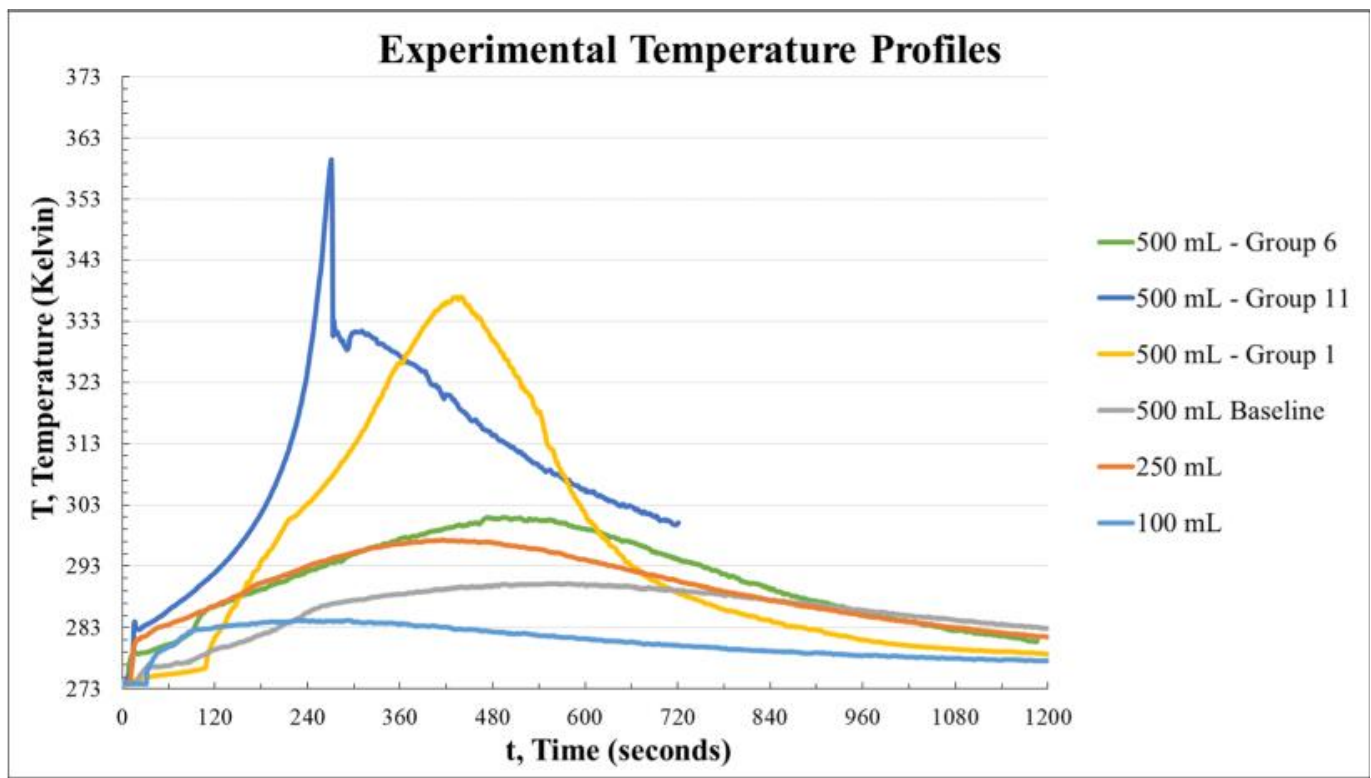

Figure 9 - Lab 2 Experimental Temperature versus Time Data

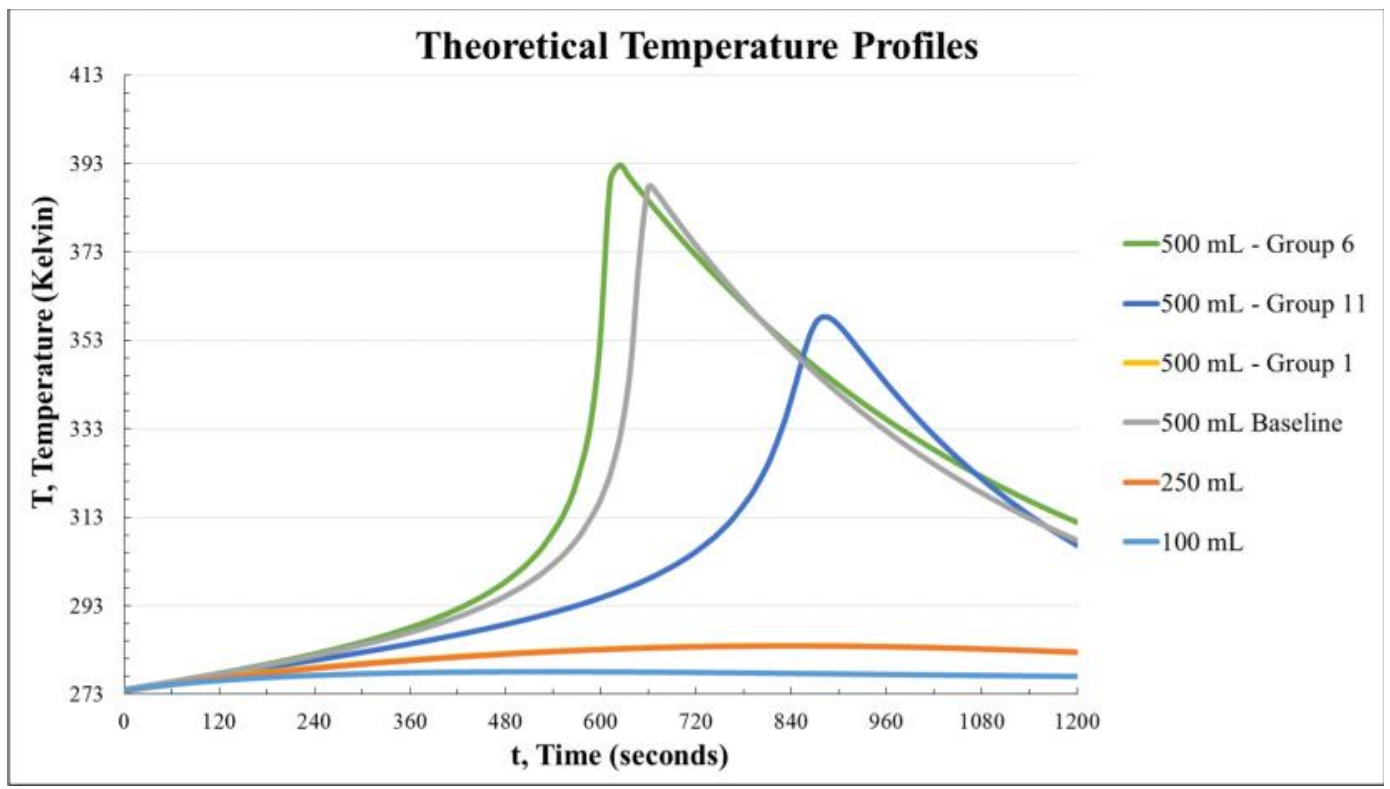

Figure 10 - Lab 2 Theoretical Temperature versus Time Results

The poor cooling conditions associated with Lab 2 are described in Table III. 
TABLE III

SUMMARY OF POOR COOLING CONDITIONS RESULTS FOR LAB 2

\begin{tabular}{|c|c|c|c|c|}
\hline Flask & $\begin{array}{c}\text { Stirring in } \\
\text { Flask / Ice Bath }\end{array}$ & $\begin{array}{c}\text { Submersion } \\
\text { in Ice Bath }\end{array}$ & $\begin{array}{c}\text { Peak Reaction } \\
\text { Temperature } \\
\text { (Kelvin) }\end{array}$ & $\begin{array}{c}\text { Runaway } \\
\text { reaction was } \\
\text { observed }\end{array}$ \\
\hline $100 \mathrm{~mL}$ & Yes / Yes & Fully submerged & 284 & No \\
\hline $250 \mathrm{~mL}$ & Yes / Yes & Fully submerged & 297 & No \\
\hline $500 \mathrm{~mL}$ Baseline & Yes / Yes & Fully submerged & 290 & No \\
\hline $500 \mathrm{~mL}-$ Group 1 & No/Ycs & $60 \%$ submerged & 337 & No \\
\hline $500 \mathrm{~mL}-$ Group 11 & No / No & $25 \%$ submerged & 360 & Yes \\
\hline $500 \mathrm{~mL}-$ Group 6 & Yes / Yes & $25 \%$ submerged & 301 & No \\
\hline
\end{tabular}

When analyzing the differences in poor cooling conditions, students generally found that stirring had a more significant effect on the cooling than the level of submersion in the ice bath. Table XX shows that all of the flasks with poor cooling conditions resulted in higher peak reaction temperatures than the flasks that had adequate cooling. The most dramatic spike in temperature was observed in the "500 $\mathrm{mL}$ - Group 6" run which was only $25 \%$ submerged and had no stirring in either the ice bath or the flask. From these results, I concluded that manipulating the stirring in the ice bath and reaction flask was the best way to mimic poor cooling conditions.

\section{Student Experience Survey Results}

\section{Overview}

Valuable knowledge can be learned from the student experience survey results from the “CHE 486 Unit Ops II" overall survey and the "Exothermic Reactor Scale-Up Lab” survey. The survey results are an accurate representation of all of the students who were enrolled in the class and those who specifically performed the exothermic reactor scale-up lab. All of the 61 students enrolled in the Spring 2018 Unit Ops II course received a "CHE 486 
Unit Ops II" survey. Of those students, 51 students completed the survey resulting in a response rate of $83 \%$. During the semester, 37 students performed the Exothermic Reactor Scale-Up lab and all of them received the survey designed specifically for the lab. Of those students, 33 completed the survey resulting in a response rate of $89 \%$. For the overall Unit Ops II survey, $63 \%$ of participants were male, $35 \%$ were female and $2 \%$ preferred not to answer. For the same survey, $86 \%$ of participants were white and $14 \%$ were minorities. For the exothermic reactor lab survey, $64 \%$ of participants were male and $36 \%$ were female. For the same survey, $94 \%$ of the participants were white and $6 \%$ were minorities.

\section{Summary of Exothermic Reactor Survey Results}

Analysis of the exothermic reactor scale-up lab shows that the majority of students who performed the lab reported a positive experience. These results show an overall student approval for the lab as it has been designed by me. This shows that the lab has been well received and that students benefit from the way it was taught to them.

Figure 11 shows descriptive statistics for the exothermic reactor scale-up survey. Of the 22 questions asked on the survey, five questions received $100 \%$ positive feedback. These questions are highlighted in blue in Figure 11. In addition to those five questions, eight other questions received either positive feedback or neutral responses only meaning $0 \%$ of the responses were negative. These questions are highlighted in green in Figure 11. This gives a total of 13 questions out of 22 receiving no negative responses. Refer to Figures 4 and 5 to see the full questions. Analysis of these responses answer the question of whether or not the new teaching approach as described in the Methods section of this work actually benefits student learning. 
Questions 1-7 on the exothermic reactor survey ask for students' opinions regarding their prelab experience. Questions 1 and 2 received $100 \%$ positive feedback (students agreed or strongly agreed with the statement) indicating that students found the interactive prelab discussion adequately prepared them to perform the experiment on their scheduled lab day and was very useful in helping them understand the overall purpose of the lab. Question 7 also received 100\% positive feedback indicating that students believed the prelab assignment was very useful in terms of helping them understanding the importance of learning about the hazards of exothermic reaction scale-up. Positive responses to Question 3 show that the whole prelab experience including both the interactive prelab discussion and the prelab assignment helped students when writing their final reports. For these reasons, the Unit Ops lab course should adopt a similar format of interactive prelab discussions and short prelab assignments.

Questions 8-15 on the exothermic reactor survey ask for students' opinions regarding their experiences while performing the lab on their scheduled lab day. The positive results from questions 9,12 and 13 indicate that students significantly benefit from having a teaching assistant available during lab time who will actually interact with the students in an effort to facilitate learning during the laboratory experiment. It is recommended that teaching assistants intentionally ask students questions throughout the lab in order to get them thinking about the underlying concepts of the lab. Teaching assistants should also be prepared to answer any questions students may have concerning the theory or real world implications of the lab.

Lastly, questions 16-22 cover the calculation review day and the students' overall experience with the lab. These results indicate that students felt prepared when performing 
their calculations and writing the results and discussion sections of their lab reports. This is probably directly related to the structured calculation guidelines and final report deliverables described previously. Furthermore, students believe that performing this lab increased their awareness of the dangers of exothermic reaction scale-up. The majority of students agree that every student should be able to see the exothermic reaction runaway firsthand. Because of this, it is recommended that each Unit Ops lab have structured calculation guidelines and a short list of what is expected for the final report. Neither one of these resources should be all inclusive but rather should serve as a starting point. Also, moving forward, the exothermic reactor lab should be structured so that each student has the opportunity to personally see a runaway reaction take place. This experience is invaluable in showing students the dangers of exothermic reactions.

\begin{tabular}{|l|r|r|r|r|r|r|r|r|r|r|}
\hline Variable & $\begin{array}{r}\text { Total } \\
\text { Count }\end{array}$ & $\mathrm{N}$ & Mean & SE Mean & StDev & Minimum & Maximum & Mode & $\begin{array}{r}\text { N for } \\
\text { Mode }\end{array}$ & $\begin{array}{c}\text { N for } \\
\text { Mode (\%) }\end{array}$ \\
\hline Q1 & 33 & 33 & 3 & 0 & 0 & 3 & 3 & 3 & 33 & $100 \%$ \\
\hline Q2 & 33 & 33 & 3 & 0 & 0 & 3 & 3 & 3 & 33 & $100 \%$ \\
\hline Q3 & 33 & 33 & 2.9697 & 0.0303 & 0.1741 & 2 & 3 & 3 & 32 & $97 \%$ \\
\hline Q5 & 33 & 33 & 2.727 & 0.109 & 0.626 & 1 & 3 & 3 & 27 & $82 \%$ \\
\hline Q6 & 33 & 33 & 2.697 & 0.111 & 0.637 & 1 & 3 & 3 & 26 & $79 \%$ \\
\hline Q7 & 33 & 33 & 2.758 & 0.107 & 0.614 & 1 & 3 & 3 & 28 & $85 \%$ \\
\hline Q8 & 33 & 33 & 3 & 0 & 0 & 3 & 3 & 3 & 33 & $100 \%$ \\
\hline Q9 & 33 & 33 & 2.8788 & 0.0577 & 0.3314 & 2 & 3 & 3 & 29 & $88 \%$ \\
\hline Q10 & 33 & 33 & 2.7576 & 0.0976 & 0.5607 & 1 & 3 & 3 & 27 & $82 \%$ \\
\hline Q11 & 33 & 33 & 2.9091 & 0.0669 & 0.3844 & 1 & 3 & 3 & 31 & $94 \%$ \\
\hline Q12 & 33 & 33 & 2.9697 & 0.0303 & 0.1741 & 2 & 3 & 3 & 32 & $97 \%$ \\
\hline Q13 & 33 & 33 & 3 & 0 & 0 & 3 & 3 & 3 & 33 & $100 \%$ \\
\hline Q14 & 33 & 33 & 2.9091 & 0.0669 & 0.3844 & 1 & 3 & 3 & 31 & $94 \%$ \\
\hline Q15 & 33 & 33 & 2.9697 & 0.0303 & 0.1741 & 2 & 3 & 3 & 32 & $97 \%$ \\
\hline Q16 & 33 & 33 & 2.9091 & 0.0508 & 0.2919 & 2 & 3 & 3 & 30 & $91 \%$ \\
\hline Q17 & 33 & 33 & 2.8485 & 0.0634 & 0.3641 & 2 & 3 & 3 & 28 & $85 \%$ \\
\hline Q18 & 33 & 33 & 2.9394 & 0.0606 & 0.3482 & 1 & 3 & 3 & 32 & $97 \%$ \\
\hline Q19 & 33 & 33 & 2.7879 & 0.0844 & 0.4846 & 1 & 3 & 3 & 27 & $82 \%$ \\
\hline Q20 & 33 & 33 & 2.8788 & 0.0577 & 0.3314 & 2 & 3 & 3 & 29 & $88 \%$ \\
\hline Q21 & 33 & 33 & 2.9091 & 0.0508 & 0.2919 & 2 & 3 & 3 & 30 & $91 \%$ \\
\hline Q22 & 33 & 33 & 2.8485 & 0.0769 & 0.4417 & 1 & 3 & 3 & 29 & $88 \%$ \\
\hline
\end{tabular}

FIGURE 11 - Descriptive Statistics for Exothermic Reactor Scale-Up Lab Survey 


\section{Comparison between Exothermic Reactor Lab and Overall Unit Ops Surveys}

In order to compare the results from the exothermic reactor lab survey and the results from the overall Unit Ops II lab survey, both a two-sample T-test and a one-way ANOVA was performed using Minitab 2018. Note that the overall Unit Ops II lab survey was divided into two sections: favorite lab and least favorite lab. Seven questions were identical between the three sets of survey results. Questions 1, 2, 8, 15, 16, 17 and 18 on the exothermic reactor lab survey correspond to questions $1,2,3,4,5,6$ and 7 on both portions of the overall Unit Ops II lab survey respectively.

The two-sample T-test results from comparing the exothermic reactor lab survey results to the "least favorite lab" portion of the overall Unit Ops II lab survey are summarized in Table IV. This method of analysis cannot be done for questions 1 and 2 from the exothermic reactor lab survey because all of the responses for both of these questions were the same. This is because these two questions received $100 \%$ positive responses from the survey participants. For the remaining five questions in this comparison, analysis of the two-sample t-test indicates that there is a significant difference between the responses from the exothermic reactor lab survey and the "least favorite lab" portion of the overall Unit Ops II survey.

The two-sample T-test results from comparing the exothermic reactor lab survey results to the "favorite lab" portion of the overall Unit Ops II lab survey are summarized in Table V. Again, this method of analysis cannot be done for questions 1 and 2 from the exothermic reactor lab survey because all of the responses for both of these questions are the same. However, analysis of the results for the other five questions indicate that there is only a significant difference between question Q15 (from the exothermic reactor survey) 
and 4F (from the "favorite lab" portion of the overall survey) and between question Q16 and $5 \mathrm{~F}$.

The one-way ANOVA was performed to compare the seven identical questions that appeared in each survey. Figure 12 shows the ANOVA results yielded a p-value equal to zero meaning that at least some of the groups included in the analysis were statistically different. Further, analysis of the ANOVA results involved Tukey pairwise comparisons. In a Tukey pairwise comparison, if two groups share a letter then these groups are not significantly different. If two groups do not share a letter then they are statistically different. The results of the Tukey pairwise comparisons for the ANOVA results are shown in Figure 13.

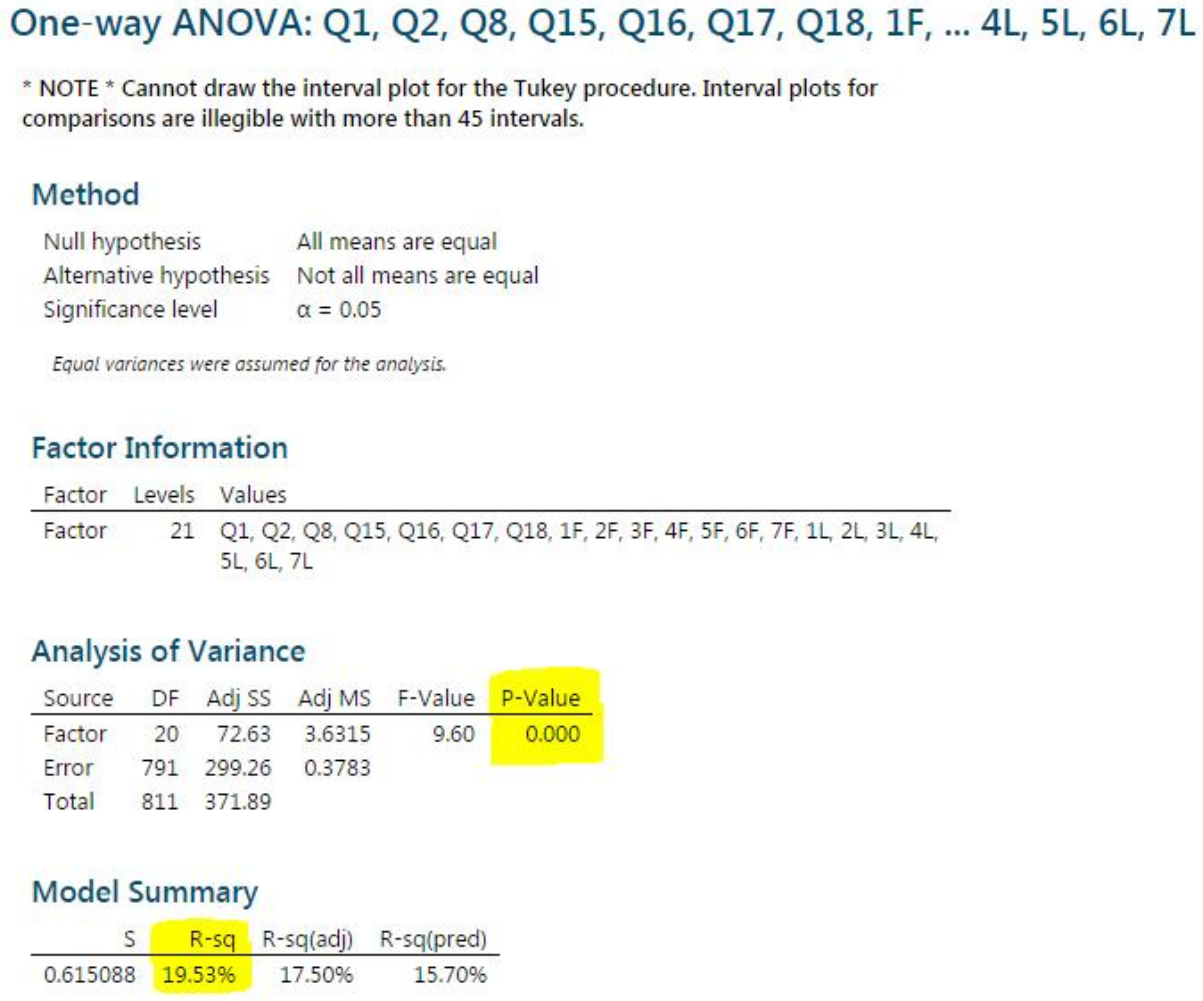

FIGURE 12 - One-Way ANOVA Results for Comparing Seven Identical Survey Questions 


\section{Tukey Pairwise Comparisons}

\section{Grouping Information Using the Tukey Method and 95\% Confidence}

\begin{tabular}{lrrrllll} 
Factor & N & Mean & & Grouping & \\
\hline Q2 & 33 & 3.000 & A & & & & \\
Q1 & 33 & 3.000 & A & & & & \\
Q15 & 33 & 2.9697 & A & & & & \\
Q18 & 33 & 2.9394 & A & & & & \\
7F & 33 & 2.9091 & A & B & & & \\
3F & 33 & 2.9091 & A & B & & & \\
Q16 & 33 & 2.9091 & A & B & & & \\
Q8 & 33 & 2.8788 & A & B & & & \\
Q17 & 33 & 2.8485 & A & B & C & & \\
6F & 33 & 2.697 & A & B & C & D & \\
4F & 33 & 2.697 & A & B & C & D & \\
1F & 33 & 2.667 & A & B & C & D & \\
3L & 50 & 2.5800 & A & B & C & D & \\
5F & 33 & 2.576 & A & B & C & D & \\
2F & 33 & 2.576 & A & B & C & D & \\
7L & 50 & 2.4200 & & B & C & D & \\
1L & 50 & 2.380 & & & C & D & E \\
2L & 50 & 2.320 & & & & D & E \\
4L & 50 & 2.300 & & & & D & E \\
5L & 50 & 2.220 & & & & D & E \\
$6 \mathrm{~L}$ & 50 & 1.980 & & & & & E
\end{tabular}

Means that do not share a letter are significantly different.

FIGURE 13- Tukey Pairwise Comparisons for Seven Identical Survey Questions

Because the results for the selected questions are ordered from highest to lowest mean, Figure 13 also gives insight that can be used to compare general differences between the three sets of survey responses. Items containing "Q" followed by a number indicates the questions from the exothermic reactor lab survey. Items beginning with a number and followed by "F" indicate questions from the "favorite lab" portion of the overall Unit Ops II survey. Items beginning with a number and followed by "L" indicate questions from the "favorite lab" portion of the overall Unit Ops II survey. The top four questions receiving 
the most positive responses (as indicated by higher means) come from the Exothermic Reactor Scale-Up Lab survey. The six questions that received the most negative responses (as indicated by lower means) all come from the "least favorite lab" portion of the overall CHE 486 Unit Ops II survey.

Further analysis of the Tukey comparisons show that the results from the exothermic reactor lab survey questions (Q1, Q2, Q8, Q15, Q16, Q17 and Q18) are statistically different from the identical questions asked on the "least favorite lab" portion of the overall Unit Ops II survey (1L, 2L, 3L, 4L, 5L, 6L and 7L). This is evidenced by the fact that these questions do not share any letters (A, B, C, D or E) with their counterparts in the Tukey test results shown in Figure 14 when comparing the results of the exothermic reactor lab survey with the "favorite lab" portion of the overall Unit Ops II survey $(1 \mathrm{~F}, 2 \mathrm{~F}$, $3 \mathrm{~F}, 4 \mathrm{~F}, 5 \mathrm{~F}, 6 \mathrm{~F}$ and $7 \mathrm{~F}$ ), I found the ANOVA results do not indicate any significant differences. However, similar analysis between the "favorite lab" and "least favorite lab" results show that only Question 6 (6F and 6L) showed a statistically significant difference. This means that for the grand majority of the survey questions the "favorite lab" and "least favorite lab" survey results were statistically the same. This gives an indication that the Exothermic Reactor experiment was in fact appreciably different from the "favorite lab" results even if not statistically significantly different. Tables IV and V summarize the results of both the two-sample T-test and the ANOVA. 


\section{TABLE IV}

SUMMARY OF TWO-SAMPLE T-TEST AND ONE-WAY ANOVA RESULTS

COMPARING EXOTHERMIC REACTOR LAB TO “LEAST FAVORITE”

\begin{tabular}{c|c|c|c|c|c|c|}
\multicolumn{2}{|c|}{$\begin{array}{c}\text { Exothermic Reactor Scale- } \\
\text { Up Lab Survey }\end{array}$} & $\begin{array}{c}\text { Overall Unit Ops II Lab } \\
\text { Survey - Least Favorite } \\
\text { Lab }\end{array}$ & \multicolumn{2}{c|}{ 2 Sample T-Test Results } & $\begin{array}{c}\text { One-Way } \\
\text { ANOVA } \\
\text { Results }\end{array}$ \\
\hline $\begin{array}{c}\text { Question \# as } \\
\text { it appears on } \\
\text { survey }\end{array}$ & $\begin{array}{c}\text { Minitab } \\
\text { Equivalent } \\
\text { Question \# }\end{array}$ & $\begin{array}{c}\text { Question \# } \\
\text { as it appears } \\
\text { on survey }\end{array}$ & $\begin{array}{c}\text { Minitab } \\
\text { Equivalent } \\
\text { Question \# }\end{array}$ & p-value & $\begin{array}{c}\text { Significant? } \\
\text { (Yes if p-value } \\
<0.05)\end{array}$ & $\begin{array}{c}\text { Significa } \\
\text { nt? (Yes } \\
\text { if no } \\
\text { letter }\end{array}$ \\
\hline 1 & Q1 & 1 & $1 \mathrm{~L}$ & Error & Inconclusive & Yes \\
\hline 2 & $\mathrm{Q} 2$ & 2 & $2 \mathrm{~L}$ & Error & Inconclusive & Yes \\
\hline 8 & $\mathrm{Q} 8$ & 3 & $3 \mathrm{~L}$ & 0.007 & Yes & Yes \\
\hline 15 & $\mathrm{Q} 15$ & 4 & $4 \mathrm{~L}$ & 0.000 & Yes & Yes \\
\hline 16 & $\mathrm{Q} 16$ & 5 & $5 \mathrm{~L}$ & 0.000 & Yes & Yes \\
\hline 17 & $\mathrm{Q} 17$ & 6 & $6 \mathrm{~L}$ & 0.000 & Yes & Yes \\
\hline 18 & $\mathrm{Q} 18$ & 7 & $7 \mathrm{~L}$ & 0.000 & Yes & Yes \\
\hline
\end{tabular}

TABLE V

SUMMARY OF TWO-SAMPLE T-TEST AND ONE-WAY ANOVA RESULTS COMPARING EXOTHERMIC REACTOR LAB TO “FAVORITE”

\begin{tabular}{c|c|c|c|c|c|c|}
\multicolumn{2}{c|}{$\begin{array}{c}\text { Exothermic Reactor Scale- } \\
\text { Up Lab Survey }\end{array}$} & \multicolumn{2}{c|}{$\begin{array}{c}\text { Overall Unit Ops II Lab } \\
\text { Survey - Favorite Lab }\end{array}$} & \multicolumn{2}{c|}{ 2 Sample T-Test Results } & $\begin{array}{c}\text { One-Way } \\
\text { ANOVA }\end{array}$ \\
\cline { 1 - 4 } $\begin{array}{c}\text { Question \# as } \\
\text { it appears on } \\
\text { survey }\end{array}$ & $\begin{array}{c}\text { Minitab } \\
\text { Equivalent } \\
\text { Question \# }\end{array}$ & $\begin{array}{c}\text { Question \# } \\
\text { as it appears } \\
\text { on survey }\end{array}$ & $\begin{array}{c}\text { Minitab } \\
\text { Equivalent } \\
\text { Question \# }\end{array}$ & p-value & $\begin{array}{c}\text { Significant? } \\
\text { (Yes if p-value } \\
<0.05)\end{array}$ & $\begin{array}{c}\text { Significa } \\
\text { nt? (Yes } \\
\text { if no } \\
\text { letter }\end{array}$ \\
\hline 1 & Q1 & 1 & $1 \mathrm{~F}$ & Error & Inconclusive & No \\
\hline 2 & Q2 & 2 & $2 \mathrm{~F}$ & Error & Inconclusive & No \\
\hline 8 & $\mathrm{Q} 8$ & 3 & $3 \mathrm{~F}$ & 0.695 & No & No \\
\hline 15 & $\mathrm{Q} 15$ & 4 & $4 \mathrm{~F}$ & 0.015 & Yes & No \\
\hline 16 & $\mathrm{Q} 16$ & 5 & $5 \mathrm{~F}$ & 0.011 & Yes & No \\
\hline 17 & $\mathrm{Q} 17$ & 6 & $6 \mathrm{~F}$ & 0.241 & No & No \\
\hline 18 & $\mathrm{Q} 18$ & 7 & $7 \mathrm{~F}$ & 0.703 & No & No \\
\hline
\end{tabular}

4. Limitations of the Survey Results

Lastly, when comparing the exothermic reactor survey data with that of the "favorite" and "least favorite" labs, it is important to consider some limitations to the 
survey results based on differences between the labs that are inherent to how the class is set up. The breakdown of how many students chose each lab to be their "favorite" and "least favorite" are shown in Figures 14-17. There were six experiments for the Spring 2018 semester but students only performed three of the six labs so not every student performed each lab. Also, not all of the labs had an equal number of students performing them. According to Figure 15, the two labs that students believed they got the most out of were the distillation column and the exothermic reactor scale-up labs and the two labs that students believed they got the least out of were the cooling tower and the filtration labs. These results may be misleading if not coupled with the following information regarding how many students performed each of the labs: all of the 61 students enrolled in the Unit Ops course performed the distillation column lab; 37 students performed the exothermic reaction scale-up lab; 25 students performed filtration lab; 24 students performed the catalytic reactor lab; 24 students performed the cooling tower lab; and 12 students performed the drying lab. These results show that $49 \%$ of the students who performed the exothermic reaction scale-up lab chose it to be their favorite lab thus confirming the conclusion that the lab was well-received since this lab had the highest approval rate. Additionally, $36 \%$ of students who performed the distillation column lab chose it as their favorite. Furthermore, $63 \%$ of cooling tower lab participants chose cooling tower as their least favorite lab and $48 \%$ of filtration lab participants chose filtration as their least favorite lab. 


\section{Labs Students Believe They Benefited the Most From}

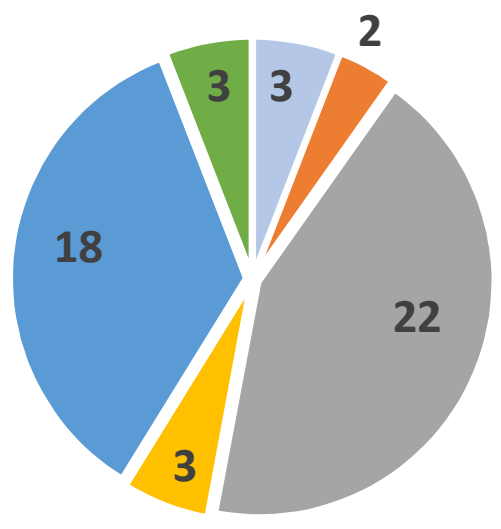

- Catalytic Reactor

- Cooling Tower

- Distillation Column

Drying

- Exothermic Reactor

- Filtration

FIGURE 14 - Labs Students Believe They Benefited the Most From (Including Exothermic Reactor)

Labs Students Believe They Benefited the Most From (Excluding Exothermic Reactor)

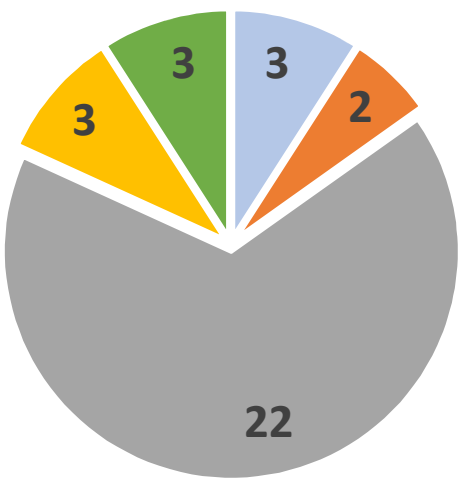

- Catalytic Reactor

- Cooling Tower

- Distillation Column

- Drying

- Filtration

FIGURE 15 - Labs Students Believe They Benefited the Most From (Excluding Exothermic Reactor) 
Labs Students Believe They Benefited the Least From

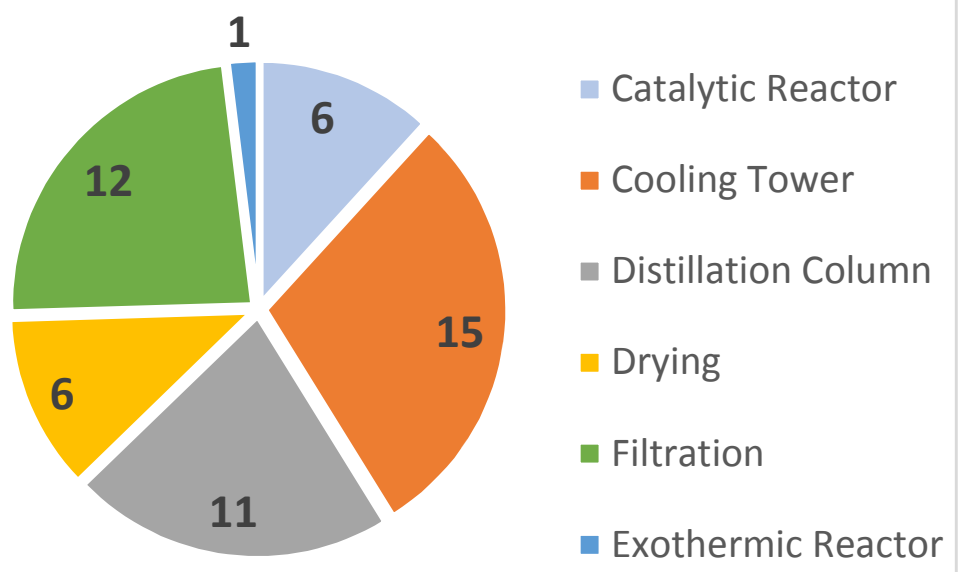

FIGURE 16 - Labs Students Believe They Benefited the Least From (Including Exothermic Reactor)

Labs Students Believe They Benefited the Least From (Excluding Exothermic Reactor)

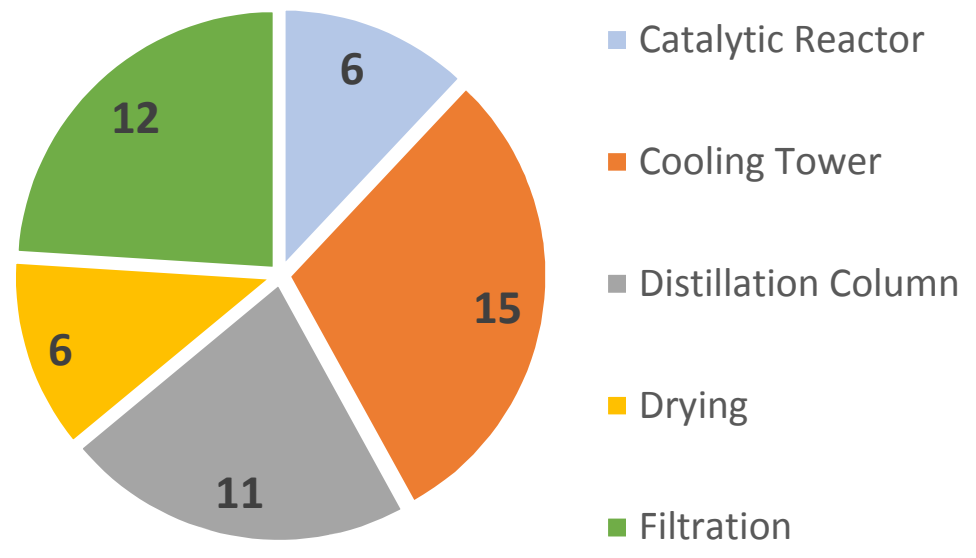

FIGURE 17 - Labs Students Believe They Benefited the Least From (Excluding Exothermic Reactor) 
Another limitation to the survey results involves how the surveys were distributed. It is important to note that I not only wrote this thesis and was the teaching assistant for the Exothermic Reaction Scale-Up lab in Spring 2018, but I also was the person who handed out the paper copies of the surveys to each student and asked for their feedback. This personal approach to the survey distribution likely led to heightened response rates for both surveys but it may have also introduced a level of bias to the results. 


\section{CONCLUSIONS}

Exothermic chemical reactions are prevalent in the chemical industry. Therefore, it is imperative for chemical engineers to understand the kinetics and heat transfer of these reactions in order to prevent dangerous runaway reactions. One noteworthy incident from recent history is the fatal explosion that occurred at T2 Laboratories in Jacksonville, FL as a result of improper scale-up and an insufficient cooling design for the system. From their investigation of the incident, the CSB recommended that the Accreditation Board for Engineering and Technology Inc. (ABET) and the American Institute of Chemical Engineers (AICHE) work together to add reactive hazard awareness to baccalaureate chemical engineering curricula requirements. In response to this recommendation, a lab teaching the hazards of exothermic reaction scale-up was created and added to the University of Louisville Chemical Engineering Department Unit Operations II Laboratory course.

This lab involves performing the exothermic iodide catalyzed decomposition of hydrogen peroxide using tabletop lab equipment and having students analyze the results of increasing reactor volume while other parameters remain constant. In this lab, students have the opportunity to witness an exothermic reaction take place in front of their eyes. The intentional design of the lab calls for poor cooling conditions to allow the highly exothermic reaction to run away. These poor cooling conditions can represent many different kinds of incidents in industry such as a complete loss of cooling medium, a loss 
of agitation or improperly scaled up cooling systems. Results of these experiments prove the proposed Exothermic Reactor Scale-Up lab was repeatable and able to be used as a viable experiment in future years of the Unit Ops II course. Furthermore, students were easily able to relate the tabletop experiment to industry and thus readily understand the real world implications of the lab.

Introducing this new experiment to the Unit Ops lab allowed for experimentation with new active learning techniques with the goal of facilitating improved student learning in the lab. In order to test whether these new changes were beneficial to student learning, two student experience surveys were created and distributed to everyone enrolled in the Spring 2018 Unit Ops II course. Results confirm that the exothermic reactor scale up lab is well-received by students and that the new active learning techniques were successful. Changes including an interactive prelab discussion, a short prelab assignment, directed verbal questions during the lab, calculation review guidelines and final report deliverables all proved to benefit the students significantly as evidenced by statistical analysis. Even when comparing the Exothermic Reactor Scale-Up lab to some other Unit Ops II labs, results show that the student experiences for the exothermic lab were significantly different from other labs. Overall, the Exothermic Reaction Scale-Up lab was a valuable addition to the Unit Ops II laboratory. 


\section{RECOMMENDATIONS}

Although the student experience survey results show that the Exothermic Reaction Scale-Up lab was successful overall, a few recommendations can help increase the repeatability of the experiment. One issue that was apparent in the results from each lab cycle was the inability to achieve adequate cooling consistently with the ice bath. Because the results repeatedly show the existence of stirring is a more significant factor affecting cooling than simply how submerged the flasks are in the ice bath, one may conjecture that better stirring will result in significantly better cooling. For this reason, I recommend that for future iterations of the exothermic reaction scale-up lab, the Unit Ops laboratory staff should purchase larger stir bars to be used in the ice bath to promote better cooling and in the reaction flasks to promote an even temperature distribution.

During Lab 3, one group observed a very obvious example of inadequate stirring when the reaction mixture initially appeared to form two distinct layers after the potassium iodide catalyst was added. Also, throughout the semester, the overall heat transfer coefficient would be very inconsistent between different trials. Theoretically, the heat transfer coefficients should be similar when the same procedure is used to produce the 
same setups. However for the $250 \mathrm{~mL}$ and $500 \mathrm{~mL}$ runs that were set up to have adequate cooling, lower heat transfer coefficients than what were expected were observed. This problem could be solved with larger stir bars.

In the interest of increasing safety for this experiment, more research should be done on how to intentionally cause the runaway reactions in a safer manner. One suggestion may be to look into running experiments to find the largest amount of hydrogen peroxide that will lead to a maximum temperature of $85{ }^{\circ} \mathrm{C}$ or less under worst case scenarios of absolutely no cooling or stirring.

It is important to relate the tabletop poor cooling conditions to what a chemical engineer may experience in industry. In future iterations of the lab, the teaching assistant should make it a point to have students identify what no stirring in the reaction flasks would be equivalent to in industry. The answers could range from having a lack of flow in cooling water to an agitation failure. This would help students be able to connect the tabletop experiment to real world industrial incidents.

Another recommendation is to have the first lab group of the week begin with the $500 \mathrm{~mL}$ flask under normal conditions so that the students on subsequent days can reference this data and compare it to their $500 \mathrm{~mL}$ reactions that have poor cooling. Another suggestion for the course is to have everyone that performs the experiment actually witness a runaway reaction. Currently, every student sees the experiment with some form of poor cooling, but the reaction is not necessarily characterized by a rapid increase in temperature and bubble production. Survey results from participants of the exothermic reactor scale-up lab show that the overwhelming majority of student believe that it would be useful for every group to see the reaction run away. 
The last recommendation is to have students watch the "elephant toothpaste" experiment during lab time to show why adequate cleaning of the lab equipment is necessary. This experiment usually involves the catalyzed decomposition of hydrogen peroxide in dish soap. The rapid oxygen production causes an eruption of foam to burst out of the reaction vessel in a matter of seconds. I watched this video with the Lab 3 groups and the students received it well. Watching the short video provides the students with a fun break from the experiment while also stressing the need for proper cleanup. 


\section{REFERENCES CITED}

Clark, William M. Lei, Melinda W. Kirechenko, Erika. Dickerson, Kellie Y. Prytko, Robert J. (2017). An Experiment to Illustrate the Hazards of Exothermic Reaction ScaleUp. Chemical Engineering Education. 51 (1). 35-40.

Dickerson, Kellie Y. Kirechenko, Erika. Lei, Melinda W. (2015). Heat Transfer in Reactor Scale-Up. A major qualifying report, Worcester Polytechnic Institute.

Domin, Daniel S. (1999). A Content Analysis of General Chemistry Laboratory Manuals for Evidence of Higher-Order Cognitive Tasks. Journal of Chemical Education, 76(1), 109-111.

Gerstle, Jim. (2017). ChE 485 - Unit Operations Laboratory I Fall 2017. J. B. Speed School of Engineering, University of Louisville.

Gerstle, Jim. (2018). ChE 486 - Unit Operations Laboratory I Spring 2018. J. B. Speed School of Engineering, University of Louisville.

Singer, Susan R. Hilton, Margaret L. Schweingruber, Heidi A. (2006). America's Lab Report: Investigations in High School Science. The National Academies Press. 76-78.

Sweeney, William. Lee, James. Abid, Nauman. DeMeo, Stephen. (2014). Efficient Method for the Determination of the Activation Energy of the Iodide-Catalyzed Decomposition of Hydrogen Peroxide. Journal of Chemical Education.

Worcester Polytechnic Institute. (2015). Experiment No. 8 Scale-up of an Exothermic Batch Reaction. Worcester Polytechnic Institute.

U.S. Chemical Safety and Hazard Investigation Board (2002). Hazard Investigation Improving Reactive Hazard Management. 2001-01-H.

U.S. Chemical Safety and Hazard Investigation Board (2009). T2 Laboratories, INC. Runaway Reaction. 2008-3-I-FL. 


\section{APPENDIX I}

\section{SAMPLE CALCULATIONS FOR DETERMINING U-VALUE AND OBTAINING}

\section{THEORETICAL RESULTS}

Calculate initial molar concentrations $[\mathrm{mol} / \mathrm{L}]$ of hydrogen peroxide and potassium iodide using density and molecular weight to determine amount of moles of each and then dividing by the total volume for each flask.

\begin{tabular}{|l|r|l|}
\hline \multicolumn{3}{|c|}{ Known Quantities } \\
\hline density of $30 \% \mathrm{H} 2 \mathrm{O} 2$ & 1.11 & $\mathrm{~g} / \mathrm{mL}$ \\
\hline density of 0.1 M KI & 1 & $\mathrm{~g} / \mathrm{mL}$ \\
\hline MW of H2O2 & 34.0147 & $\mathrm{~g} / \mathrm{mol}$ \\
\hline MW of KI & 166.0028 & $\mathrm{~g} / \mathrm{mol}$ \\
\hline delta H & -98.3 & $\mathrm{~kJ} / \mathrm{mol}$ \\
\hline ko & $3.083 \mathrm{E}+08$ & $\mathrm{~L} /(\mathrm{mol} \mathrm{s})$ \\
\hline Ea & 56 & $\mathrm{~kJ} / \mathrm{mol}$ \\
\hline R & 8.314 & $\mathrm{~J} /(\mathrm{mol} \mathrm{K})$ \\
\hline
\end{tabular}

\begin{tabular}{|c|c|c|c|c|c|c|c|}
\hline $\begin{array}{c}\text { reaction vessel/flask } \\
\text { size }\end{array}$ & $\begin{array}{c}\begin{array}{c}\text { vol of } 30 \% \\
\text { H2O2 added } \\
\text { [mL] }\end{array} \\
\end{array}$ & $\begin{array}{c}\text { vol of } 0.1 \mathrm{M} \mathrm{KI} \\
\text { solution added } \\
{[\mathrm{mL}]}\end{array}$ & $\begin{array}{c}\text { total vol of } \\
\text { initial solution } \\
{[\mathrm{mL}]}\end{array}$ & $\begin{array}{c}\text { initial amt } \\
\text { of } \mathrm{H} 2 \mathrm{O} 2 \\
{[\mathrm{~mol}]} \\
\end{array}$ & $\begin{array}{c}\text { initial } \\
\text { amt of I- } \\
\text { [mol] }\end{array}$ & $\begin{array}{c}\text { initial conc } \\
\text { of } \mathrm{H} 2 \mathrm{O} 2 \\
{[\mathrm{~mol} / \mathrm{L}]} \\
\end{array}$ & \begin{tabular}{|c} 
initial \\
conc of I- \\
{$[\mathrm{mol} / \mathrm{L}]$}
\end{tabular} \\
\hline $100 \mathrm{~mL}$ & $\begin{array}{r}30 \\
\end{array}$ & 15 & 45 & 0.293696549 & 0.0015 & 6.5266 & 0.0333 \\
\hline $250 \mathrm{~mL}$ & 75 & 37.5 & 112.5 & 0.734241372 & 0.00375 & 6.5266 & 0.0333 \\
\hline $500 \mathrm{~mL}$ & 150 & 75 & 225 & 1.468482744 & 0.0075 & 6.5266 & 0.0333 \\
\hline
\end{tabular}

Initial Molar Concentration Calculations

Calculate $\mathrm{U}$ value by plotting $\ln \left[\left(\mathrm{T}_{\mathrm{i}}-\mathrm{T}_{\mathrm{o}}\right) /\left(\mathrm{T}_{\mathrm{i}}-\mathrm{T}\right)\right]$ versus time. Only plot about 200 data points. This yields a straight line and $U$ can be obtained as

$$
U=\frac{\text { slope } * m * c_{p}}{A}
$$

Plug this $\mathrm{U}$ value into the theoretical kinetics and heat transfer equations shown below and solve simultaneously to obtain a curve to Temperature versus time and concentration versus time. 


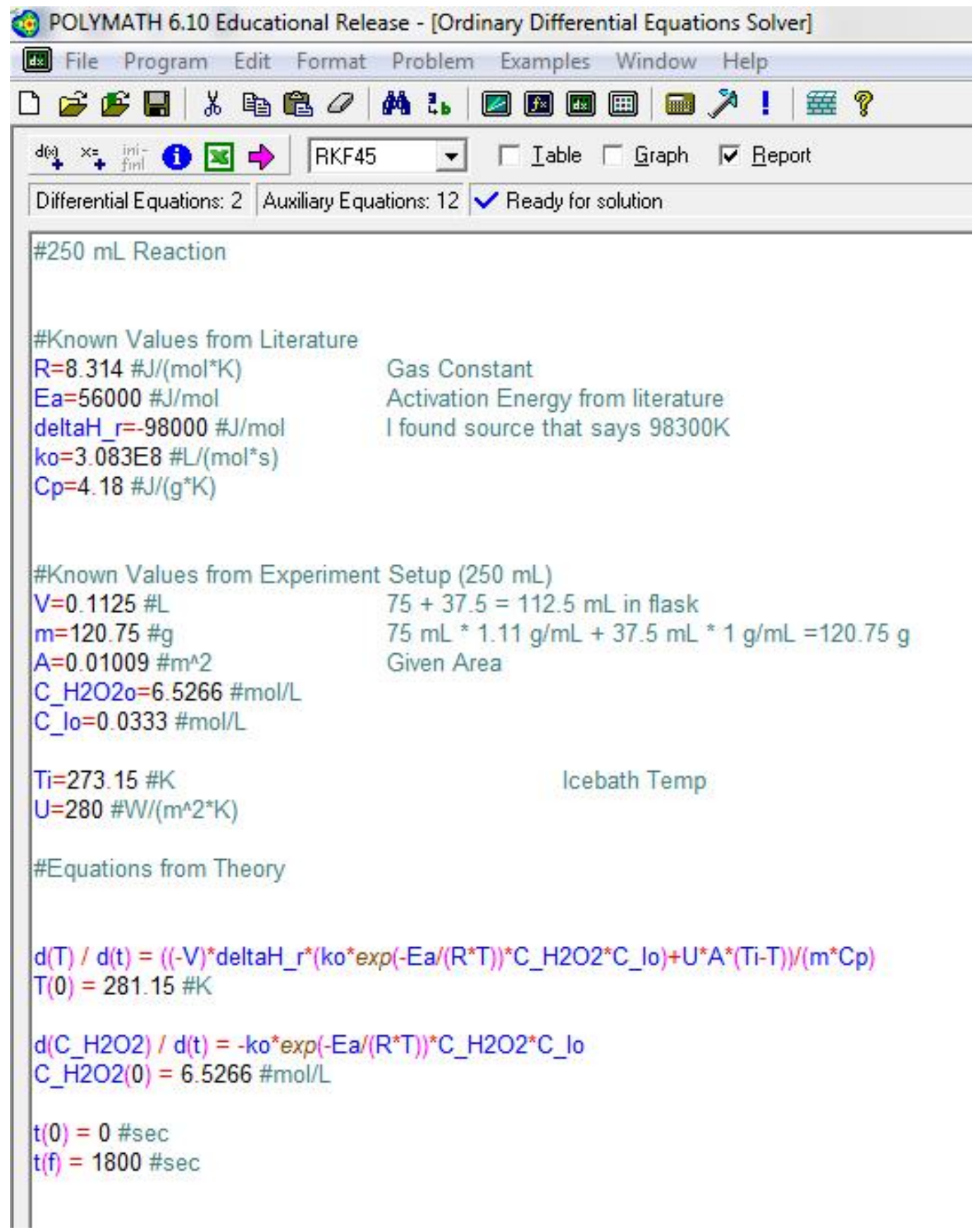

Polymath differential equation solver code for $250 \mathrm{~mL}$ reaction. 


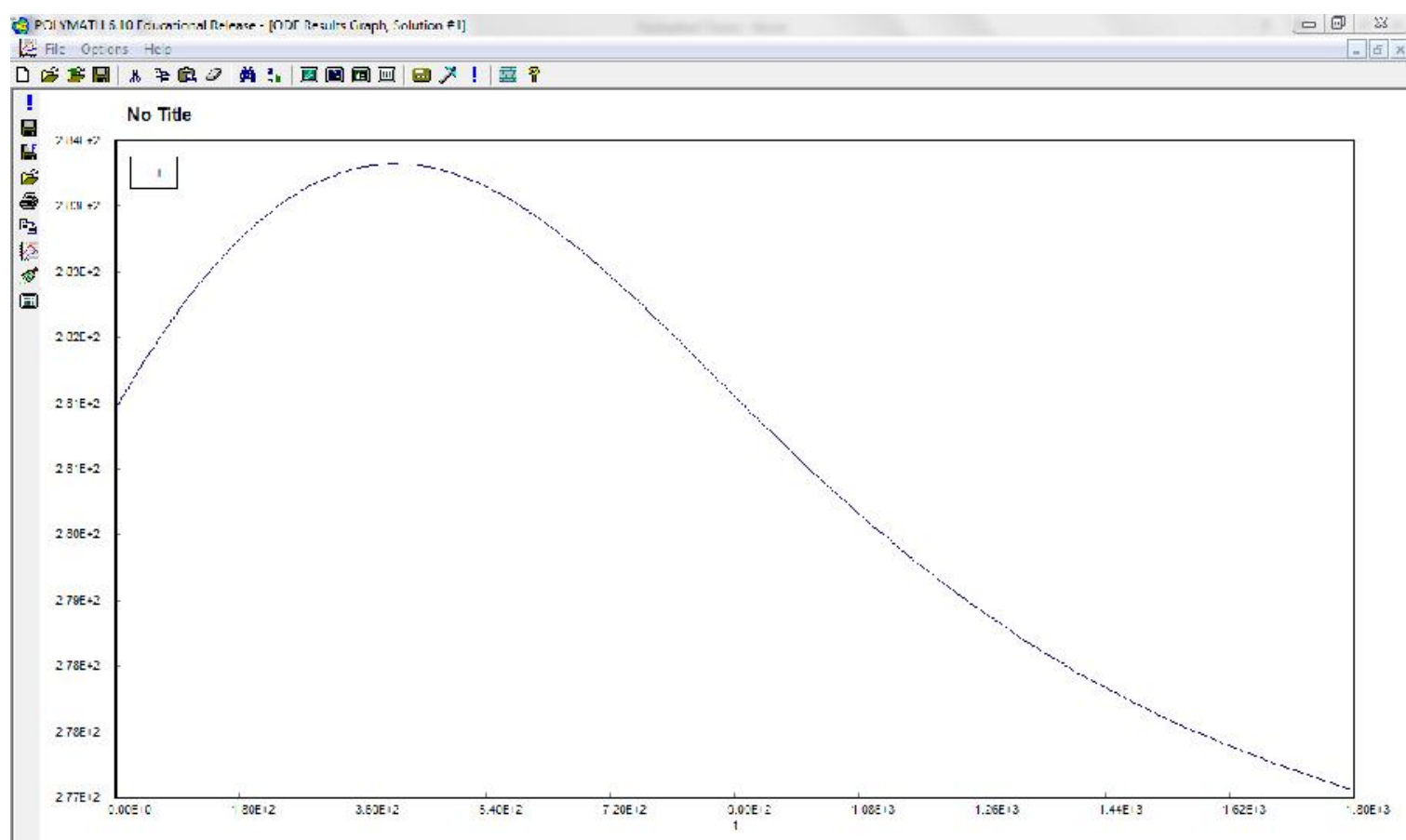

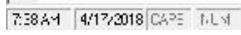

Theoretical Temperature versus Time curve where the $y$-axis is temperature $[K]$ and the $x$ axis is time [sec].

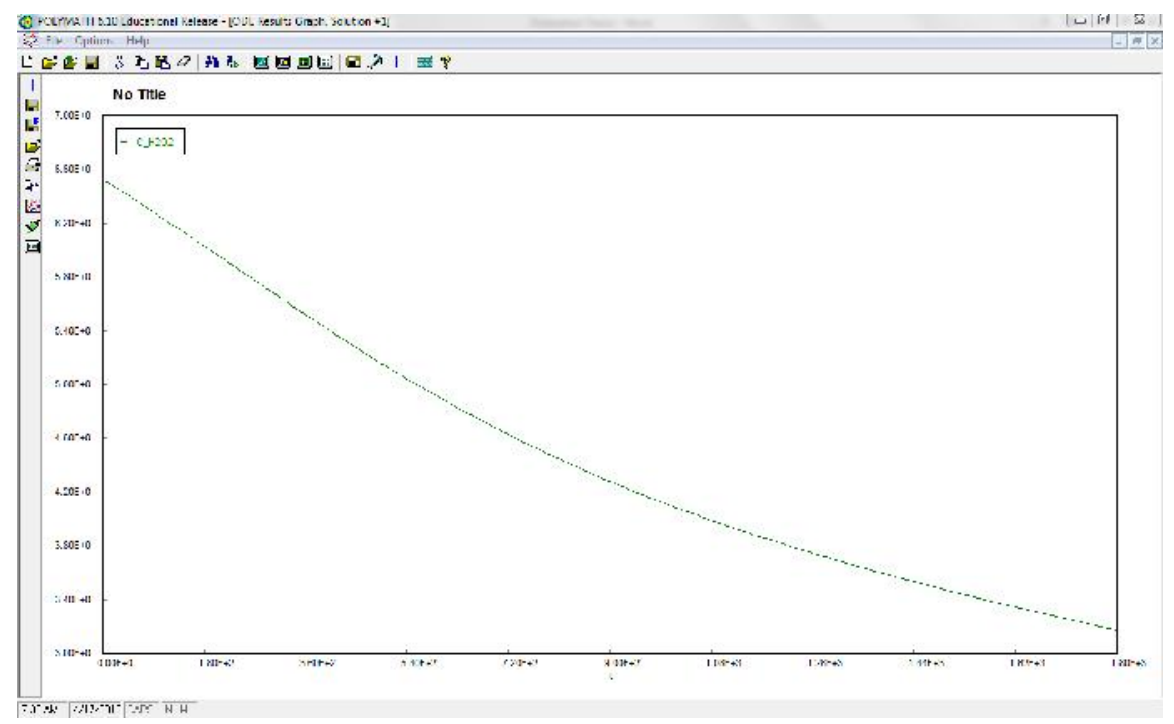

Theoretical concentration versus time graph where the y-axis is the concentration of hydrogen peroxide [mol/L] and the $\mathrm{x}$-axis is the time [sec]. 


\section{APPENDIX II}

STUDENT EXPERIENCE SURVEYS AND MINITAB ANALYSIS 
Exothermic Reaction Scale-Up Lab: Student Experience Survey

\begin{tabular}{|c|c|c|c|c|c|c|}
\hline Name: & & \multicolumn{5}{|c|}{ Group: } \\
\hline \multicolumn{7}{|c|}{$\begin{array}{l}\text { Directions: Please complete the following survey by answering each item honestly and thoroughly. Any } \\
\text { suggestions or recommendations that you provide may be incorporated into future iterations of these Unit Ops } \\
\text { labs. Some or all of the results of this survey will be presented in the Masters of Engineering Thesis written by } \\
\text { Lisa Anderson regarding the exothermic reaction scale-up lab. We will do everything we can to ensure that the } \\
\text { comments and answers remain anonymous when reporting our findings. Thank you for your feedback! }\end{array}$} \\
\hline \multicolumn{7}{|c|}{ Individual Lab Experience: For each of the items below, indicate your response: } \\
\hline $1-$ & rongly Disagree; $\quad 2$-Disagree; 3 - Neither agree nor disagree; 4 - Ag & ree; & & ong & Agre & \\
\hline \multicolumn{7}{|c|}{ Exothermic Reactor Scale-Up Lab } \\
\hline 1) & $\begin{array}{l}\text { The prelab discussion led by the Teaching Assistant (on my scheduled } \\
\text { prelab day) for this lab adequately prepared me to perform the } \\
\text { experiment on my scheduled lab day. }\end{array}$ & 1 & 2 & 3 & 4 & 5 \\
\hline 2) & $\begin{array}{l}\text { The prelab discussion led by the Teaching Assistant (on my scheduled } \\
\text { prelab day) was very useful in helping me understand the overall } \\
\text { purpose of the lab. }\end{array}$ & 1 & 2 & 3 & 4 & 5 \\
\hline 3) & $\begin{array}{l}\text { The overall prelab experience (prelab discussion and assignment) was } \\
\text { us eful for writing my final report. }\end{array}$ & 1 & 2 & 3 & 4 & 5 \\
\hline 4) & $\begin{array}{l}\text { I would have preferred to have had the prelab assignment given to me as } \\
\text { an individual assignment rather than a group assignment. }\end{array}$ & 1 & 2 & 3 & 4 & 5 \\
\hline 5) & $\begin{array}{l}\text { I would have preferred to have the prelab assignment formally graded } \\
\text { rather than informally discussed prior to performing the experiment. }\end{array}$ & 1 & 2 & 3 & 4 & 5 \\
\hline 6) & $\begin{array}{l}\text { The prelab assignment was unreasonably long in terms of how much } \\
\text { time it took to complete. }\end{array}$ & 1 & 2 & 3 & 4 & 5 \\
\hline 7) & $\begin{array}{l}\text { The prelab assignment was unnecessary and did not help me at all in } \\
\text { terms of understanding the importance of learning about the hazards of } \\
\text { exothermic reaction scale-up. }\end{array}$ & 1 & 2 & 3 & 4 & 5 \\
\hline 8) & $\begin{array}{l}\text { The written procedure provided to me for the exothermic reactor lab was } \\
\text { easy to understand and follow. }\end{array}$ & 1 & 2 & 3 & 4 & 5 \\
\hline 9) & $\begin{array}{l}\text { The additional verbal instructions given to me by the Teaching Assistant } \\
\text { throughout the lab were helpful to me. }\end{array}$ & 1 & 2 & 3 & 4 & 5 \\
\hline 10) & $\begin{array}{l}\text { I would have preferred the Teaching Assistant to have been less "hands } \\
\text { on" during the performance of the exothermic reactor lab. }\end{array}$ & 1 & 2 & 3 & 4 & 5 \\
\hline 11) & $\begin{array}{l}\text { The questions the Teaching Assistant asked my group as we performed } \\
\text { the lab helped me understand what was happening in the lab. }\end{array}$ & 1 & 2 & 3 & 4 & 5 \\
\hline 12) & $\begin{array}{l}\text { The questions the Teaching Assistant asked my group as we performed } \\
\text { the lab helped me understand the real world implications of the } \\
\text { exothermic reactor lab. }\end{array}$ & 1 & 2 & 3 & 4 & 5 \\
\hline 13) & $\begin{array}{l}\text { The Teaching Assistant was helpful in answering the questions my group } \\
\text { had while performing the lab. }\end{array}$ & 1 & 2 & 3 & 4 & 5 \\
\hline 14) & $\begin{array}{l}\text { The work for performing the experiment was divided equally between my } \\
\text { teammates and I so that we could finish in a reasonable amount of time. }\end{array}$ & 1 & 2 & 3 & 4 & 5 \\
\hline 15) & $\begin{array}{l}\text { I felt that I was given enough tasks to keep me busy throughout the } \\
\text { scheduled lab time for the exothermic reactor lab. }\end{array}$ & 1 & 2 & 3 & 4 & 5 \\
\hline 16) & $\begin{array}{l}\text { The Teaching Assistant gave me clear instructions on how to perform the } \\
\text { calculations necessary to obtain results from my experimental data. }\end{array}$ & 1 & 2 & 3 & 4 & 5 \\
\hline 17) & $\begin{array}{l}\text { I felt "lost" and did not know where to begin when writing the Results } \\
\text { and Discussion portions of our report for the exothermic reactor scale- } \\
\text { up lab. }\end{array}$ & 1 & 2 & 3 & 4 & 5 \\
\hline 18) & $\begin{array}{l}\text { My group and I clearly understood the expectations for what was to be } \\
\text { discussed in the final report for exothermic reactor scale-up. }\end{array}$ & 1 & 2 & 3 & 4 & 5 \\
\hline
\end{tabular}




\begin{tabular}{|c|c|c|c|c|c|c|}
\hline 19) & $\begin{array}{l}\text { Performing the exothermic reaction scale-up lab allowed me to see the } \\
\text { dangers of a runaway reaction first hand. }\end{array}$ & 1 & 2 & 3 & 4 & 5 \\
\hline 20) & $\begin{array}{l}\text { I think it would be useful if every group performing the exothermic } \\
\text { reaction lab would get to see the reaction run away (as characterized by } \\
\text { rapid increase in observed temperature of the reaction mixture). }\end{array}$ & 1 & 2 & 3 & 4 & 5 \\
\hline 21) & $\begin{array}{l}\text { Performing the exothermic reactoin lab has increased my awareness of } \\
\text { the dangers of exothermic reaction scale-up in industry. }\end{array}$ & 1 & 2 & 3 & 4 & 5 \\
\hline 22) & $\begin{array}{l}\text { After completing the exothermic reaction lab, I have a better } \\
\text { understanding of how runaway reactions can be prevented in industry } \\
\text { especially when scale-up is involved. }\end{array}$ & 1 & 2 & 3 & 4 & 5 \\
\hline \multicolumn{7}{|c|}{ Suggestions for Improvement: Please write out your responses to the following. } \\
\hline \multicolumn{7}{|c|}{ 1) What did you like most about the Exothermic Reaction Scale-Up Lab? (Feel free to list several things.) } \\
\hline \multicolumn{7}{|c|}{$\begin{array}{l}\text { 2) What issues did you have with the Exothermic Reaction Scale-Up Lab? (List any and all issues with the prelab, } \\
\text { procedure, performing the lab, calculation review and report writing.) }\end{array}$} \\
\hline \multicolumn{7}{|c|}{$\begin{array}{l}\text { 3) How do you think we could make the Exothermic Reaction Scale-Up Lab better? (List all suggestions pertaining } \\
\text { to the prelab, procedure, performing the lab, calculation review and report writing.) }\end{array}$} \\
\hline \multicolumn{7}{|c|}{ 4) List any additional comments you may have. } \\
\hline \multicolumn{7}{|c|}{ Individual Student Information: Please indicate your gender and race below. } \\
\hline Gender: & Male $\quad$ Female $\quad$ Prefer Not to Answer & & & & & \\
\hline Race: & Hispanic Other & wer & & & & \\
\hline
\end{tabular}


ChE 486 Unit Ops II Student Experience Survey

\begin{tabular}{|c|c|c|c|c|c|c|}
\hline Name: & & \multicolumn{5}{|c|}{ Group: } \\
\hline \multicolumn{7}{|c|}{$\begin{array}{l}\text { Directions: Please complete the following survey by answering each item honestly and thoroughly. Any } \\
\text { suggestions or recommendations that you provide may be incorporated into future iterations of these Unit Ops } \\
\text { labs. Some or all of the results of this survey will be presented in the Masters of Engineering Thesis written by } \\
\text { Lisa Anderson regarding the exothermic reaction scale-up lab. We will do everything we can to ensure that the } \\
\text { comments and answers remain anonymous when reporting our findings. Thank you for your feedback! }\end{array}$} \\
\hline \multicolumn{7}{|c|}{ Overall Experience: Please write out your responses to the following. } \\
\hline & \multicolumn{6}{|l|}{ 1) Which lab did you get the most out of? } \\
\hline & \multicolumn{6}{|l|}{ 2) Which lab did you get the least out of? } \\
\hline \multicolumn{7}{|c|}{ Individual Lab Experience: For each of the items below, indicate your response: } \\
\hline 1 - Strongly Disagree; & ongly Disagree; $\quad 2$-Disagree; 3 - Neither agree nor disagree; 4 - Agr & ree; & $5-s$ & (n) & Agre & \\
\hline \multicolumn{7}{|c|}{ Favorite Lab (the lab you got the most out of) } \\
\hline 1) & $\begin{array}{l}\text { The prelab discussion led by the Teaching Assistant (on my scheduled } \\
\text { prelab day) for the lab adequately prepared me to perform the } \\
\text { experiment on my scheduled lab day. }\end{array}$ & 1 & 2 & 3 & 4 & 5 \\
\hline 2) & $\begin{array}{l}\text { The prelab discussion led by the Teaching Assistant (on my scheduled } \\
\text { prelab day) was very useful in helping me understand the overall } \\
\text { purpose of the lab. }\end{array}$ & 1 & 2 & 3 & 4 & 5 \\
\hline 3) & $\begin{array}{l}\text { The written procedure provided to me was easy to understand and } \\
\text { follow. }\end{array}$ & 1 & 2 & 3 & 4 & 5 \\
\hline 4) & $\begin{array}{l}\text { I felt that I was given enough tasks to keep me busy throughout the } \\
\text { scheduled lab time. }\end{array}$ & 1 & 2 & 3 & 4 & 5 \\
\hline 5) & $\begin{array}{l}\text { The Teaching Assistant gave me clear instructions on how to perform the } \\
\text { calculations necessary to obtain results from my experimental data. }\end{array}$ & 1 & 2 & 3 & 4 & 5 \\
\hline 6) & $\begin{array}{l}\text { I felt "lost" and did not know where to begin when writing the Results } \\
\text { and Discussion portions of our report. }\end{array}$ & 1 & 2 & 3 & 4 & 5 \\
\hline 7) & $\begin{array}{l}\text { My group and I clearly understood the expectations for what was to be } \\
\text { discussed in the final report. }\end{array}$ & 1 & 2 & 3 & 4 & 5 \\
\hline \multicolumn{7}{|c|}{ Least Favorite Lab (the lab you got the least out of) } \\
\hline 1) & $\begin{array}{l}\text { The prelab discussion led by the Teaching Assistant (on my scheduled } \\
\text { prelab day) adequately prepared me to perform the experiment on my } \\
\text { scheduled lab day. }\end{array}$ & 1 & 2 & 3 & 4 & 5 \\
\hline 2) & $\begin{array}{l}\text { The prelab discussion led by the Teaching Assistant (on my scheduled } \\
\text { prelab day) was very useful in helping me understand the overall } \\
\text { purpose of the lab. }\end{array}$ & 1 & 2 & 3 & 4 & 5 \\
\hline 3) & $\begin{array}{l}\text { The written procedure provided to me was easy to understand and } \\
\text { follow. }\end{array}$ & 1 & 2 & 3 & 4 & 5 \\
\hline 4) & $\begin{array}{l}\text { I felt that I was given enough tasks to keep me busy throughout the } \\
\text { scheduled lab time for this experiment. }\end{array}$ & 1 & 2 & 3 & 4 & 5 \\
\hline 5) & $\begin{array}{l}\text { The Teaching Assistant gave me clear instructions on how to perform the } \\
\text { calculations necessary to obtain results from my experimental data. }\end{array}$ & 1 & 2 & 3 & 4 & 5 \\
\hline 6) & $\begin{array}{l}\text { I felt "lost" and did not know where to begin when writing the Results } \\
\text { and Discussion portions of our report for this lab. }\end{array}$ & 1 & 2 & 3 & 4 & 5 \\
\hline 7) & $\begin{array}{l}\text { My group and I clearly understood the expectations for what was to be } \\
\text { discussed in the final report for this lab. }\end{array}$ & 1 & 2 & 3 & 4 & 5 \\
\hline \multicolumn{7}{|c|}{ Individual Student Information: Please indicate your gender and race below. } \\
\hline Gender: & \multicolumn{6}{|l|}{ Male $\quad$ Female $\quad$ Prefer Not to Answer } \\
\hline Race: & \multicolumn{6}{|l|}{ 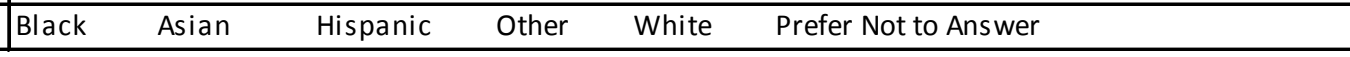 } \\
\hline
\end{tabular}


Optional Suggestions for Improvement: Please write out your responses to the following.

1) What did you like most about Unit Ops II Labs? (Feel free to list several things.)

2) What issues did you have with the Unit Ops II Labs? (List any and all issues with the prelab, procedure, performing the lab, calculation review and report writing.)

3) How do you think we could make the Unit Ops II Labs better? (List all suggestions pertaining to the prelab, procedure, performing the lab, calculation review and report writing.)

4) List any additional comments you may have. 
Descriptive Statistics: Q1, Q2, Q3, Q4, Q5, Q6, Q7, Q8, ... Q22, Gender

Statistics

\begin{tabular}{|c|c|c|c|c|c|c|c|c|c|c|}
\hline & $\begin{array}{r}\text { Tota } \\
1\end{array}$ & & & & & & & & & $\begin{array}{l}\mathrm{N} \\
\text { for }\end{array}$ \\
\hline $\begin{array}{l}\text { Variab } \\
\text { le }\end{array}$ & $\begin{array}{r}\text { Cou } \\
\text { nt }\end{array}$ & $\mathrm{N}$ & $\begin{array}{r}\text { Mea } \\
n\end{array}$ & $\begin{array}{r}\text { SE } \\
\text { Mean }\end{array}$ & StDev & $\begin{array}{r}\text { Minim } \\
\text { um }\end{array}$ & $\begin{array}{r}\text { Medi } \\
\text { an }\end{array}$ & $\begin{array}{r}\text { Maxim } \\
\text { um }\end{array}$ & Mo & Mo \\
\hline $\mathrm{Q} 1$ & 33 & $\begin{array}{l}3 \\
3\end{array}$ & $\begin{array}{r}3.00 \\
00\end{array}$ & $\begin{array}{r}0.0000 \\
00\end{array}$ & $\begin{array}{r}0.0000 \\
00\end{array}$ & 3.0000 & $\begin{array}{r}3.000 \\
0\end{array}$ & 3.0000 & 3 & 33 \\
\hline Q2 & 33 & $\begin{array}{l}3 \\
3\end{array}$ & $\begin{array}{r}3.00 \\
00\end{array}$ & $\begin{array}{r}0.0000 \\
00\end{array}$ & $\begin{array}{r}0.0000 \\
00\end{array}$ & 3.0000 & $\begin{array}{r}3.000 \\
0\end{array}$ & 3.0000 & 3 & 33 \\
\hline Q3 & 33 & $\begin{array}{l}3 \\
3\end{array}$ & $\begin{array}{r}2.96 \\
97\end{array}$ & 0.0303 & 0.1741 & 2.0000 & $\begin{array}{r}3.000 \\
0\end{array}$ & 3.0000 & 3 & 32 \\
\hline Q4 & 33 & $\begin{array}{l}3 \\
3\end{array}$ & $\begin{array}{r}2.72 \\
7\end{array}$ & 0.109 & 0.626 & 1.000 & 3.000 & 3.000 & 3 & 27 \\
\hline Q5 & 33 & $\begin{array}{l}3 \\
3\end{array}$ & $\begin{array}{r}2.69 \\
7\end{array}$ & 0.111 & 0.637 & 1.000 & 3.000 & 3.000 & 3 & 26 \\
\hline Q6 & 33 & $\begin{array}{l}3 \\
3\end{array}$ & $\begin{array}{r}2.75 \\
8\end{array}$ & 0.107 & 0.614 & 1.000 & 3.000 & 3.000 & 3 & 28 \\
\hline Q7 & 33 & $\begin{array}{l}3 \\
3\end{array}$ & $\begin{array}{r}3.00 \\
00\end{array}$ & $\begin{array}{r}0.0000 \\
00\end{array}$ & $\begin{array}{r}0.0000 \\
00\end{array}$ & 3.0000 & $\begin{array}{r}3.000 \\
0\end{array}$ & 3.0000 & 3 & 33 \\
\hline Q8 & 33 & $\begin{array}{l}3 \\
3\end{array}$ & $\begin{array}{r}2.87 \\
88\end{array}$ & 0.0577 & 0.3314 & 2.0000 & $\begin{array}{r}3.000 \\
0\end{array}$ & 3.0000 & 3 & 29 \\
\hline Q9 & 33 & $\begin{array}{l}3 \\
3\end{array}$ & $\begin{array}{r}3.00 \\
00\end{array}$ & $\begin{array}{r}0.0000 \\
00\end{array}$ & $\begin{array}{r}0.0000 \\
00\end{array}$ & 3.0000 & $\begin{array}{r}3.000 \\
0\end{array}$ & 3.0000 & 3 & 33 \\
\hline Q10 & 33 & $\begin{array}{l}3 \\
3\end{array}$ & $\begin{array}{r}2.75 \\
76\end{array}$ & 0.0976 & 0.5607 & 1.0000 & $\begin{array}{r}3.000 \\
0\end{array}$ & 3.0000 & 3 & 27 \\
\hline Q11 & 33 & $\begin{array}{l}3 \\
3\end{array}$ & $\begin{array}{r}2.90 \\
91\end{array}$ & 0.0669 & 0.3844 & 1.0000 & $\begin{array}{r}3.000 \\
0\end{array}$ & 3.0000 & 3 & 31 \\
\hline Q12 & 33 & $\begin{array}{l}3 \\
3\end{array}$ & $\begin{array}{r}2.96 \\
97\end{array}$ & 0.0303 & 0.1741 & 2.0000 & $\begin{array}{r}3.000 \\
0\end{array}$ & 3.0000 & 3 & 32 \\
\hline Q13 & 33 & $\begin{array}{l}3 \\
3\end{array}$ & $\begin{array}{r}3.00 \\
00\end{array}$ & $\begin{array}{r}0.0000 \\
00\end{array}$ & $\begin{array}{r}0.0000 \\
00\end{array}$ & 3.0000 & $\begin{array}{r}3.000 \\
0\end{array}$ & 3.0000 & 3 & 33 \\
\hline Q14 & 33 & $\begin{array}{l}3 \\
3\end{array}$ & $\begin{array}{r}2.90 \\
91\end{array}$ & 0.0669 & 0.3844 & 1.0000 & $\begin{array}{r}3.000 \\
0\end{array}$ & 3.0000 & 3 & 31 \\
\hline Q15 & 33 & $\begin{array}{l}3 \\
3\end{array}$ & $\begin{array}{r}2.96 \\
97\end{array}$ & 0.0303 & 0.1741 & 2.0000 & $\begin{array}{r}3.000 \\
0\end{array}$ & 3.0000 & 3 & 32 \\
\hline Q16 & 33 & $\begin{array}{l}3 \\
3\end{array}$ & $\begin{array}{r}2.90 \\
91\end{array}$ & 0.0508 & 0.2919 & 2.0000 & $\begin{array}{r}3.000 \\
0\end{array}$ & 3.0000 & 3 & 30 \\
\hline Q17 & 33 & $\begin{array}{l}3 \\
3\end{array}$ & $\begin{array}{r}2.84 \\
85\end{array}$ & 0.0634 & 0.3641 & 2.0000 & $\begin{array}{r}3.000 \\
0\end{array}$ & 3.0000 & 3 & 28 \\
\hline Q18 & 33 & $\begin{array}{l}3 \\
3\end{array}$ & $\begin{array}{r}2.93 \\
94\end{array}$ & 0.0606 & 0.3482 & 1.0000 & $\begin{array}{r}3.000 \\
0\end{array}$ & 3.0000 & 3 & 32 \\
\hline Q19 & 33 & $\begin{array}{l}3 \\
3\end{array}$ & $\begin{array}{r}2.78 \\
79\end{array}$ & 0.0844 & 0.4846 & 1.0000 & $\begin{array}{r}3.000 \\
0\end{array}$ & 3.0000 & 3 & 27 \\
\hline
\end{tabular}




$\begin{array}{lrrrlllrlll}\text { Q20 } & 33 & 3 & 2.87 & 0.0577 & 0.3314 & 2.0000 & 3.000 & 3.0000 & 3 & 29 \\ & & 3 & 88 & & & & 0 & & & \\ \text { Q21 } & 33 & 3 & 2.90 & 0.0508 & 0.2919 & 2.0000 & 3.000 & 3.0000 & 3 & 30 \\ & & 3 & 91 & & & & 0 & & & \\ \text { Q22 } & 33 & 3 & 2.84 & 0.0769 & 0.4417 & 1.0000 & 3.000 & 3.0000 & 3 & 29 \\ & & 3 & 85 & & & & 0 & & & \\ \text { Gende } & 33 & 3 & 1.63 & 0.0850 & 0.4885 & 1.0000 & 2.000 & 2.0000 & 2 & 21 \\ \text { r } & & 3 & 64 & & & & 0 & & & \end{array}$

Two-Sample T-Test and CI: Q1, 1L

* ERROR * All values in column are identical.

Two-Sample T-Test and CI: Q2, 2L

* ERROR * All values in column are identical.

Two-Sample T-Test and CI: Q8, 3L

Method

1: mean of Q8

$\mu_{2}$ : mean of $3 \mathrm{~L}$

Difference: $1-\mu_{2}$

Equal variances are not assumed for this analysis.

Descriptive Statistics

\begin{tabular}{lrrrr} 
Sample & N & Mean & StDev & SE Mean \\
\hline Q8 & 33 & 2.879 & 0.331 & 0.058 \\
3L & 50 & 2.580 & 0.642 & 0.091
\end{tabular}

Estimation for Difference

\begin{tabular}{rc} 
Difference & $\begin{array}{c}95 \% \text { CI for } \\
\text { Difference }\end{array}$ \\
\hline 0.299 & $(0.085,0.513)$
\end{tabular}

Test

Null hypothesis $\quad \mathrm{H}_{0}:{ }_{1}-\mu_{2}=0$

Alternative hypothesis $\mathrm{H}_{1}:{ }_{1}-\mu_{2} \neq 0$

\begin{tabular}{rrr} 
T-Value & DF & P-Value \\
\hline 2.78 & 77 & 0.007
\end{tabular}

Two-Sample T-Test and CI: Q15, 4L

Method

${ }_{1}$ : mean of Q15

$\mu_{2}$ : mean of $4 \mathrm{~L}$

Difference: $1-\mu_{2}$

Equal variances are not assumed for this analysis.

Descriptive Statistics

\begin{tabular}{lrrrr} 
Sample & N & Mean & StDev & SE Mean \\
\hline Q15 & 33 & 2.970 & 0.174 & 0.030
\end{tabular} 
$\begin{array}{lllll}4 \mathrm{~L} & 50 & 2.300 & 0.863 & 0.12\end{array}$

Estimation for Difference 95\% CI for

\begin{tabular}{rc} 
Difference & Difference \\
\hline 0.670 & $(0.418,0.922)$
\end{tabular}

Test

Null hypothesis $\quad \mathrm{H}_{0}:{ }_{1}-\mu_{2}=0$

Alternative hypothesis $\mathrm{H}_{1}:{ }_{1}-\mu_{2} \neq 0$

\begin{tabular}{rrr} 
T-Value & DF & P-Value \\
\hline 5.33 & 54 & 0.000
\end{tabular}

Two-Sample T-Test and CI: Q16, 5L

Method

1: mean of Q16

$\mu_{2}$ : mean of $5 \mathrm{~L}$

Difference: $1-\mu_{2}$

Equal variances are not assumed for this analysis.

Descriptive Statistics

\begin{tabular}{lrrrr} 
Sample & N & Mean & StDev & SE Mean \\
\hline Q16 & 33 & 2.909 & 0.292 & 0.051 \\
5L & 50 & 2.220 & 0.815 & 0.12
\end{tabular}

Estimation for Difference 95\% CI for

\begin{tabular}{rc} 
Difference & Difference \\
\hline 0.689 & $(0.437,0.941)$
\end{tabular}

Test

Null hypothesis $\quad \mathrm{H}_{0}:{ }_{1}-\mu_{2}=0$

Alternative hypothesis $\mathrm{H}_{1}:{ }_{1}-\mu_{2} \neq 0$

\begin{tabular}{rrr} 
T-Value & DF & P-Value \\
\hline 5.47 & 66 & 0.000
\end{tabular}

Two-Sample T-Test and CI: Q17, 6L

Method

1: mean of Q17

$\mu_{2}$ : mean of $6 \mathrm{~L}$

Difference: $1-\mu_{2}$

Equal variances are not assumed for this analysis.

Descriptive Statistics

\begin{tabular}{lrrrr} 
Sample & N & Mean & StDev & SE Mean \\
\hline Q17 & 33 & 2.848 & 0.364 & 0.063 \\
6L & 50 & 1.980 & 0.845 & 0.12
\end{tabular}

Estimation for Difference 


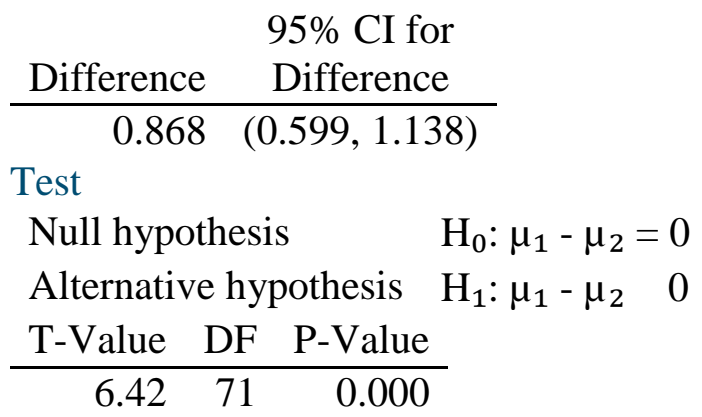

Two-Sample T-Test and CI: Q18, 7L

Method

1: mean of Q18

$\mu_{2}$ : mean of $7 \mathrm{~L}$

Difference: $1-\mu_{2}$

Equal variances are not assumed for this analysis.

Descriptive Statistics

\begin{tabular}{lrrrr} 
Sample & N & Mean & StDev & SE Mean \\
\hline Q18 & 33 & 2.939 & 0.348 & 0.061 \\
7L & 50 & 2.420 & 0.702 & 0.099
\end{tabular}

Estimation for Difference 95\% CI for

Difference Difference

$0.519 \quad(0.288,0.751)$

Test

Null hypothesis $\quad \mathrm{H}_{0}:{ }_{1}-\mu_{2}=0$

Alternative hypothesis $\mathrm{H}_{1}:{ }_{1}-\mu_{2} \neq 0$

\begin{tabular}{rrr} 
T-Value & DF & P-Value \\
\hline 4.46 & 76 & 0.000
\end{tabular}

Two-Sample T-Test and CI: Q1, 1F

* ERROR * All values in column are identical.

Two-Sample T-Test and CI: Q2, 2F

* ERROR * All values in column are identical.

Two-Sample T-Test and CI: Q8, 3F

Method

1: mean of Q8

$\mu_{2}$ : mean of $3 \mathrm{~F}$

Difference: $1-\mu_{2}$

Equal variances are not assumed for this analysis.

Descriptive Statistics

\begin{tabular}{lrrrr} 
Sample & N & Mean & StDev & SE Mean \\
\hline Q8 & 33 & 2.879 & 0.331 & 0.058
\end{tabular}




$$
\begin{array}{lll}
33 & 2.909 & 0.292
\end{array}
$$

0.051

Estimation for Difference

$$
95 \% \text { CI for }
$$

Difference Difference

$$
-0.0303 \quad(-0.1840,0.1234)
$$

Test

Null hypothesis $\quad \mathrm{H}_{0}:{ }_{1}-\mu_{2}=0$

Alternative hypothesis $\mathrm{H}_{1}:{ }_{1}-\mu_{2} \neq 0$

\begin{tabular}{rrr} 
T-Value & DF & P-Value \\
\hline-0.39 & 62 & 0.695
\end{tabular}

Two-Sample T-Test and CI: Q15, 4F

Method

1: mean of Q15

$\mu_{2}$ : mean of $4 \mathrm{~F}$

Difference: $1-\mu_{2}$

Equal variances are not assumed for this analysis.

Descriptive Statistics

\begin{tabular}{lrrrr} 
Sample & N & Mean & StDev & SE Mean \\
\hline Q15 & 33 & 2.970 & 0.174 & 0.030 \\
4F & 33 & 2.697 & 0.585 & 0.10
\end{tabular}

Estimation for Difference

\begin{tabular}{rc} 
Difference & $\begin{array}{c}95 \% \text { CI for } \\
\text { Difference }\end{array}$ \\
\hline 0.273 & $(0.057,0.488)$
\end{tabular}

Test

Null hypothesis $\quad \mathrm{H}_{0}:{ }_{1}-\mu_{2}=0$

Alternative hypothesis $\mathrm{H}_{1}:{ }_{1}-\mu_{2} \neq 0$

\begin{tabular}{rrr} 
T-Value & DF & P-Value \\
\hline 2.56 & 37 & 0.015
\end{tabular}

Two-Sample T-Test and CI: Q16, 5F

Method

1: mean of Q16

$\mu_{2}$ : mean of $5 \mathrm{~F}$

Difference: $1-\mu_{2}$

Equal variances are not assumed for this analysis.

Descriptive Statistics

\begin{tabular}{lrrrr} 
Sample & N & Mean & StDev & SE Mean \\
\hline Q16 & 33 & 2.909 & 0.292 & 0.051 \\
5F & 33 & 2.576 & 0.663 & 0.12
\end{tabular}

Estimation for Difference 


\begin{tabular}{rc} 
Difference & $\begin{array}{c}95 \% \text { CI for } \\
\text { Difference }\end{array}$ \\
\hline 0.333 & $(0.079,0.588)$
\end{tabular}

Test

Null hypothesis $\quad \mathrm{H}_{0}:{ }_{1}-\mu_{2}=0$

Alternative hypothesis $\mathrm{H}_{1}:{ }_{1}-\mu_{2} \neq 0$

\begin{tabular}{rrr} 
T-Value & DF & P-Value \\
\hline 2.64 & 43 & 0.011
\end{tabular}

Two-Sample T-Test and CI: Q17, 6F

Method

1: mean of Q17

$\mu_{2}$ : mean of $6 \mathrm{~F}$

Difference: $1-\mu_{2}$

Equal variances are not assumed for this analysis.

Descriptive Statistics

\begin{tabular}{lrrrr} 
Sample & N & Mean & StDev & SE Mean \\
\hline Q17 & 33 & 2.848 & 0.364 & 0.063 \\
6F & 33 & 2.697 & 0.637 & 0.11
\end{tabular}

Estimation for Difference 95\% CI for

Difference Difference

$0.152 \quad(-0.105,0.408)$

Test

Null hypothesis $\quad \mathrm{H}_{0}:{ }_{1}-\mu_{2}=0$

Alternative hypothesis $\mathrm{H}_{1}:{ }_{1}-\mu_{2} \neq 0$

T-Value DF P-Value

$\begin{array}{lll}1.19 & 50 & 0.241\end{array}$

Two-Sample T-Test and CI: Q18, 7F

Method

1: mean of Q18

$\mu_{2}$ : mean of $7 F$

Difference: $1-\mu_{2}$

Equal variances are not assumed for this analysis.

Descriptive Statistics

\begin{tabular}{lrrrr} 
Sample & N & Mean & StDev & SE Mean \\
\hline Q18 & 33 & 2.939 & 0.348 & 0.061
\end{tabular}

$\begin{array}{lllll}7 \mathrm{~F} & 33 & 2.909 & 0.292 & 0.051\end{array}$

Estimation for Difference 95\% CI for

\begin{tabular}{rc} 
Difference & Difference \\
\hline 0.0303 & $(-0.1278,0.1884)$
\end{tabular} 
Test

Null hypothesis $\quad \mathrm{H}_{0}:{ }_{1}-\mu_{2}=0$

Alternative hypothesis $\mathrm{H}_{1}:{ }_{1}-\mu_{2} \neq 0$

\begin{tabular}{rrr} 
T-Value & DF & P-Value \\
\hline 0.38 & 62 & 0.703
\end{tabular}

One-way ANOVA: Q1, Q2, Q8, Q15, Q16, Q17, Q18, 1F, ... 4L, 5L, 6L, 7L

* NOTE * Cannot draw the interval plot for the Tukey procedure. Interval plots for comparisons are illegible with more than 45 intervals.

Method

Null hypothesis All means are equal

Alternative hypothesis Not all means are equal

Significance level $\quad \alpha=0.05$

Equal variances were assumed for the analysis.

Factor Information

Facto Level

\begin{tabular}{lrl}
$\mathrm{r}$ & $\mathrm{s}$ & Values \\
\hline Facto & 21 & $\mathrm{Q} 1, \mathrm{Q} 2, \mathrm{Q8}, \mathrm{Q15}, \mathrm{Q16}, \mathrm{Q17}, \mathrm{Q18}, 1 \mathrm{~F}, 2 \mathrm{~F}, 3 \mathrm{~F}, 4 \mathrm{~F}, 5 \mathrm{~F}, 6 \mathrm{~F}, 7 \mathrm{~F}, 1 \mathrm{~L}, 2 \mathrm{~L}$, \\
$\mathrm{r}$ & & 3L, 4L, \\
& 5L, 6L, 7L
\end{tabular}

Analysis of Variance

\begin{tabular}{lrrrrr} 
Source & DF & Adj SS & Adj MS & F-Value & P-Value \\
\hline Factor & 20 & 72.63 & 3.6315 & 9.60 & 0.000 \\
Error & 791 & 299.26 & 0.3783 & & \\
Total & 811 & 371.89 & & &
\end{tabular}

Model Summary

\begin{tabular}{lrrrc}
\multicolumn{1}{r}{ S } & R-sq & R-sq(adj) & R-sq(pred) \\
\hline $\begin{array}{l}\text { 0.615088 } \\
\text { Means }\end{array}$ & $19.53 \%$ & $17.50 \%$ & $15.70 \%$ \\
Factor & N & Mean & StDev & $95 \%$ CI \\
\hline Q1 & 33 & 3.000 & 0.000 & $(2.790,3.210)$ \\
Q2 & 33 & 3.000 & 0.000 & $(2.790,3.210)$ \\
Q8 & 33 & 2.8788 & 0.3314 & $(2.6686,3.0890)$ \\
Q15 & 33 & 2.9697 & 0.1741 & $(2.7595,3.1799)$ \\
Q16 & 33 & 2.9091 & 0.2919 & $(2.6989,3.1193)$ \\
Q17 & 33 & 2.8485 & 0.3641 & $(2.6383,3.0587)$ \\
Q18 & 33 & 2.9394 & 0.3482 & $(2.7292,3.1496)$ \\
1F & 33 & 2.667 & 0.645 & $(2.456,2.877)$ \\
2F & 33 & 2.576 & 0.663 & $(2.366,2.786)$ \\
3F & 33 & 2.9091 & 0.2919 & $(2.6989,3.1193)$ \\
4F & 33 & 2.697 & 0.585 & $(2.487,2.907)$ \\
5F & 33 & 2.576 & 0.663 & $(2.366,2.786)$ \\
6F & 33 & 2.697 & 0.637 & $(2.487,2.907)$
\end{tabular}




$\begin{array}{lrrrc}\text { 7F } & 33 & 2.9091 & 0.2919 & (2.6989,3.1193) \\ \text { 1L } & 50 & 2.380 & 0.805 & (2.209,2.551) \\ \text { 2L } & 50 & 2.320 & 0.819 & (2.149,2.491) \\ \text { 3L } & 50 & 2.5800 & 0.6417 & (2.4092,2.7508) \\ \text { 4L } & 50 & 2.300 & 0.863 & (2.129,2.471) \\ \text { 5L } & 50 & 2.220 & 0.815 & (2.049,2.391) \\ \text { 6L } & 50 & 1.980 & 0.845 & (1.809,2.151) \\ \text { 7L } & 50 & 2.4200 & 0.7025 & (2.2492,2.5908)\end{array}$

Pooled StDev $=0.615088$

Tukey Pairwise Comparisons

Grouping Information Using the Tukey Method and 95\% Confidence

\begin{tabular}{lrrrllll} 
Factor & $\mathrm{N}$ & Mean & & \multicolumn{3}{c}{ Grouping } \\
\hline $\mathrm{Q} 2$ & 33 & 3.000 & $\mathrm{~A}$ & & & & \\
$\mathrm{Q} 1$ & 33 & 3.000 & $\mathrm{~A}$ & & & & \\
$\mathrm{Q} 15$ & 33 & 2.9697 & $\mathrm{~A}$ & & & & \\
$\mathrm{Q} 18$ & 33 & 2.9394 & $\mathrm{~A}$ & & & & \\
7F & 33 & 2.9091 & $\mathrm{~A}$ & $\mathrm{~B}$ & & & \\
3F & 33 & 2.9091 & $\mathrm{~A}$ & $\mathrm{~B}$ & & & \\
$\mathrm{Q} 16$ & 33 & 2.9091 & $\mathrm{~A}$ & $\mathrm{~B}$ & & & \\
$\mathrm{Q} 8$ & 33 & 2.8788 & $\mathrm{~A}$ & $\mathrm{~B}$ & & & \\
$\mathrm{Q} 17$ & 33 & 2.8485 & $\mathrm{~A}$ & $\mathrm{~B}$ & $\mathrm{C}$ & & \\
6F & 33 & 2.697 & $\mathrm{~A}$ & $\mathrm{~B}$ & $\mathrm{C}$ & $\mathrm{D}$ & \\
4F & 33 & 2.697 & $\mathrm{~A}$ & $\mathrm{~B}$ & $\mathrm{C}$ & $\mathrm{D}$ & \\
1F & 33 & 2.667 & $\mathrm{~A}$ & $\mathrm{~B}$ & $\mathrm{C}$ & $\mathrm{D}$ & \\
3L & 50 & 2.5800 & $\mathrm{~A}$ & $\mathrm{~B}$ & $\mathrm{C}$ & $\mathrm{D}$ & \\
5F & 33 & 2.576 & $\mathrm{~A}$ & $\mathrm{~B}$ & $\mathrm{C}$ & $\mathrm{D}$ & \\
2F & 33 & 2.576 & $\mathrm{~A}$ & $\mathrm{~B}$ & $\mathrm{C}$ & $\mathrm{D}$ & \\
7L & 50 & 2.4200 & & $\mathrm{~B}$ & $\mathrm{C}$ & $\mathrm{D}$ & \\
1L & 50 & 2.380 & & & $\mathrm{C}$ & $\mathrm{D}$ & $\mathrm{E}$ \\
2L & 50 & 2.320 & & & & $\mathrm{D}$ & $\mathrm{E}$ \\
4L & 50 & 2.300 & & & & $\mathrm{D}$ & $\mathrm{E}$ \\
5L & 50 & 2.220 & & & & $\mathrm{D}$ & $\mathrm{E}$ \\
6L & 50 & 1.980 & & & & & $\mathrm{E}$
\end{tabular}

Means that do not share a letter are significantly different. 


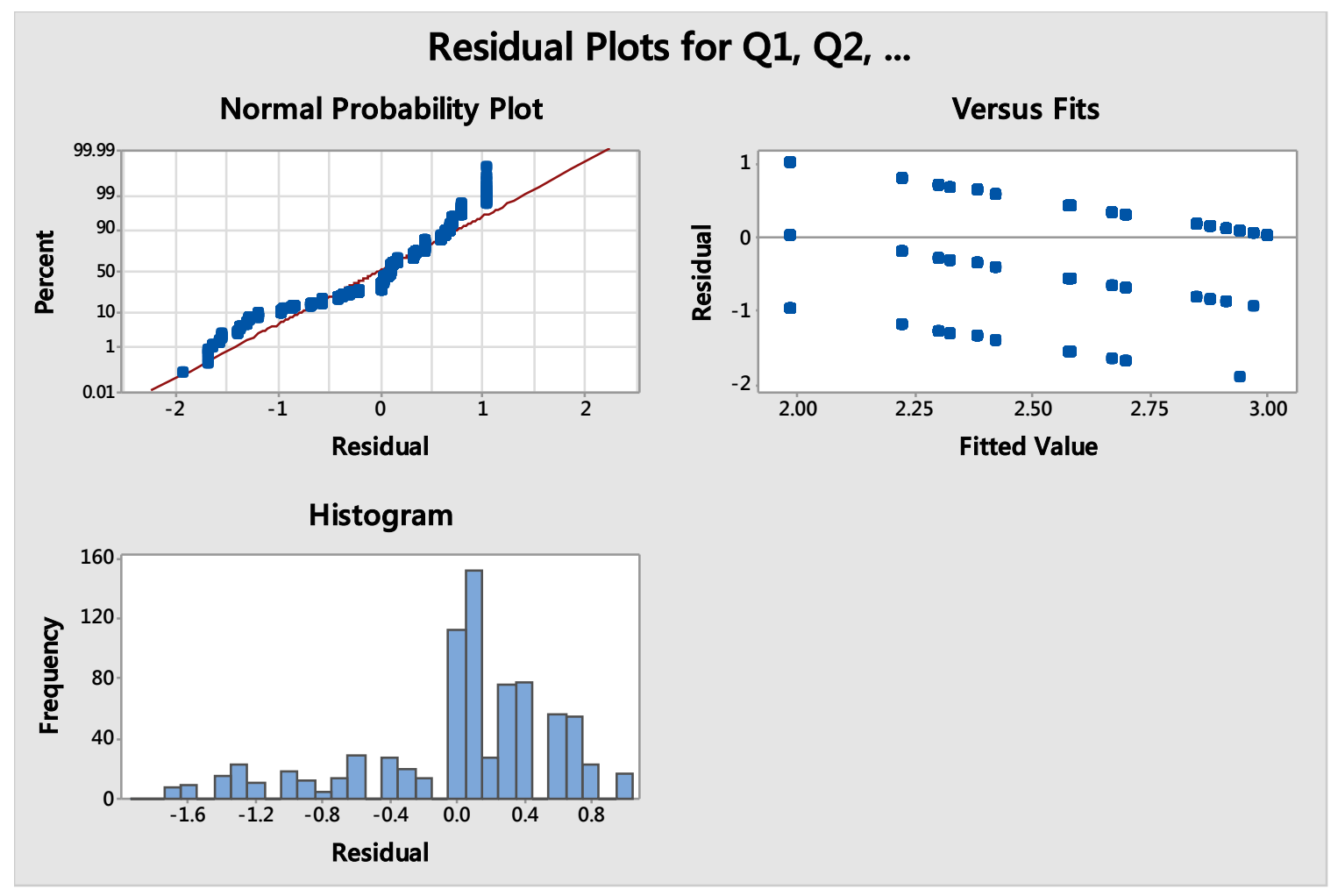




\section{APPENDIX III}

\section{RESOURCES FOR TEACHING ASSISTANT}

These resources include the prelab checklist, post-lab checklist, procedure for preparing $0.1 \mathrm{M}$ KI solution, calculation review discussion and grading guidelines and the complete experimental lab procedure used for Lab 3 of the Spring 2018 semester.

\section{Hazards of Exothermic Reaction Scale Up - TA Prelab Checklist}

This checklist is to be used by the Teaching Assistant for the Unit Ops Exothermic Reaction lab to prepare for each lab.

Check that ice chest has ice on the Monday of the week the labs are to be performed. If the chest is empty, plug it in.

Refrigerate $\mathrm{H} 2 \mathrm{O} 2$ using the refrigerator in Room 303 in Ernst at least 2 hours before the start of lab. Be sure to mark any containers place in the fridge with "Unit Ops".

Chill $500 \mathrm{~mL}$ cold water by placing graduated cylinder in the ice chest.

Set out materials/equipment for the lab

- Stir plate

- Clamp stands and clamps

- Stir bars

- Chilled $\mathrm{H} 2 \mathrm{O} 2$

- KI volumetric flask

○ Pipette and bulb

○ Round bottom flasks

○ Graduated cylinders

○ Funnels

- Thermocouples (1 per station)

o Thermometers (2 per station)

- Additional ice bucket

Label each station ("water only" or "H2O2 reaction")

Label prep area ("KI prep" and "H2O2 prep") 


\section{Hazards of Exothermic Reaction Scale Up - Cleanup and Post-lab Checklist}

This checklist is to be used by the Teaching Assistant for the Unit Ops Exothermic

Reaction lab to ensure proper cleanup after each time the lab is performed. Students are required to assist with the cleanup process as directed by the TA once they have completed their assigned tasks for the lab.

Watch an "elephant toothpaste" experiment on YouTube with the lab group and encourage students to thoroughly rinse the glassware they wash. (Example: https://www.youtube.com/watch?v=K28I5WCwcak\&t=178s) This can be done after the second reaction has reached its max temperature and is cooling down.

Discard waste into designated waste container. Be sure to use a funnel if stir bar is still in flask.

Thoroughly rinse out every container/piece of equipment used during the lab.

○ Flasks

- Funnels

○ Graduated cylinders

- Beakers

- 12 quart bowls

Wipe down all temperature probes.

Disassemble clamp/clamp stand setup.

Return thermometers, thermocouples, stir bars, clamps and funnels neatly next to each stir plate for the following day. Otherwise, store equipment appropriately in designated storage area.

Return KI to designated storage area.

Place $\mathrm{H} 2 \mathrm{O} 2$ in refrigerator in Room 303 for the following day. Otherwise, store $\mathrm{H} 2 \mathrm{O} 2$ in designated storage area.

Remind students to email data to the TA before the end of the day.

Remind students to wash hands before leaving the lab. 


\section{Hazards of Exothermic Reaction Scale Up - Procedure for Preparing 0.1M KI}

Safety Equipment:

- Safety glasses

- Nitrile gloves

- Long sleeves/pants

- Closed-toe shoes

Materials needed:

- $1000 \mathrm{~mL}$ volumetric flask and stopper

- Potassium iodide concentrate*

- DI water wash bottle

- DI water

*Fixanal/Fluka Analytical "Potassium iodide concentrate 0.1 mol for $1 \mathrm{~L}$ standard solution MW: $166 \mathrm{~g} / \mathrm{mol}$ "

Procedure:

1. Acquire a clean $1000 \mathrm{~mL}$ volumetric flask and appropriate stopper.

2. Label the flask " $0.1 \mathrm{M}$ potassium iodide solution; Unit Ops 2" and date.

3. Add about $500 \mathrm{~mL}$ DI water into the volumetric flask.

4. Put the ampoule on the volumetric flask. Fix the lower part and rotate the upper part counter clockwise (at most two turns).

5. Remove the funnel and replace it firmly upside down so that the membrane opens.

6. Hold the ampoule at an angle and rotate it while thoroughly rinsing it out.

7. Fill the volumetric flask to the mark at $20 \mathrm{deg} \mathrm{C}$ and mix thoroughly.

8. Put the stopper on the volumetric flask and store.

Note: Steps 4-7 give information specific to using Fixanal apparatus for adding in potassium iodide.

Hazards of Exothermic Reaction Scale Up - Calculation Review Discussion These guidelines are to be used by the Teaching Assistant for the Unit Ops Exothermic Reaction lab to prepare students to perform calculations for this lab. The calculations are divided into three sections: overall heat transfer coefficient calculations, theoretical calculations and the presentation of the sample calculations.

\section{Overall Heat Transfer Coefficient, U Calculations}

Define To as the maximum temperature reached after the warm water was added to the cold water. (Think of To as your initial temperature once the cooling begins.)

Use the appropriate amount of data points for plot starting at To. This should be about 200-250 points.

Have the y-intercept equal to 0 . (Why? Look at the equation you are using.) 
Use the correct constants for the specific flask size. This includes mass, surface area and specific heat.

Use the correct equation to calculate $\mathrm{U}: U=\frac{\text { slope } * m * c_{p}}{A}$

The plot used to determine slope for this equation is adequately labeled including title, axes labels, units, trend-line and $\mathrm{R}$ squared value. (What can that $\mathrm{R}$ squared value tell us when interpreting results?)

\section{Theoretical Calculations}

Include the code for Polymath (or equivalent DE solver program) clearly showing each parameter and equation used for calculation. Units must be included as a string of text next to any numerical values. ("Use that hashtag generously to clearly annotate your calculations.")

Display correct rate law equation.

Display correct dT/dt equation. (The mistake is usually because of a misplaced negative sign.)

Use correct constants for the specific flask size. This includes mass, volume, surface area, concentration, etc.

Clearly show resulting plots with titles and axes labels (with units). Results from multiple experiments may be shown on a single plot provided there is a clear legend included. (Don't report the exact same graphs that Polymath gives. Export the data for those graphs into Excel and make your own neater version.)

\section{Sample Calculations}

Include thoroughly explained steps for obtaining the following: initial concentration for each reactant, overall heat transfer coefficient for each flask and theoretical temperature vs. time and concentration vs. time plots. Are neat and easy to follow so that calculations can be easily repeated. (Remember, sample calculations are meant to be a tool for others to use in order to repeat your experiment. Keep that in mind when presenting them.) 


\section{Hazards of Exothermic Reaction Scale Up - Calculation Grading Guidelines}

These guidelines are to be used by the Teaching Assistant for the Unit Ops Exothermic Reaction lab to grade the calculations for each lab report.

The grading is divided into three sections: overall heat transfer coefficient calculations, theoretical calculations and the presentation of the sample calculations.

\section{Overall Heat Transfer Coefficient, U Calculations (20 POINTS)}

Define To as the maximum temperature reached after the warm water was added to the cold water.

Use the appropriate amount of data points for plot starting at To. This should be about 200-250 points.

Have the y-intercept equal to 0 .

Use the correct constants for the specific flask size. This includes mass, surface area and specific heat.

Use the correct equation to calculate $\mathrm{U}: U=\frac{\text { slope } * m * c_{p}}{A}$

The plot used to determine slope for this equation is adequately labeled including title, axes labels, units, trend-line and $\mathrm{R}$ squared value.

\section{Theoretical Calculations (20 POINTS)}

Include the code for Polymath (or equivalent DE solver program) clearly showing each parameter and equation used for calculation. Units must be included as a string of text next to any numerical values.

Display correct rate law equation.

Display correct dT/dt equation.

Use correct constants for the specific flask size. This includes mass, volume, surface area, concentration, etc.

Clearly show resulting plots with titles and axes labels (with units). Results from multiple experiments may be shown on a single plot provided there is a clear legend included.

\section{Sample Calculations (10 POINTS)}

Include thoroughly explained steps for obtaining the following: initial concentration for each reactant, overall heat transfer coefficient for each flask and theoretical temperature vs. time and concentration vs. time plots. Are neat and easy to follow so that calculations can be easily repeated. 


\section{Hazards of Exothermic Reaction Scale-up}

\section{Objectives}

In this lab, students will discover the hazards associated with improper scale-up of exothermic reactors by performing the iodide catalyzed decomposition of hydrogen peroxide reaction in different sized vessels. After completing this lab, students should be able to do the following:

- Discuss the dangers of runaway reactions using evidence from well-known industrial accidents

- Explain how runaway reactions can be prevented especially when caused by improper scale-up

- Use kinetics and heat transfer principles to predict when runaway reactions will occur

- Compare experimental and theoretical temperature versus time data for exothermic reactions

- Relate the components of the tabletop reaction to the process of scaling up in industry.

\section{Background}

According to the Chemical Safety Board's 2002 report entitled "Improving Reactive Hazard Management," the CSB identified 167 serious accidents involving uncontrolled chemical reactions in the United States between 1980 and 2001 causing 108 deaths and hundreds of millions of dollars in property damage. The majority of these accidents could have been prevented simply by having a better understanding of the chemistry behind these reactions and implementing the appropriate engineering controls.

Many of these incidents were due to improper scale-up of the reaction. In most cases of scale-up, the cooling mechanism is not sufficient for the exponentially increasing amount of heat generation of the larger reaction. Because exothermic chemical reactions are prevalent in the chemical industry, it is imperative for chemical engineers to understand the kinetics and heat transfer of these reactors in order to prevent runaway reactions.

In this lab, students will study the iodidwt-catalyzed decomposition of hydrogen peroxide

$$
\mathrm{H}_{2} \mathrm{O}_{2} \stackrel{\sharp K I I}{\longrightarrow} \mathrm{H}_{2} \mathrm{O}+\frac{1}{2} \mathrm{O}_{2}
$$

The students will perform the experiment in different sized flasks and observe the differences in behavior in each of them. In each case, an ice bath will be used as the cooling mechanism to keep the reaction under control. Students will obtain temperature versus time data for each reaction.

\section{Theory}

The iodide catalyzed decomposition of hydrogen peroxide is described by the following rate equation: 


$$
\text { rate }=\frac{-d\left[\mathrm{H}_{2} \mathrm{O}_{2}\right]}{d t}=k_{o} \exp \left(\frac{-E a}{R T}\right)\left[\mathrm{H}_{2} \mathrm{O}_{2}\right]\left[I^{-}\right]
$$

with the total amount of heat in a system given by

$$
Q=Q_{g}+Q_{r}
$$

where $\mathrm{Q}_{\mathrm{g}}$ is the amount of heat generated and $\mathrm{Q}_{\mathrm{r}}$ is the amount of heat removed. The heat of a system can be expressed as

$$
Q=m c_{p} \frac{d T}{d t}
$$

where $\mathrm{C}$ is the specific heat and $\mathrm{m}$ is the mass of the solution. Heat is removed from the reaction via an ice bath and is given by

$$
Q_{r}=U A\left(T_{i}-T\right)
$$

where $\mathrm{U}$ is the overall heat transfer coefficient, $\mathrm{A}$ is the area available for heat transfer and $\mathrm{T}_{\mathrm{i}}$ is the temperature of the ice bath. Throughout the experiment, the ice bath temperature can be assumed to remain nearly constant at $0{ }^{\circ} \mathrm{C}$. This is possible when the ice bath is sufficiently stirred and an adequate amount of ice is maintained.

The heat generated by the reaction is given by

$$
Q_{g}=-V \Delta H^{o}(\text { rate })
$$

As this reaction is exothermic the heat of reaction is negative and it follows that $\mathrm{Q}_{\mathrm{g}}$ is positive or heat is indeed generated. On the other hand, $Q_{r}$ is negative because $T_{i}$ is less than the reaction temperature T. Any imbalance between the rate of heat generation and rate of heat removal will result in energy accumulation and a concomitant temperature change within the reactor given by

$$
m c_{p} \frac{d T}{d t}=-V \Delta H^{o}(\text { rate })+U A\left(T_{i}-T\right)
$$

Both the specific heat and the mass are assumed to be constant here. (Neglect any loss of mass due to water saturated oxygen bubbles.) Solving Equations 2 and 7 simultaneously provides information for $\mathrm{T}$ and $\left[\mathrm{H}_{2} \mathrm{O}_{2}\right]$ in the reactor as a function of time. The constants, $\mathrm{c}_{\mathrm{p}}, \quad \mathrm{H}^{\mathrm{o}}$, and Ea can be found in the literature to be $4.18 \mathrm{~J} / \mathrm{g} \mathrm{K}$ (assuming the value for water), $-98.3 \mathrm{~kJ} / \mathrm{mol}$, and $56 \mathrm{~kJ} / \mathrm{mol}$, respectively. The value of $\mathrm{U}$ can be estimated in a separate experiment using only water. This is done by using an ice bath to cool a known mass of water, $\mathrm{m}$, at a known initial temperature, $\mathrm{T}_{\mathrm{o}}$ with an experimental setup almost 
identical to the decomposition reaction experiment. Because there is no reaction taking place, the rate term in Equation 7 is zero. Rearranging and integrating Equation 7 gives

$$
\frac{\left(T_{i}-T_{o}\right)}{\left(T_{i}-T\right)}=\exp \left(\frac{U A t}{m c_{p}}\right)
$$

To find $U$, plot $\ln \left[\left(\mathrm{T}_{\mathrm{i}}-\mathrm{T}_{\mathrm{o}}\right) /\left(\mathrm{T}_{\mathrm{i}}-\mathrm{T}\right)\right]$ versus $\mathrm{t}$. This yields a straight line and $\mathrm{U}$ can be obtained as

$$
U=\frac{\text { slope } * m * c_{p}}{A}
$$

To complete the solution of Equations 2 and 7, the pre-exponential constant, $\mathrm{k}_{\mathrm{o}}$, must be known or estimated. For this lab experiment use the estimated value of $3.083 \times 10^{8}$ L/mol s.

\section{Final Report Deliverables}

- Report the overall heat transfer coefficient results for each reactor (clearly stating the conditions at which the data was taken).

- Compare experimental and calculated temperature versus time results for each reactor.

- Report concentration of hydrogen peroxide versus time results and compare to experimental observations.

- Explain the differences in behavior between the reactors. Include an explanation of the behavior of the $500 \mathrm{~mL}$ flasks that had poor cooling.

- Discuss the practical implications of this lab that set it in a grander context. (Why should chemical engineering students learn this?)

\section{Safety}

Hydrogen peroxide (CAS No. 7722-84-1) and potassium iodide (CAS no. 7681-11-0) are toxic and skin irritants. Peroxide is also a strong oxidant. Gloves and safety glasses should be worn when handling these materials. Round-bottom flask reactors need to be open to the atmosphere to avoid pressure build-up from the oxygen produced. No flammable materials or ignition sources should be present during the production of oxygen via the reaction. Temperatures near or above the boiling point of the mixture $\left(\sim 100^{\circ} \mathrm{C}\right)$ can be reached in any flask that is removed from the ice bath before the reaction is complete. Care should be taken when handling these mixtures and especially in avoiding contact with escaping steam from the flasks.

\section{Procedure}

There are two parts to this lab: the water-only experiment to determine the U value and the hydrogen peroxide decomposition reactions. When performing the decomposition reaction, students should take detailed notes documenting their observations. Refer to Figures 1 and 2 for guidance on how to set up the experiment. Refer to Table 1 for a list of how much reactant (or water) to add for each flask size. 
Place the thermocouple probe in the spout that is clamped.

Use a funnel to carefully add liquids.

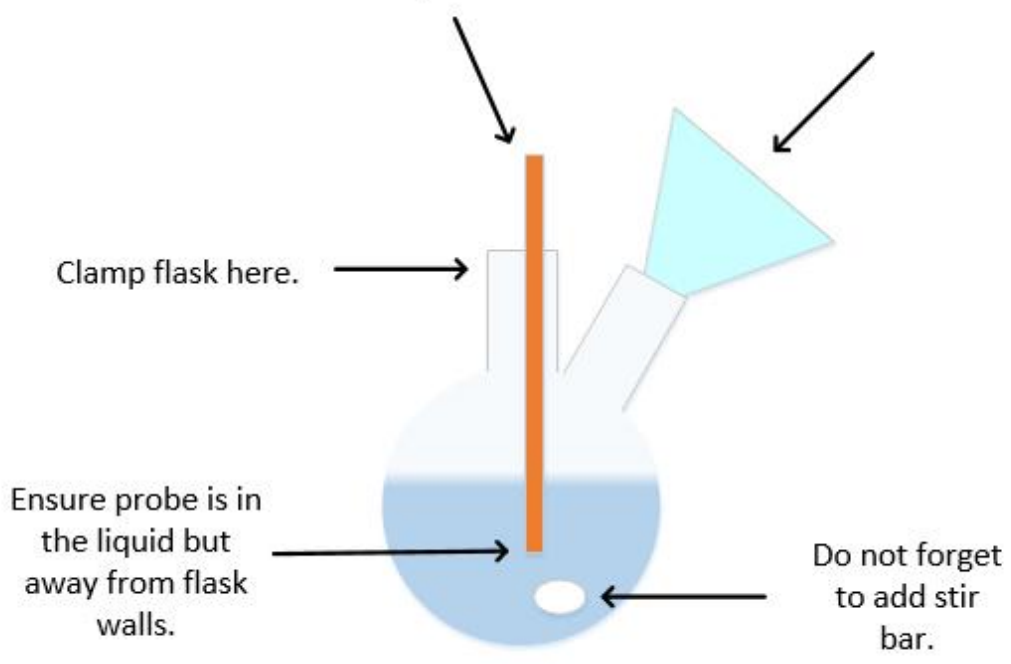

Figure 1: Sketch of round bottom flask setup.

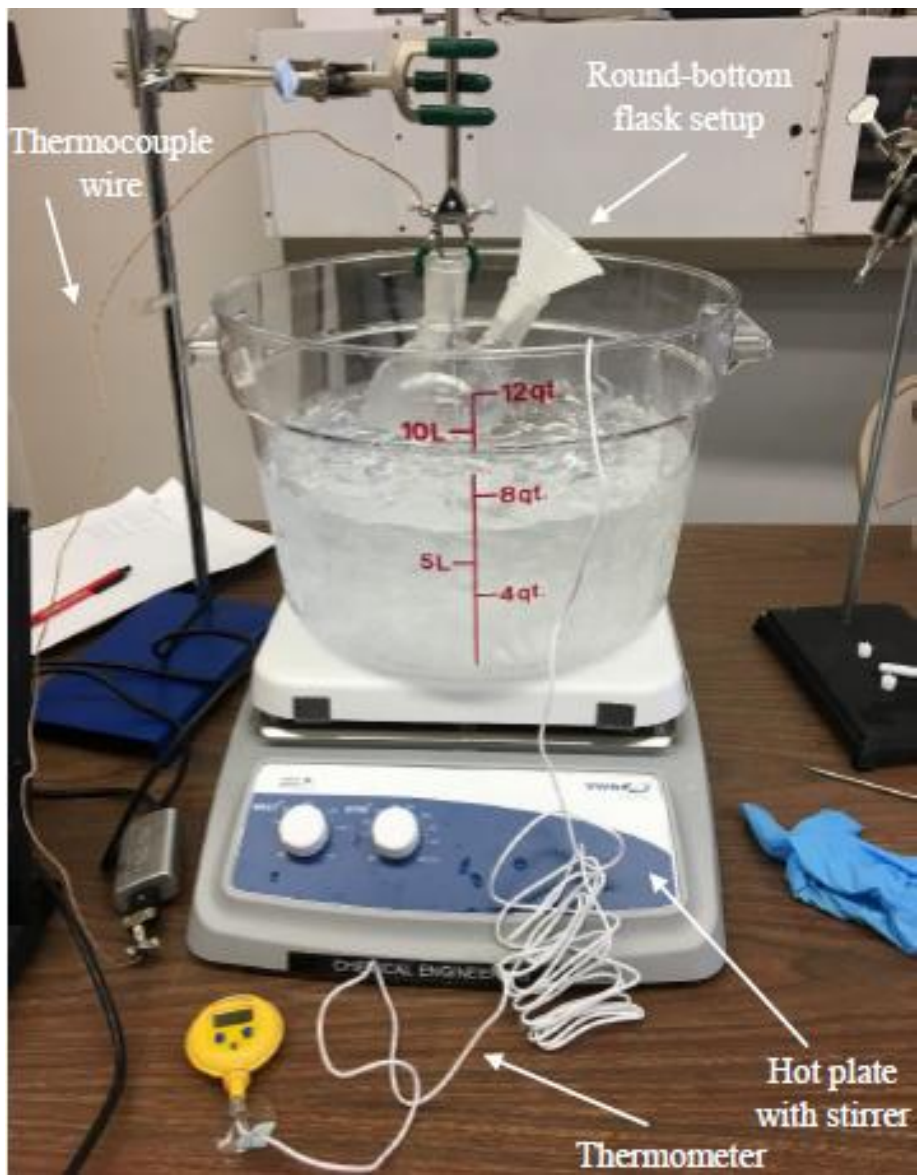

Figure 2: Proper setup of round bottom flask in ice bath showing major equipment. 


\begin{tabular}{|c|c|c|}
\hline \multicolumn{3}{|c|}{$\begin{array}{l}\text { Table 1: Volumes of reactants (and water) for experimental } \\
\text { measurements in different flasks. }\end{array}$} \\
\hline Flask Size & $\begin{array}{l}\text { Volume of } 30 \% \mathrm{H}_{2} \mathrm{O}_{2} \\
\text { (cold water) }\end{array}$ & $\begin{array}{l}\text { Volume of } 0.1 \mathrm{M} \mathrm{KI} \\
\text { (hot water) }\end{array}$ \\
\hline (ml) & $(\mathrm{ml})$ & $(\mathrm{ml})$ \\
\hline 100 & 30 & 15 \\
\hline 250 & 75 & 37.5 \\
\hline 500 & 150 & 75 \\
\hline
\end{tabular}

\begin{tabular}{|c|c|}
\hline Table 2: Surface areas of heat transfer for each flask (assuming 50\% \\
liquid level)
\end{tabular}

\section{Experiment to determine overall heat transfer coefficient, $U$ for flasks (WATER ONLY)}

1. Prepare both ice baths. Take one of the 12 quart plastic bowls and fill it with about 5 liters of water from a faucet. Pour approximately half of this water into the other plastic bowl. Put 3 large scoops of ice into each plastic bowl. The second ice bath is for the hydrogen peroxide decomposition reaction.

2. Place a large stir bar in the center of the ice bath and slowly turn on the stir plate $(\sim 500 \mathrm{rpm})$. Insert a Traceable ${ }^{\circledR}$ thermometer probe into the water near the center of the container careful not to disturb the spinning of the stir bar. Ensure the ice bath has enough ice to keep the water at $0^{\circ} \mathrm{C}$ throughout the entirety of the experiment.

3. Acquire cold water from the TA. To keep the water cold for the second experiment, keep ice cubes in the cold water container.

4. Set up the experiment as shown in Figure 1 so that the flask is submerged in the ice bath. Remember to add a stir bar to each of the flasks!

5. Insert a thermocouple probe into the flask. Plug the thermocouple into the USB port of a laptop and click "Run TC01Launcher.exe" then "Temperature Logger" to get to the data collection window. You may have to find and select the TC01 Launcher in your computer's devices. Do not "start logging" the temperature yet. (This would gather unnecessary data.) Change the units to Celsius and type a description for your specific experiment in the description box (e.g. Group \#, water-only or reaction, experimental conditions).

6. Using a funnel, pour the appropriate amount of cold water into your group's assigned flask size (refer to Table 1). Monitor the temperature of the cold water in 
each flask. Use this time to ensure the temperature probes of both TC01

thermocouples are positioned adequately (below the liquid level of the flask, away from flask wall if possible). Also, make sure each flask is positioned low enough so that the stir bars in the flasks spin.

7. Using Table 1, acquire the appropriate amount of hot water from a faucet. Once the temperature of the cold water in each flask stops decreasing $\left(\sim 1^{\circ} \mathrm{C}\right)$, measure and record the temperature of the hot water.

8. STOP. CHECK IN WITH YOUR TA BEFORE PROCEEDING.

9. With the approval of the TA, make sure your "description" is correct and then start the temperature logging by clicking "Start Logging". Pour the appropriate amount of hot water into each flask using a funnel.

10. Record the temperature of the contents of the flask for 10 minutes.

11. "Stop logging" the data. Copy and paste the data into an Excel file.

12. Empty the water from the flask into a drain and set the flask aside.

13. Repeat steps 2-10 with the other assigned flask for your group. Pay special attention to the poor cooling conditions you are assigned to test.

14. While waiting for all of the data to be collected for the second flask, begin cleaning up the used lab equipment. Thoroughly rinse out all glassware and graduated cylinders. When using soap, be sure to adequately flush away all soap used on the equipment. Failure to do so will result in a totally different experiment the next time that glassware is used for the reaction portion of the lab (search "hydrogen peroxide soap experiment" on YouTube if you don't believe me).

15. After cleaning up the experiment, remove your gloves and wash your hands before leaving the lab.

\section{Exothermic decomposition of hydrogen peroxide experiment}

1. Acquire the appropriate amounts of hydrogen peroxide for your group's assigned flasks (refer to Table 1). Use a funnel. Measure as closely as you can and discard any excess hydrogen peroxide into the waste container (rather than back into the original container).

2. Using a pipette and bulb, carefully remove the appropriate amount of KI for your group's assigned flasks (refer to Table 1).

3. Set up the experiment as shown in Figure 1. Position them so that the flask is submerged in the ice bath. Remember to add a stir bar to the flask!

4. Insert a thermocouple probe into the flask. Plug the thermocouple into the USB port of a laptop and click "Run TC01Launcher.exe" then "Temperature Logger" to get to the data collection window. You may have to find and select the TC01 Launcher in your computer's devices. Do not "start logging" the temperature yet. (This would gather unnecessary data.) Change the units to Celsius and type a description for your specific experiment in the description box (e.g. Group \#, water-only or reaction, experimental conditions).

5. Using a funnel, pour the appropriate amount of hydrogen peroxide into your assigned flask. Monitor the temperature of the hydrogen peroxide. Use this time to ensure the temperature probes of both TC01 thermocouples are positioned adequately (below the liquid level of the flask, away from flask wall if possible). 
Also, make sure each flask is positioned low enough so that the stir bars in the flasks spin.

6. Once the hydrogen peroxide in each flask stops decreasing $\left(\sim 1^{\circ} \mathrm{C}\right)$, measure and record the temperature of the potassium iodide.

7. STOP. CHECK IN WITH YOUR TA BEFORE PROCEEDING.

8. With the approval of the TA, make sure your "description" is correct and then start the temperature logging by clicking "Start Logging". Be sure to record detailed observations of the reaction. Take pictures. Note any changes and the times the changes take place.

9. Using a funnel, pour the appropriate amount of KI into your assigned flask.

10. Record the temperature of the contents of both flasks for about 20 minutes.

11. "Stop logging" the data. Select all of the data (CTRL+A), copy (CTRL+C) and paste $(\mathrm{CTRL}+\mathrm{V})$ the data into an Excel file. Email this Excel spreadsheet to your TA for data compilation.

12. Repeat steps 3-11 with a $500 \mathrm{~mL}$ flask and apply the poor cooling conditions as your TA directs you to.

13. Once your reaction mixture temperature begins to decrease, have one person begin to clean up while the other continues to observe the reaction. Thoroughly rinse out all glassware and graduated cylinders. When using soap, be sure to adequately flush away all soap used on the equipment. Failure to do so will result in a totally different experiment the next time that glassware is used for the reaction portion of the lab (search "hydrogen peroxide soap experiment" on YouTube if you don't believe me).

14. After cleaning up the experiment, remove your gloves and wash your hands before leaving the lab. 


\section{APPENDIX IV}

\section{PRELAB ASSIGNMENT AND FINAL REPORT DELIVERABLES}

\section{Hazards of Exothermic Reaction Scale-up Prelab Assignment}

Complete the following items as a team and be ready to discuss them with your TA on the day of your lab. You are encouraged to work with your group.

1. Choose two completed investigations from the Chemical Safety Board (CSB) that involve dangerous runaway reactions and improper scale-up. For each of these incidents, write a paragraph describing the cause of the accident and the results. Explain what you could have done as a chemical engineer working in these facilities to prevent the accident from happening. Be sure to include the CSB investigation title, location, date and number of injuries/fatalities associated with the incident as well as the sources you used for this information.

2. Based on the information given in the procedure, determine the initial concentrations (mol/L) of $\mathrm{H}_{2} \mathrm{O}_{2}$ and $\mathrm{I}^{-}$for each of the three flask sizes used in this lab. Remember, the reactants are $30 \% \mathrm{H}_{2} \mathrm{O}_{2}$ and $0.10 \mathrm{M} \mathrm{KI}$. List the values of $\mathrm{k}_{\mathrm{o}}$, $\mathrm{E}_{\mathrm{a}}, \mathrm{R}$ and $\mathrm{H}$ for this experiment. (Refer to procedure before googling anything.)

3. Relate the different components of this tabletop laboratory experiment to what a chemical engineer would actually experience in industry. In other words, if we were to scale up this reaction to be industrial sized, what equipment would we use for the following: ice bath, round bottom flask, thermometers/thermocouples, containers used to add in reactants, stir bar/stir plate and laptop with data acquisition interface?

\section{Hazards of Exothermic Reaction Scale-up Final Report Deliverables}

- Report the overall heat transfer coefficient results for each reactor.

- Compare experimental and calculated temperature versus time results for each reactor.

- Report concentration of hydrogen peroxide versus time results.

- Explain the differences in behavior between the reactors. Include an explanation of the behavior of the $500 \mathrm{~mL}$ flask that had poor cooling.

- Discuss the practical implications of this lab that set it in a grander context. Why should chemical engineering students learn this? 
Lisa A. Anderson

\section{EDUCATION}

Master of Engineering student in Chemical Engineering at the University of Louisville, May 2017 - present. Thesis title: "Addition of Exothermic Reaction Scale-Up Lab to Unit Ops Curriculum"

Bachelor of Science (May 2018) in Chemical Engineering, University of Louisville, Louisville, KY

\section{ACADEMIC EMPLOYMENT}

Graduate Teaching Assistant, Department of Chemical Engineering, University of Louisville, August 2017 - present. Responsibilities include: supervising students to ensure safe completion of Unit Operations laboratories and grading lab reports. Undergraduate Teaching Assistant, Department of Chemical Engineering, University of Louisville, May 2015 - July 2017. Responsibilities included preparing and presenting course material during supplemental instruction and problem solving sessions for various undergraduate chemical engineering courses.

\section{EMPLOYMENT}

Chemical Engineering Co-Op, Monument Chemical, Brandenburg, KY, January 2015 - August 2016. Responsibilities included designing/sizing pumps of various sizes and services to increase efficiency of unit; writing and managing Management of Change documents; leading hazard reviews and pre-startup safety reviews; and calculating and presenting quality metrics for unit production. 


\section{ACADEMIC AWARDS}

Robert Neiman Scholarship for Outstanding Academic Performance (2016)

Zeon Chemical Company Graduate Fellowship (2017)

University of Louisville Chemical Engineering Department Alumni Award (2018) 